Aus der Klinik für Unfallchirurgie, Orthopädie und Plastische Chirurgie (Prof. Dr. med. W. Lehmann)

der Medizinischen Fakultät der Universität Göttingen

\title{
Der Effekt von Strontiumranelat auf lumbale Wirbelkörper osteopenischer Ratten
}

\author{
INAUGURAL-DISSERTATION \\ zur Erlangung des Doktorgrades \\ der Medizinischen Fakultät der \\ Georg-August-Universität zu Göttingen
}

vorgelegt von

Arvin Abdan

aus

Teheran, Iran

Göttingen 2020 
Dekan:

\section{Betreuungsausschuss}

Betreuer/in:

Ko-Betreuer/in:

\section{Prüfungskommission}

Referent/in:

Prof. Dr. med. S. Sehmisch

Ko-Referent/in:

Drittreferent/in:
Prof. Dr. med. W. Brück

Prof. Dr. med. S. Sehmisch

Dr. rer. nat. M. Komrakova

Datum der mündlichen Prüfung: 13.07.2021 
Hiermit erkläre ich, die Dissertation mit dem Titel "Der Effekt von Strontiumranelat auf lumbale Wirbelkörper osteopenischer Ratten" eigenständig angefertigt und keine anderen als die von mir angegebenen Quellen und Hilfsmittel verwendet zu haben.

Göttingen, den

(Unterschrift) 
Einige Daten, die in der vorliegenden Arbeit präsentiert sind, wurden teilweise publiziert:

Saul D, Harlass BL, Ahrabi A, Kosinsky RL, Hoffmann DB, Wassmann M, Wigger R, Böker KO, Sehmisch S, Komrakova M (2018): Effect of strontium ranelate on the muscle and vertebrae of ovariectomized rats. Calcif Tissue Int 102, $705-71$ 


\section{Inhaltsverzeichnis}

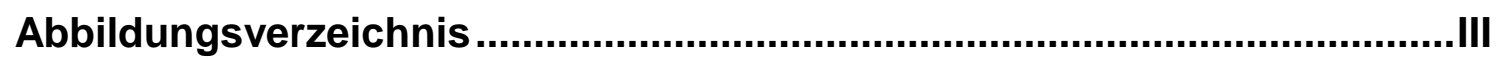

Tabellenverzeichnis .................................................................................. IV

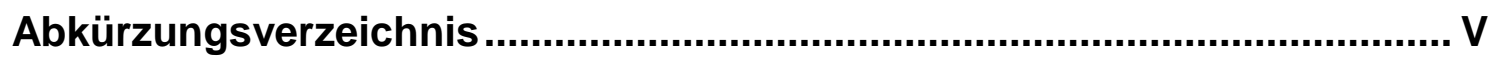

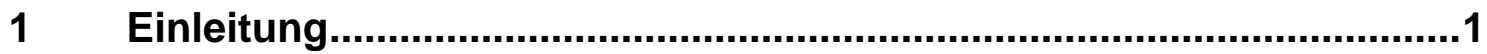

$1.1 \quad$ Thematik und Fragestellung der Arbeit ...................................................1

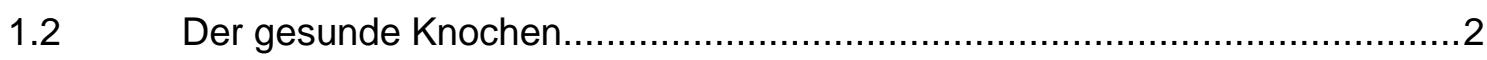

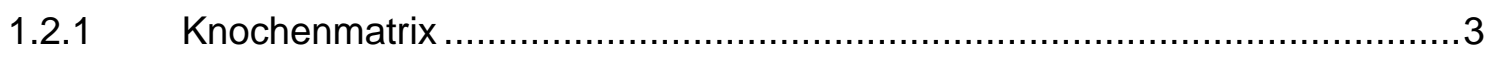

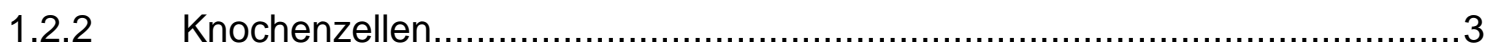

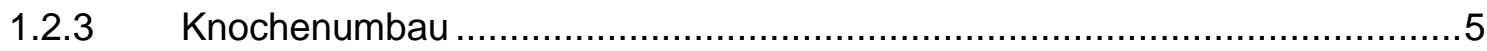

$1.3 \quad$ Osteoporose

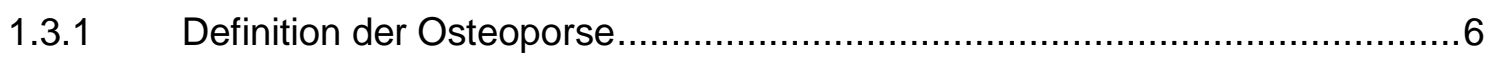

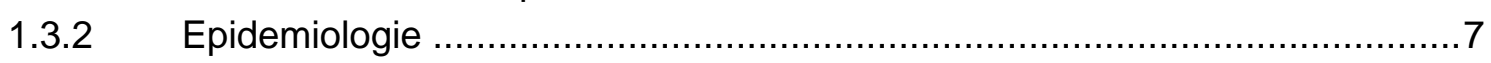

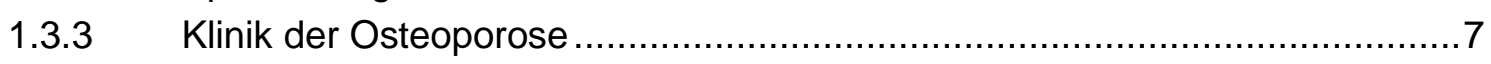

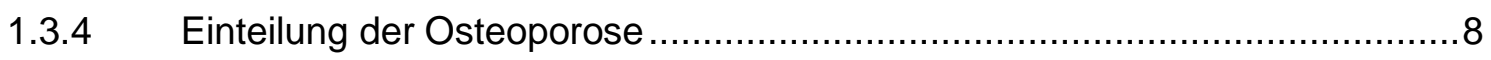

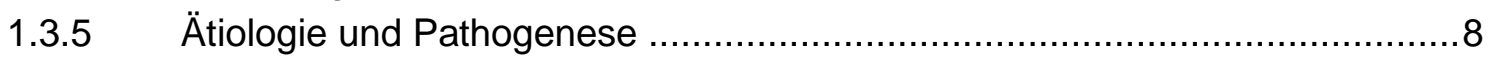

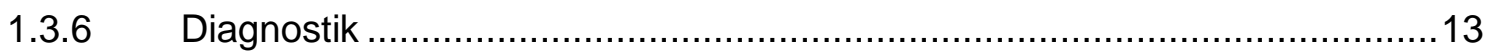

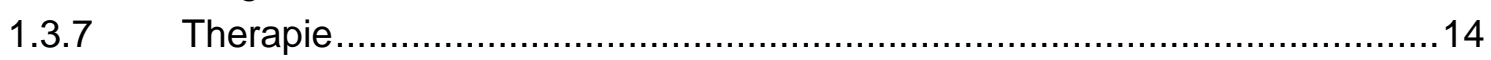

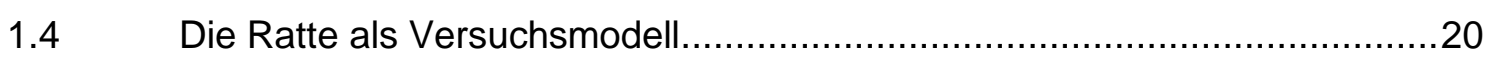

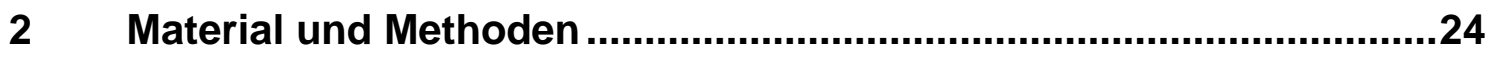

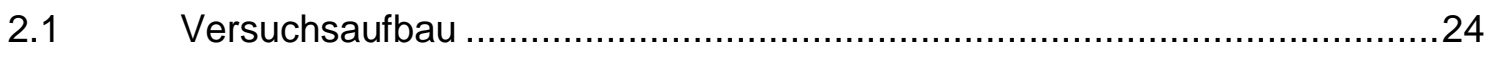

$2.2 \quad$ Versuchstiere und Tierhaltung............................................................25

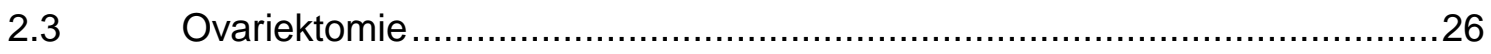

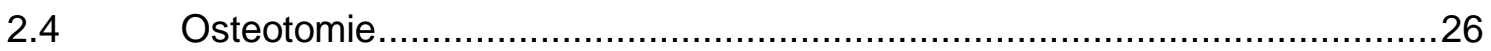

$2.5 \quad$ Obduktion und Präparation der Lendenwirbelkörper .................................27

2.6 Biomechanischer Kompressionstest..................................................27

2.6.1 Prinzip und Versuchsdurchführung....................................................27

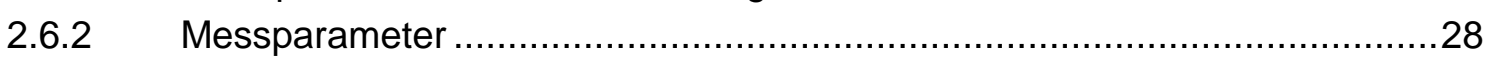

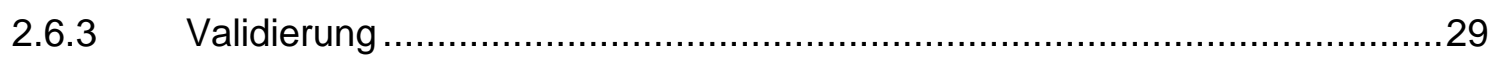

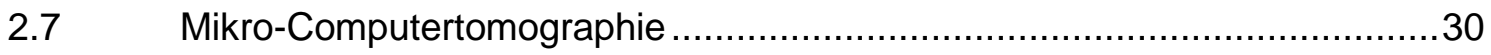

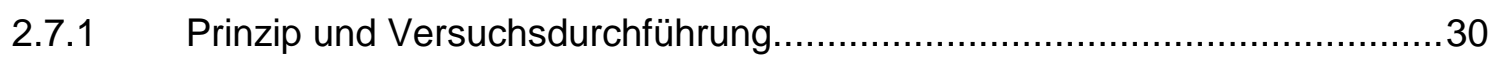

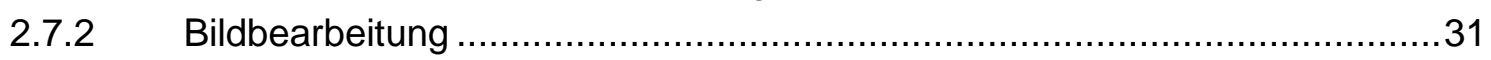

2.7.3 Auswertung der Mikro-CT-Ergebnisse.....................................................

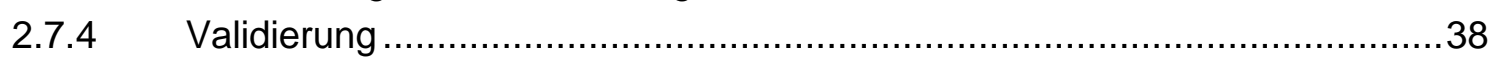

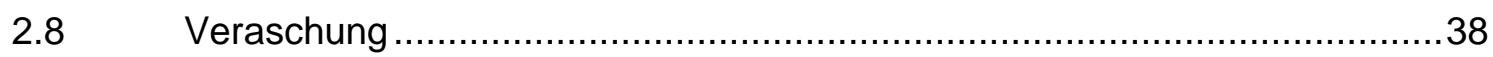

2.8.1 Bestimmung der organischen und anorganischen Knochensubstanz..........39

2.8.2 Bestimmung des Calcium- und Phosphatgehalts .......................................40

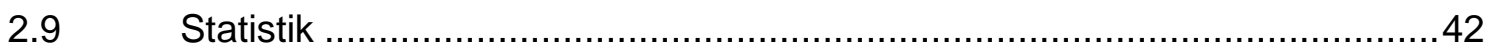




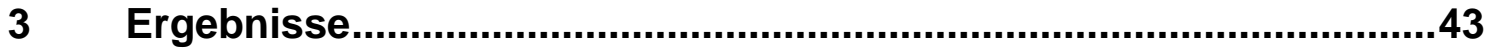

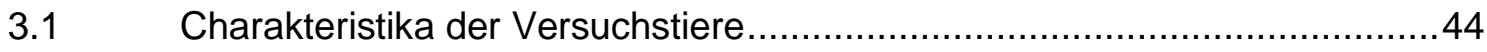

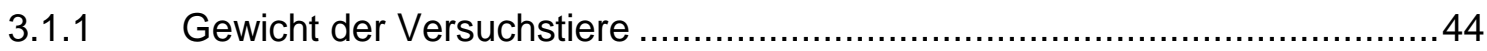

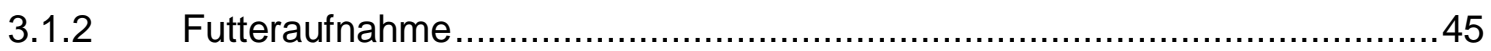

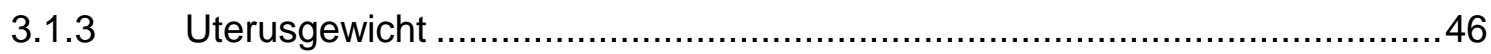

3.1.4 Zusammenfassung der Versuchstier-Charakteristika ...............................46

3.2 Ergebnisse des biomechanischen Kompressionstests ............................47

3.2.1 Maximale Kraft $\left(F_{\max }\right)$ und Streckgrenze (yield load) ..............................47

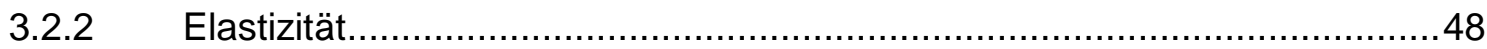

3.2.3 Repräsentatives Kraft-Weg-Diagramm .................................................49

3.2.4 Zusammenfassung der Ergebnisse des biomechanischen

3.3 Ergebnisse der Mikro-Computertomographie .........................................50

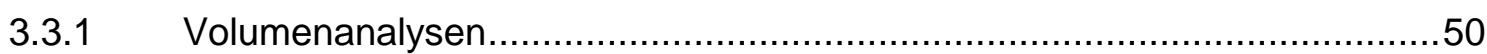

3.3.2 Auswertungsergebnisse der Knochenmineraldichte (BMD) .......................51

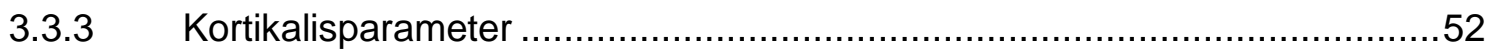

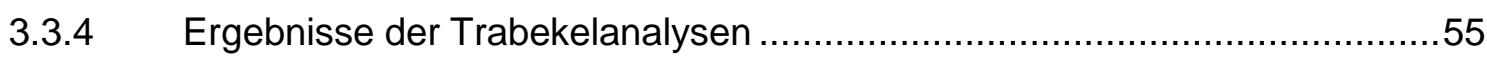

3.3.5 Zusammenfassung der Ergebnisse im Mikro-CT .....................................59

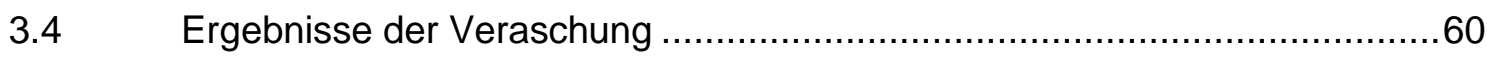

3.4.1 Organische und anorganische Knochensubstanz..................................60

3.4.2 Phosphatgehalt der Knochen ............................................................. 61

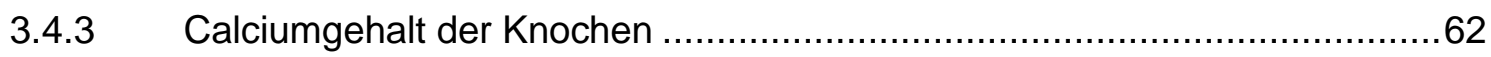

3.4.4 Verhältnis von Calcium zu Phosphat .......................................................63

3.4.5 Zusammenfassung der Veraschungsergebnisse .......................................64

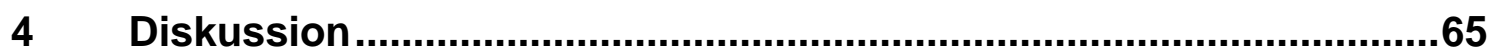

4.1 Futteraufnahme, Körper- und Uterusgewicht der Ratten.............................65

4.2 Diskussion der Ergebnisse des biomechanischen Kompressionstests ........67

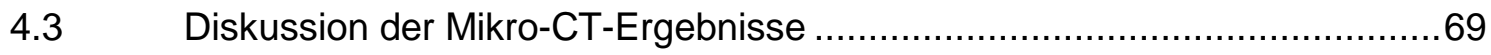

4.4 Diskussion der Ergebnisse der Veraschung ......................................... 72

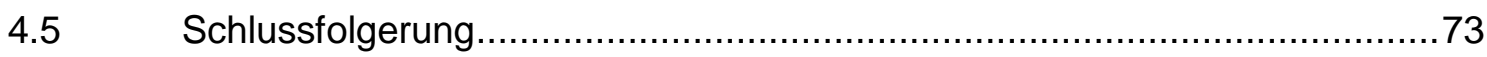

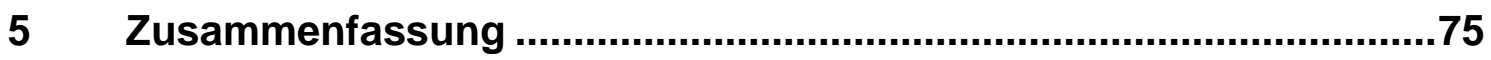

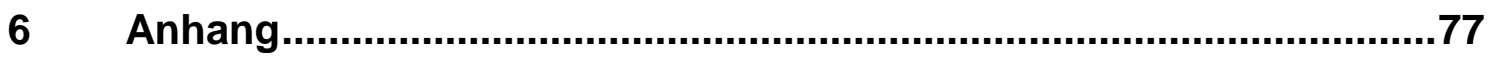

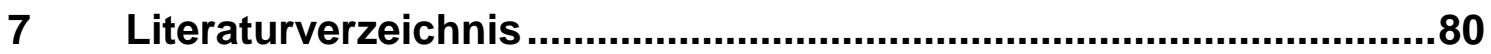




\section{Abbildungsverzeichnis}

Abbildung 1: Frakturrisiko der Skelettabschnitte

Abbildung 2: Beispiel eines gesunden Knochens und eines osteoporotischen

Knochens 21

Abbildung 3: Beispiel eines Kraft-Weg-Diagramms 28

Abbildung 4: Umrandung und Ausschnitt eines Corpus vertebrae in einer 3D-Rekonstruktion. 32

Abbildung 5: Beispiel eines Grauwerthistogramms. 33

Abbildung 6: Optimale Darstellung von Trabekelstrukturen und Kortikalis ..................33

Abbildung 7: Graphische Darstellung der linearen Regression 36

Abbildung 8: Bestimmung der Kortikalisdicke anhand von fünf Referenzmessungen 37

Abbildung 9: 2D-Bilder für die Trabekelanalyse. 38

Abbildung 10: Gewichtsentwicklung der Versuchstiere . .44

Abbildung 11: Mittleren tägliche Futteraufnahme .45

Abbildung 12: Uterusgewicht in den Versuchsgruppen .......................................... 46

Abbildung 13: Ergebnisse der Maximalkraft ...................................................... 47

Abbildung 14: Ergebnisse der Streckgreze ........................................................ 47

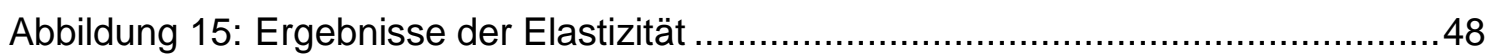

Abbildung 16: Kraft-Weg-Diagramm aus den Gruppen „OVX“ und „SR pr+th“ ............49

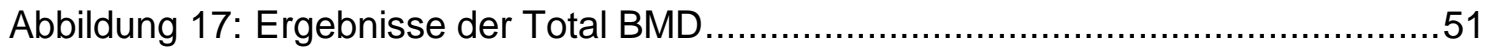

Abbildung 18: Ergebnisse der Gesamtfläche der Kortikalis ...................................52

Abbildung 19: Ergebnisse der Kortikalisdicke am ventralen WK..............................53

Abbildung 20: Ergebnisse der Kortikalisdicke am dorsalen WK ...............................53

Abbildung 21: Ergebnisse der Kortikalisdichte......................................................54

Abbildung 22: Eigene 2D-Bilddaten aus Mikro-CT-Scans.........................................55

Abbildung 23: Ergebnisse der Trabekeldichte der Wirbelkörper .................................56

Abbildung 24: Ergebnisse der mittleren Trabekeldicke der Wirbelkörper .....................56

Abbildung 25: Ergebnisse der Gesamtfläche der Trabekel......................................57

Abbildung 26: Ergebnisse der trabekulären Konnektivität....................................58

Abbildung 27: Ergebnisse Anteil organische Knochensubstanz ............................60

Abbildung 28: Ergebnisse Anteil anorganische Knochensubstanz ...........................60

Abbildung 29: Ergebnisse des Calcium-Phosphat-Verhältnisses..............................63 


\section{Tabellenverzeichnis}

Tabelle 1: WHO-Klassifikation der Osteoporose ...................................................

Tabelle 2: $\quad$ Einteilung der Versuchstiere in die Untersuchungsgruppen ...................25

Tabelle 3: $\quad$ Phantomdichten mit den ermittelten Dichtewerten in GVal .....................35

Tabelle 4: $\quad$ Symbolische Darstellung der Signifikanzen .......................................43

Tabelle 5: $\quad$ Ergebnisse des biomechanischen Tests.........................................48

Tabelle 6: Ergebnisse der gesamten Mineraldichte (Total BMD) und der Knochenmineraldichte (Bone BMD) .........................................51

Tabelle 7: $\quad$ Ergebnisse der Kortikalisfläche......................................................... 52

Tabelle 8: Ergebnisse der Kortikalidicke am ventrale und dorsalen WK ................53

Tabelle 9: $\quad$ Ergebnisse der kortikalen Knochendichte ..........................................54

Tabelle 10: Ergebnisse der Trabekeldichte und mittleren Trabekeldicke .................56

Tabelle 11: Ergebnisse der Gesamtfläche der Trabekel.....................................57

Tabelle 12: Ergebnisse der Trabekelknotenzahl und der trabekulären

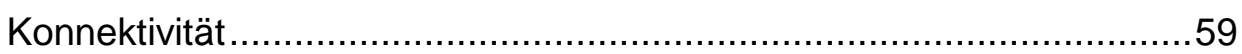

Tabelle 13: Ergebnisse der Anteile an organischer und anorganischer Knochensubstanz .................................................................. 61

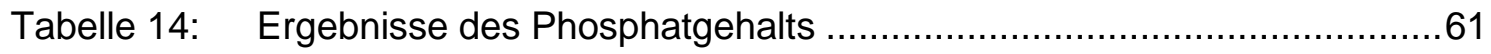

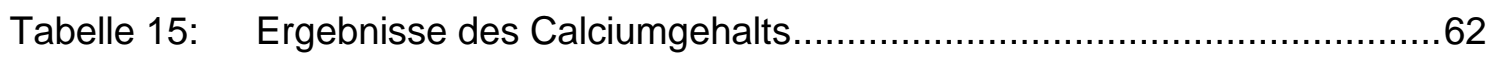

Tabelle 16: Ergebnisse des Calcium-Phosphat-Verhältnisses...............................63

Tabelle A1: Gewichtsentwicklung der Versuchstiere ........................................ 77

Tabelle A2: Darstellung der täglichen Futteraufnahme ........................................ 78

Tabelle A3: Uterusgewicht.............................................................................. 78

Tabelle A4: Ergebnisse der Volumenanalysen ............................................... 79 


\section{Abkürzungsverzeichnis}

ASBMR

BMD

BV

CT

Ct.d

Ct.Th

Ct.v

CTXA

DVO

DXA/DEXA

GVal

HK

i.p.

LWS

LWK

$\mathrm{N}$

NON-OVX

N.Nd

OPG

OVX

pQCT

QCT

QUS

RANK

RANKL

S.C.

SERMs

SR

SR pr

SR pr+th

$\mathrm{SR}$ th

$\mathrm{Tb}$

Tb.Ar

TBS
American Society for Bone and Mineral Research

bone mineral density, Knochenmineraldichte

bone volume, Knochenvolumen

Computertomographie

Areal der dorsalen Kortikalis

Kortikalisdicke

Areal der ventralen Kortikalis

CT-basierte DXA-Messung

Dachverband Osteologie e.V.

dual-energy-x-ray-absorptiometrie, Zwei-Energien-RöntgenAbsorptiometrie

grey value, Grauwert

Hinterkante des Wirbelkörpers

intraperitoneal

Lendenwirbelsäule

Lendenwirbelkörper

Newton (Krafteinheit)

nicht ovariektomiert

Anzahl der Trabekelknoten

Osteoprotegerin

Zustand nach Ovariektomie

periphere quantitative Computertomographie

quantitative Computertomographie

quantitativer Ultraschall

receptor activator for nuclear factor kappa, Zellrezeptor

RANK-Ligand

subcutan

selektive Östrogen-Rezeptor-Modulatoren

Strontiumranelat

Strontiumranelat-Prophylaxe

Strontiumranelat-Prophylaxe und -therapie

Strontiumtranelat-Therapie

Trabekelanzahl

Trabekelareal

trabecular bone score 
TV

VFA

VK

WHO

WK total volume, Gesamtvolumen

vertebrales Fraktur-Assessment

Vorderkante des Wirbelkörpers

World Health Organization

Wirbelkörper 


\section{$1 \quad$ Einleitung}

\subsection{Thematik und Fragestellung der Arbeit}

Osteoporose ist eine systemische Knochenerkrankung, von der weltweit schätzungsweise 200 Millionen Menschen und davon vorwiegend Frauen in der Postmenopause betroffen sind (Cooper et al. 1992). Auf die Diagnostik und Behandlung der Osteoporose entfallen rund $3 \%$ der europäischen Gesundheitsausgaben (Reginster et al. 2015). Im Jahr 2000 wurden 9 Millionen Frakturen bei zugrunde liegender Osteoporose registriert. Hiervon entfielen ca. 1,4 Millionen auf vertebrale Frakturen (Johnell und Kanis 2006), welche mit einem erhöhten Risiko für nachfolgende Frakturen und damit einem rapiden Krankheitsprogress einhergehend (Melton et al. 1999).

Bei der Osteoporose ist die physiologische Balance zwischen Knochenauf- und Knochenabbau zugunsten des Abbaus verschoben. Sie geht mit einer herabgesetzten Knochenstabilität einher, die unter anderem anhand der Knochenmineralisationsdichte (BMD) objektiviert werden kann.

Laut aktueller Leitlinie des Dachverbands für Osteologie (DVO) sind neben Hüftfrakturen auch Wirbelkörper-Frakturen relevante Endpunkte des Krankheitsbildes, deren Vorliegen zur Indikation einer Osteoporose-Therapie dient (DVO 2017). Ein Großteil der dafür zugelassenen Medikamente unterstützt aber entweder nur den Knochenaufbau oder wirkt dem Knochenabbau entgegen (McLendon und Woodis 2014). Mit Strontium existiert dagegen eine Substanz, die den osteoanabolen und den antiresorptiven Effekt in sich kombiniert (Geng et al. 2018). Eine Langzeittherapie mit Strontium wies einen Anstieg der Knochenmineralisationsdichte und eine Antifraktureffizienz nach (Boivin et al. 2012). So haben Strontium-Verbindungen ein hohes Potential in der Osteoporose-Therapie und der Frakturprophylaxe.

Aufgrund dessen wird in der vorliegenden Arbeit die prophylaktische und therapeutische Wirkung von Strontium auf die Knochenstabilität, die Mikroarchitektur und die Mineralisation mit Depotfunktion am Beispiel von Strontiumranelat an der Lendenwirbelsäule von Ratten untersucht. 


\subsection{Der gesunde Knochen}

Das menschliche Skelett ist aus 220 Knochen zusammengesetzt. Mit einem Gewicht von ca. $10 \mathrm{~kg}$ macht es einen Anteil von etwa $15 \%$ des Körpergewichtes aus und erfüllt wichtige Aufgaben, wie Stütz- und Schutzfunktionen. Rippen und Sternum schirmen beispielweise die intrathorakalen Organe ab, Schädel und Wirbelsäule schützen das zentrale Nervensystem. Durch den Ansatz der Muskulatur an den Knochen ist das Skelett auch maßgeblich an der Fortbewegung beteiligt. Außerdem dient es der Speicherung eines Großteils an Mineralien und stellt ein riesiges Depot dar, das $99 \%$ des gesamten Calciums, $85 \%$ des Phosphates und $50 \%$ des Magnesiums im Körper speichert. Auch Proteine wie Kollagen Typ I, Glykoprotein, Osteokalzin oder Osteonektin werden im Knochen produziert und gespeichert. Zudem findet hier die Hämatopoese statt (Bartl und Bartl 2004).

Das Skelett wird in ein axiales oder Rumpfskelett und in ein appendikuläres, das Extremitäten-Skelett gegliedert (Bartl und Bartl 2004).

Die größte äußere Schicht der Knochen wird von der Kortikalis gebildet. Sie besteht histologisch aus Osteonen - etwa $5 \mathrm{~mm}$ langen Zylindern, die parallel zur Längsrichtung des Knochens angeordnet sind. Die Kortikalis ist dicht gepackt, sehr hart und weist eine nur geringe Knochenumbaurate auf. Deshalb wird sie deutlich langsamer als der trabekuläre Knochen umgebaut, der sich im Knocheninneren befindet und ein Gitternetz aus dünnen Platten und Bälkchen bildet - die sogenannte Spongiosa. Das Knochenmark füllt die Maschen zwischen den Trabekeln. Die Abgrenzung zwischen Kortikalis und Knochenmarkräumen erfolgt durch das Endost, bestehend aus einer dünnen Schicht nicht mineralisierter Kollagenfibrillen sowie einer Lage aus ruhenden Osteoklasten, ruhenden Osteoblasten, Osteoprogenitorzellen und mesenchymalen Stammzellen (als lining cells zusammengefasst). Die äußere Begrenzung des Knochens bildet das Periost aus straffem Bindegewebe und ebenfalls einer Schicht lining cells (Bartl und Bartl 2004; Lüllmann-Rauch 2019).

$\mathrm{Zu}$ unterscheiden ist zwischen Geflecht- und Lamellenknochen. Der sich rasch aufbauende Geflechtknochen entsteht in der Entwicklung und bei der Frakturheilung. In ihm liegen die Kollagenfibrillen miteinander verflochten in Bündeln vor. Im Rahmen des natürlichen Knochenumbaus ersetzt der sich langsamer 
entwickelnde, aber biochemisch wertvollere Lamellenknochen dann den Geflechtknochen nach und nach (Havers-Umbau) (Lüllmann-Rauch 2019).

\subsubsection{Knochenmatrix}

Die Knochenmatrix verleiht dem Knochen seine typischen Eigenschaften. Aufgrund ihrer Verkalkung hält sie hoher Biege- und Torsionsbeanspruchung statt und hat eine enorme Zug- und Druckfestigkeit. Die Knochenmatrix besteht zu $30 \%$ aus organischem Material. $90 \%$ davon entfallen auf Kollagenfasern vom Typ I und $10 \%$ auf andere Proteine, wie Glykoprotein, Osteokalzin, Osteonektin oder alkalische Knochenphosphatase. Die Kollagenfasern sind in einer Lamelle annähernd parallel zueinander ausgerichtet, wechseln jedoch ihre Ausrichtung in benachbarten Lamellen. $45 \%$ der Knochenmatrix machen die anorganischen Bestandteile aus und werden zum Großteil aus Hydroxylapatit gebildet, einer kristallinen Form des Calciumphosphats. Vermutet wird, dass sich aus Fortsätzen von Osteoblasten Vesikel abspalten, die frei in der Matrix liegen und in deren Inneren die Apatitkristalle entstehen, die im Verlauf ihres Wachstums die Vesikelmembran aufreißen und in die Matrix ragen. Hier lagern sich Kollagenfibrillen an und wachsen weiter. Die Mineralisierung erfolgt hauptsächlich durch die alkalische Phosphatase (Deller 2018).

Die verbliebenen 25 \% der Knochenmatrix bestehen aus Wasser (Deller 2018).

\subsubsection{Knochenzellen}

\subsubsection{Osteoblasten}

Osteoblasten sind die knochenbildenden Zellen des wachsenden und ausgereiften Knochens, die sich über die Osteoprogenitorzellen aus mesenchymalen Stammzellen entwickeln. Im aktiven Zustand sind sie kubische bis prismatische Zellen, die sich epithelartig an der Matrixoberfläche anordnen. Sie sind reich an alkalischer Phosphatase und sezernieren unter anderem Kollagen Typ I und Proteoglykane. Die wichtigste Aufgabe der Osteoblasten ist die Bildung und Mineralisation der Knochenmatrix. Die ursprünglich produzierte und noch nicht verkalkte Knochenmatrix wird Osteoid genannt. Im Rahmen der Knochen- 
entwicklung oder Knochenneubildung finden sich die Osteoblasten praktisch überall an der Knochenoberfläche. Bereits ab dem 20. Lebensjahr sind sie aber deutlich seltener nachweisbar als in der Wachstumsphase. Sie gehen im Verlauf inres Lebens in Osteozyten über, werden inaktiv und bilden die sogenannten endostalen Saumzellen ( $=$ bone-lining cells) oder gehen durch Apoptose zugrunde (Deller 2018).

\subsubsection{Osteozyten}

Viele Funktionen, die ursprünglich den Osteoblasten zugeschrieben wurden, übernehmen nach neusten Erkenntnissen die Osteozyten. Sie sind morphologisch veränderte, ausdifferenzierte Osteoblasten, die in Lakunen der Knochenmatrix liegen. Über die Ausbildung von mechanosensitiven Membrankanälen können sie die Beanspruchung oder auch Schäden des Knochens wahrnehmen und darauf reagieren. Bei starker Beanspruchung des Knochens wird beispielsweise die Sclerostinausschüttung aus den Osteozyten gehemmt, was zu einer Zunahme der Knochenmasse führt. Außerdem stimulieren die Osteozyten über Rezeptoren, an denen Parathormon an innen bindet die Ausreifung von Osteoklasten und leiten so die Knochenresorption ein. Über Kalzitriol, die aktive Form des Vitamin $D_{3}$, wird in den Osteozyten die Bildung des Faktors RANKL (engl. receptor activator for nuclear factor kappa-Ligand) gefördert. RANKL wiederum bindet an seinen Rezeptor RANK auf den Osteoklasten und aktiviert damit ebenfalls die Knochenresorption. Diese Bindung kann durch Osteoprotegerin (OPG), das ebenfalls von Osteozyten gebildet wird, antagonisiert werden (= RANK/RANKL/OPG-Weg). Werden Osteozyten mit ausreichend Nährstoffen über Gefäße der Havers-Kanäle versorgt, können sie jahrelang überleben (Deller 2018).

\subsubsection{Osteoklasten}

Osteoklasten sind mehrkernige Zellen, die aus Stammzellen des Knochenmarkes entstehen und mit Makrophagen verwandt sind. Im spongiösen Knochen liegen sie in selbst geschaffenen Höhlen der Knochenoberfläche, den sogenannten Howship-Lakunen. Dort bildet die Membran reifer Osteoklasten einen schmalen 
Faltensaum, der einem ständigen Wandel unterliegt und dadurch aktive Bewegungen ausführt.

Die Osteoklasten sind gemeinsam mit den Osteozyten für die Resorption der verkalkten Knochenmatrix im Rahmen des Knochenumbaus verantwortlich. Dieser findet im Bereich der Faltenoberfläche der Howship-Lakunen statt. Dazu sezernieren die Osteoklasten Säure sowie lysosomale und nicht lysosomale Enzyme. Kalzitonin aus der Schilddrüse hemmt die Osteoklastenaktivität, während Faktoren, wie RANKL der Osteozyten sie aktivieren und deren Ausreifung stimulieren. Osteoklasten überleben in der Regel nur einige Tage und gehen dann durch Apoptose zugrunde (Deller 2018).

\subsubsection{Knochenumbau}

Zur Überwachung und Steuerung des Knochenumbaus besitzt das Skelett ein komplexes Netzwerk ineinandergreifender Systeme, um eine gesunde Balance zwischen Knochenauf- und -abbau zu gewährleisten. Zu diesen Steuersystemen gehören systemische Hormone, lokale Zytokine und Signale, Vitamine und Mineralien, mechanische Belastung, transkriptionale Regulation und Gene sowie zentrale Regulationsmechanismen, wie Leptin (Bartl und Bartl 2004). Eine wesentliche Rolle spielt die hormonelle Steuerung, insbesondere durch Parathormon aus der Nebenschilddrüse, Kalzitonin aus der Schilddrüse und Sexualhormone wie Östrogen. Das Parathormon bewirkt eine gesteigerte Calciumresorption im Darm, aktiviert im Knochen die Osteoklasten, die durch Knochenabbau Calcium freisetzen und bewirkt an der Niere eine Calciumresorption und eine Phosphatausscheidung. Kalzitonin antagonisiert die Wirkung des Parathormons durch Hemmung der Osteoklastenaktivität (Adler 1998). Das Sexualhormon Östrogen steuert direkt die Funktion der Osteoblasten, die Synthese von Kollagen Typ I, zahlreicher Matrixproteine und der alkalischen Knochenphosphatase, die essentiell für die Knochenmineralisation ist. Gleichzeitig hemmt es die Osteoklastenaktivität und bewirkt durch Bindung an einen spezifischen Östrogen-Rezeptor einen programmierten Zelltod, was dem Knochenabbau aktiv entgegenwirkt (Nakamura et al. 2007; Leidenberger et al. 2009). 
Die stärksten physiologischen Umbauvorgänge laufen zum Zeitpunkt der Skelettentwicklung ab. Nach der Entwicklung findet ein langsamer, aber stetig fortlaufender Umbauprozess statt, bei dem das Skelett innerhalb von 40-50 Jahren vollständig erneuert wird. Der physiologische Verlust an Knochenmasse ist dabei durch die Abnahme an Osteozyten und die damit einhergehende verzögerte Mineralisation bedingt, während die osteoklastäre Resorption unverändert weiterläuft. Dabei passt sich der Knochen den an inn gestellten mechanischen Ansprüchen permanent an (Adler 1998).

\subsection{Osteoporose}

Das Krankheitsbild der Osteoporose wurde erstmals 1885 vom Innsbrucker Pathologen Gustav Adolf Pommer beschrieben und zählt heute zu den häufigsten Erkrankungen weltweit (Kremling 2005). Die nachfolgende Darstellung der Erkrankung orientiert sich an der aktuellen Leitlinie des Dachverbands der Deutschsprachigen Wissenschaftlichen Osteologischen Gesellschaft e.V., die online publiziert wurde (DVO 2017).

\subsubsection{Definition der Osteoporose}

\subsubsection{Definition nach dem DVO (2017)}

„Die Osteoporose ist eine systemische Skeletterkrankung, die durch eine niedrige Knochenmasse und eine mikroarchitektonische Verschlechterung des Knochengewebes charakterisiert ist, mit einem konsekutiven Anstieg der Knochenfragilität und der Neigung zu Frakturen. Sind bereits Frakturen als Folge der Osteoporose aufgetreten, liegt eine manifeste Osteoporose vor." (DVO 2017)

\subsubsection{Definition der World Health Organization (WHO) 1994}

"Eine Osteoporose liegt dann vor, wenn der Knochenmineralgehalt in einer DXAKnochendichtemessung an der Lendenwirbelsäule und/oder am proximalen Femur (Gesamtareal oder Schenkelhals) um $\leq-2,5$ Standardabweichungen vom Mittelwert einer 20-29-jährigen Frau abweicht" (Kanis und WHO Study Group 
1994). Treten zusätzlich Frakturen auf, spricht man von einer manifesten Osteoporose. Diese in Standardabweichungen angegebene Divergenz der Knochendichte bezeichnet man als T-Score (Tabelle 1). Er kann auch auf Männer ab dem 50. Lebensjahr angewendet werden (Kanis und WHO Study Group 1994). Neben dem T-Score wird ein zusätzlicher Wert, der Z-Score angegeben, der sich auf ein gesundes Kollektiv von Männern bzw. Frauen gleichen Alters bezieht.

Tabelle 1: WHO-Klassifikation der Osteoporose

\begin{tabular}{|c|c|}
\hline T-Wert & $\begin{array}{c}\text { Klassifikation nach } \\
\text { WHO }\end{array}$ \\
\hline$\geq-1$ & Normalbefund \\
\hline-1 bis $-2,5$ & Osteopenie \\
\hline$\leq-2,5$ & Osteoporose \\
\hline$\leq-2,5$ mit Fraktur & manifeste Osteoporose \\
\hline
\end{tabular}

\subsubsection{Epidemiologie}

Osteoporose gehört zu den häufigsten Erkrankungen, die sowohl Männer als auch Frauen betreffen kann. Weltweit sind schätzungsweise 200 Millionen Menschen betroffen (Cooper et al. 1992). Laut der bone evaluation study mit Erhebungen zwischen 2006 und 2009 liegt die Prävalenz der Osteoporose in Deutschland bei den über 50-Jährigen bei $14 \%$. Damit leben hochgerechnet etwa 6,3 Millionen Osteoporose-Betroffene in Deutschland (5,2 Mio Frauen und 1,1 Mio Männer). Die Inzidenz beträgt ca. 2,1\% pro Jahr. $52 \%$ der neu erkrankten Personen entwickelten im Beobachtungszeitraum Frakturen (Hadji et al. 2013). Osteoporosebedingte Frakturen führen seit langem zu mehr Aufenthaltstagen im Krankenhaus als Diabetes, Myokardinfarkte oder Brustkrebs (Kanis et al. 1997; Lippuner et al. 1997).

\subsubsection{Klinik der Osteoporose}

Die Klinik der Osteoporose wird durch Osteoporose-bedingte Frakturen und ihre Folgen geprägt und schränkt die Lebensqualität der betroffenen Patienten deutlich 
ein. Dies betrifft vor allem hüftgelenksnahe und vertebrale Frakturen (Cockerill et al. 2004; Lips und van Schoor 2005). Sie führen zu akuten und später chronischen Schmerzen sowie funktionellen Einschränkungen (Morin et al. 2012; Silverman et al. 2012). Nach Wirbelkörper-Fakturen wurden vermehrt Refluxbeschwerden beobachtet (Kanis et al. 2004b). Bei Osteoporose-assoziierten peripheren Frakturen wie auch bei Wirbelkörper-Frakturen besteht eine erhöhte Mortalität, wobei der Mortalitätsanstieg im ersten Jahr nach Fraktur am höchsten ist (Johnell et al. 2004a). Beschwerden oder Symptome, die rein durch die Osteoporose hervorgerufen werden, sind nicht bekannt.

\subsubsection{Einteilung der Osteoporose}

Im Hinblick auf die ätiologische Einteilung der Osteoporose unterscheidet man zwei Formen - die primäre und die sekundäre Osteoporose.

Die primäre Osteoporose tritt idiopathisch oder postmenopausal auf und bildet den größten Anteil der Osteoporose-Fälle (Herold 2019), für den in erster Linie die sinkende Östrogenkonzentration im Serum verantwortlich ist. Das weibliche Sexualhormon bildet einen wichtigen Faktor beim Erhalt der Vitalität und der Unterdrückung der Apoptose von Osteozyten und Osteoblasten bei gesunden Individuen (Tomkinson et al. 1997; 1998).

Die sekundäre Osteoporose wird durch zahlreiche Grunderkrankungen, Medikamente oder Umweltfaktoren ausgelöst, die unter 1.3.5.2 ausführlicher besprochen werden.

\subsection{5 Ätiologie und Pathogenese}

Beim Gesunden besteht eine ausgewogene Balance zwischen Knochenaufbau und Knochenabbau (Manolagas 2000). Man spricht dabei von der physiologischen Knochenumsatzrate (Link und Majumdar 2003; Felsenberg und Boonen 2005). Sobald eine Dysbalance zwischen Auf- und Abbau entsteht, sich die Lebensdauer der Osteoblasten verkürzt und der Lebenszyklus der Osteoklasten verlängert, resultiert ein gesteigerter Knochenabbau und eine dadurch abnehmende Knochenstabilität, wie sie bei Frauen in der Postmenopause durch den sinkenden Östrogenspiegel zu beobachten ist (Manolagas 2000; Seeman 2003). Mit dem 
Östrogen entfällt ein wichtiger Faktor im komplexen System des Knochenumbaus, der den Knochenabbau dämpft. Osteolytische Zytokine wie Interleukin 1, Interleukin 6 und Tumornekrosefaktor a gewinnen Überhand (Pacifici et al. 1991; Rickard et al. 1992; Siegenthaler und Blum 2006). Der Knochenabbau steigt, der Knochenumbau ist beschleunigt und Knochenabbauprodukte akkumulieren, was die knöcherne Stabilität insgesamt reduziert (Garnero et al. 1996).

\subsubsection{Einfluss der Knochendichte und Knochenqualität auf das Frakturrisiko}

Die Knochenstabilität wird maßgeblich von zwei Faktoren bestimmt: der Knochendichte und der mikrostrukturellen Knochenqualität (NIH Consensus Development Panel 2001). Zur Beurteilung der Knochendichte wird die sogenannte Knochenmineraldichte (engl. bone mineral density = BMD) herangezogen. Sie beschreibt die Beziehung zwischen dem T- und Z-Score und ist damit ein Maß für die erwartete Knochenmineraldichte unter Berücksichtigung von Alter und Geschlecht (National Osteoporosis Foundation 2005). Sie wird in $\mathrm{g} / \mathrm{cm}^{2}$ oder $\mathrm{g} / \mathrm{cm}^{3}$ angegeben (Compston 1995). Zahlreiche Studien konnten belegen, dass das Frakturrisiko mit verminderter BMD steigt (Cummings et al. 1993; Marshall et al. 1996; EPOS Group 2002; Miller et al. 2002), wodurch sich die Bestimmung der BMD zu einem Standardverfahren zur Bewertung einer Osteoporose vor Therapie etabliert hat. Dennoch scheint die BMD allein nicht auszureichen, um das Frakturrisiko eines Patienten abschätzen zu können. Studien mit antiresorptiven Medikamenten wiesen ein vermindertes Risiko für Wirbel-Frakturen nach, ohne dass dabei ein wesentlicher Einfluss auf die BMD beobachtet wurde (Cummings et al. 2002). Aus diesem Grund ist die Betrachtung einer weiteren Komponente, nämlich der mikrostrukturellen Knochenqualität sinnvoll. Strukturelle und materielle Eigenschaftes des Knochens machen diese aus (Link und Majumdar 2003; Felsenberg und Boonen 2005). Strukturellen Eigenschaften sind dabei die Knochengeometrie, also Größe und Form sowie die Mikroarchitektur (z. B. Trabekeldicke und Vernetzung/Konnektivität oder Kortikalisdicke). Zu den Materialeigenschaften zählen Mineralisation, Kollagenzusammensetzung, aber auch die Verletzungshäufigkeit des Knochens, beispielsweise durch stattgehabte Mikrofrakturen. 
Bei der Abschätzung des individuellen Risikos zur Entwicklung einer Osteoporose und osteoporotischer Frakturen spielen zahlreiche beeinflussbare und nicht beeinflussbare Risikofaktoren eine Rolle, die direkt oder indirekt die Knochenstabilität vermindern und im Folgenden Abschnitt erläutert werden.

\subsubsection{Risikofaktoren für die Entstehung der Osteoporose und die Ent- wicklung osteoporotischer Frakturen}

Zahlreiche, teils sich gegenseitig beeinflussende oder völlig autarke Risikofaktoren bedingen die Entwicklung einer Osteoporose und das daraus resultierende Frakturrisiko bei Männern und Frauen.

Durch die ovariale Dysfunktion in der Menopause und den dadurch sinkenden Östrogenspiegel kommt es bei Frauen zu einem Verlust an Knochenmasse, weshalb das Alter einer Patientin wie auch das weibliche Geschlecht starke Risikofaktoren sind (Cooper und Melton 1992; Kanis et al. 2001; EPOS Group 2002; Mora und Gilsanz 2003; Kanis et al. 2005b; Pluijm et al. 2009). Das Frakturrisiko einer 50-jährigen Frau beträgt $16 \%$ für vertebrale Frakturen und Frakturen des proximalen Femurs sowie $15 \%$ für Radiusfrakturen. Das statistische Gesamtfrakturrisiko für Frauen in der frühen Menopause liegt über $50 \%$ (Kanis et al. 2000).

Neben Alter und Geschlecht scheint auch die Herkunft und die damit verbundenen genetischen Determinanten eine wichtige Rolle zu spielen. So scheinen über 50jährige Asiatinnen im Vergleich zu gleichaltrigen Frauen anderer Herkunft eine verminderte Knochenmasse und ein damit deutlich erhöhtes Risiko für Hüftfrakturen zu haben (NIH Consensus Development Panel 2001; Fang et al. 2004). Auch bereits stattgehabte Wirbelkörper-Frakturen begünstigen - je nach Anzahl und Schweregrad - die Ausbildung weiterer Frakturen (Kanis et al. 2004a; Johnell et al. 2004b; Roux et al. 2007).

Zu den weiteren, allgemeinen Risikofaktoren zählen zudem multiple Stürze (Balzer et al. 2010; Centre for Clinical Practice at NICE (UK) 2013), Immobilität (Feskanich et al. 2002; Jokinen et al. 2010), Rauchen und chronisch-obstruktive Lungenerkrankung (Law und Hackshaw 1997; Kanis et al. 2005a; Shen et al. 2015), niedriges Körpergewicht und niedriger Körperfettanteil (Meyer et al. 1995; Ravn et al. 1999; Tromp et al. 2000; Colón-Emeric et al. 2002) sowie Vitamin D- und 
Calciummangel (Meyer et al. 1997; Cummings et al. 1998; Michaëlsson et al. 2003; Cauley et al. 2008).

Zahlreiche Grunderkrankungen bedingen ein erhöhtes Frakturrisiko. Eine vollständige Übersicht zu allen erkrankungsbedingten Risikofaktoren bietet die Leitlinie des DVO 2017. Zu nennen wären endokrinologische Krankheiten wie die Hyperthyreose (Vestergaard und Mosekilde 2003; Yan et al. 2016) oder Diabetes mellitus Typ I (Schwartz et al. 2001; Vestergaard 2007) und Typ II (Schwartz et al. 2011; Giangregorio et al. 2012). Auch rheumatologische Erkrankungen wie rheumatoide Arthritis (van Staa et al. 2006; Dennison et al. 2012) sowie gastroenterologische Krankheiten wie Zöliakie und chronisch-entzündliche Darmerkrankungen mit dem damit verbundenen Vitamin D-Mangel zeigten in Studien ein erhöhtes Frakturrisiko (Hippisley-Cox und Coupland 2009; Heikkilä et al. 2015). Neurologischen Erkrankungen zu denen die Epilepsie mit Einnahme von Antiepileptika (Andress et al. 2002; Carbone et al. 2010) oder die Schizophrenie (Stubbs et al. 2015) zählen erhöhen ebenso wie die Herzinsuffizienz (Sennerby et al. 2009; Majumdar et al. 2012) und der Alkoholabusus mit der alkoholischen Leberzirrhose (Bang et al. 2015; Zhang et al. 2015) Studien zufolge das Risiko für Frakturen.

Nicht zuletzt spielen auch Medikamente bei der Frakturentwicklung eine große Rolle. Wichtig sind hier vor allem Glukokortikoide in Abhängigkeit der Dosis und der Anwendungsdauer (Van Staa et al. 2000; 2002) sowie Medikamente, die Stürze begünstigen - z. B. Sedativa oder Neuroleptika (Cumming und Le Couteur 2003; Lewis et al. 2007).

Die häufigsten Lokalisationen osteoporotischer Frakturen am menschlichen Skelett sind in Abb. 1 unter Berücksichtigung der nicht beeinflussbaren Risikofaktoren "Herkunft" und "Alter" dargestellt. 


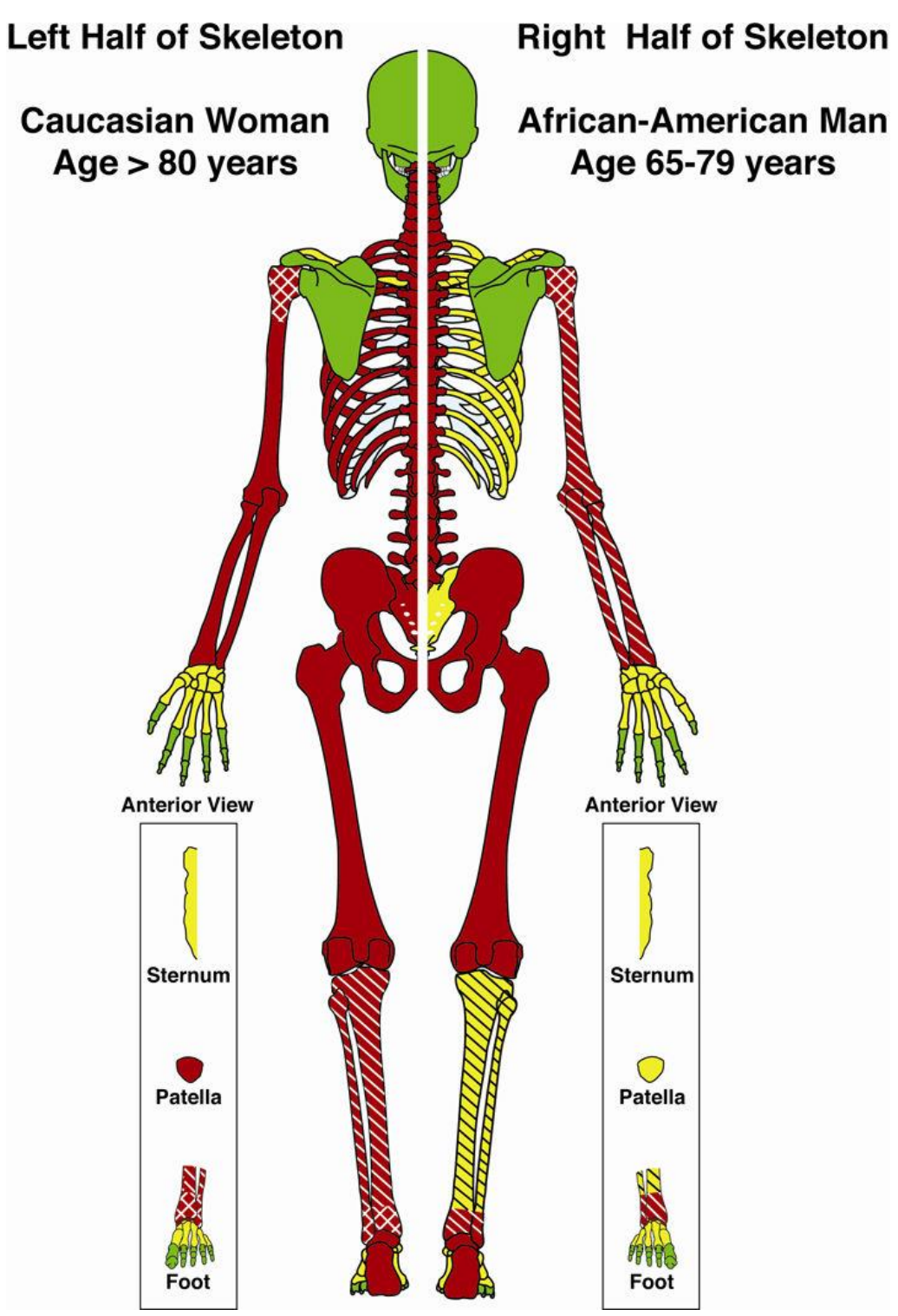

Abb. 1: Frakturrisiko der Skelettabschnitte - getrennt nach den Risikofaktoren Herkunft und Alter (rechts/links).

Drei farbcodierte Risikolevel: Rot $=$ höchstwahrscheinlich osteoporotisch bedingt, Gelb = mittlere Wahrscheinlichkeit eines kausalen Zusammenhangs zu

Osteoporose,

Grün = unwahrscheinlich osteoporotisch bedingt

Schraffurmuster: offene Fraktur ist unwahrscheinlicher osteoporotisch bedingt als geschlossene Fraktur (einfaches Schraffurmuster: Unwahrscheinlichkeit hoch, doppeltes Schraffurmuster: Unwahrscheinlichkeit sehr hoch)

Basierend auf (Warriner et al. 2011)

Verwendung mit freundlicher Genehmigung des Journal of Clinical Epidemiology 


\subsubsection{Diagnostik}

Zur empfohlenen Basisdiagnostik der Osteoporose gehören neben der Anamnese zur Evaluation allgemeiner und spezieller Risikofaktoren und der klinischen Untersuchung mit zahlreichen Tests eine Knochendichtemessung und ein Basislabor. Besteht darüber hinaus der Verdacht auf osteoporotische Wirbelkörper-Frakturen sind auch bildgebende Verfahren indiziert.

Die Basisdiagnostik wird generell für Frauen und Männer ab dem 70. Lebensjahr und prinzipieller Therapiebereitschaft empfohlen (DVO 2017).

\subsubsection{Knochendichtemessung}

Das standardmäßig zum Einsatz kommende Verfahren zur Messung der Knochendichte ist die Osteodensitometrie mittels Zwei-Energien-RöntgenAbsorptiometrie (engl. dual-energy-x-ray-absorptiometrie $=\mathrm{DXA} / \mathrm{DEXA}$ ). Entsprechend den physikalischen Grundlagen der photoelektrischen Absorption und der Compton-Streuung kann beim Durchtritt der Röntgenstrahlung durch den Knochen die Knochendichte ermittelt werden (Kurth et al. 2001). Die DXAMethode dient der Überprüfung, ob eine Osteoporose nach WHO-Definition anhand des T-Scores vorliegt und/oder ermöglicht die Prüfung der Wirksamkeit einer medikamentösen Therapie. Sie wird an der Lendenwirbelsäule und dem proximalen Femur angewandt.

Neben der Röntgen-basierten DXA-Methode existieren weitere Verfahren zur Beurteilung der Knochendichte. Dazu gehören der quantitative Ultraschall und die CT-messung (QUS und QCT) sowie der trabecular bone score (TBS). Lediglich das CT-basierte CTXA-Verfahren bietet die Möglichkeit, DXA-äquivalente TScores der Hüfte zu ermitteln (Engelke et al. 2015). QUS, QCT und TBS erbringen keine vergleichbaren Daten, die der WHO-Definition entsprechen. Sie sind eigenständige Untersuchungsmethoden, die optional zur Beurteilung des Frakturrisikos hinzugezogen werden können (Engelke et al. 2015; Silva et al. 2015). 


\subsubsection{Basislabor}

Das Basislabor dient der Aufdeckung laborchemischer Veränderungen, die auf eine sekundäre Osteoporose oder klinisch nicht fassbare Frakturrisiken hinweisen oder eine zusätzliche Diagnostik erfordern bzw. einer speziellen Therapie bedürfen (Tannenbaum et al. 2002; Jamal et al. 2005; Ryan et al. 2011). Eine Auflistung aller Bestandteile des Basislabors, der wichtigsten zur Osteoporose abgrenzbaren Differentialdiagnosen sowie optionaler Laboruntersuchungen findet sich in der Leitlinie des Dachverbands der Deutschsprachigen Wissenschaftlichen Osteologischen Gesellschaft e.V. (DVO 2017).

\subsubsection{Bildgebende Verfahren}

Die Bildgebung dient der Erfassung vertebrogener Frakturen. Indikation zur Bildgebung sind laut DVO akute, neu aufgetretene, starke und/oder unverändert über Tage bestehende lokale Rückenschmerzen sowie chronische Rückenschmerzen, die noch nicht abgeklärt wurden. Ebenso das Vorliegen von mindestens einem klinischen Risikofaktor für Wirbelkörper-Brüche. Dazu zählen unter anderem hohes Alter, Größenverlust seit dem 25. Lebensjahr um mehrere Zentimeter oder um mehr als $2 \mathrm{~cm}$ in Verlaufskontrollen, niedrige Knochendichte und periphere Frakturen (Gunnes et al. 1996; Kaptoge et al. 2004). Primär verwendet werden Röntgenaufnahmen der BWS und LWS oder das vertebrale Fraktur-Assessment (VFA) mittels DXA. Diese dokumentieren zwar das Vorhandensein von Wirbelkörper-Frakturen, lassen oft aber keine weiteren Rückschlüsse auf die Genese, das Frakturalter oder die knöcherne Stabilität zu (Hospers et al. 2009). Zur Klärung dieser Fragen sind dann oft weitere bildgebende Verfahren wie CT oder MRT indiziert (Ito et al. 2006). Auch die Knochenbiopsie kann in individuellen Fällen herangezogen werden (DVO 2017).

\subsubsection{Therapie}

Da der Osteoporose sehr mannigfaltige Ursache zugrunde liegen können, ist deren Therapie entsprechend breit gefächert. Gegenstand dieses Abschnittes sollen lediglich Therapiemöglichkeiten der primären Osteoporose bei Männern und 
postmenopausalen Frauen darstellen. Die Behandlung der sekundären Osteoporose richtet sich in erster Linie nach der Behandlung der zugrunde liegenden Erkrankung oder dem Management einer Osteoporose-induzierenden Medikation.

\subsubsection{Basistherapie}

Zum Basismanagement gehören laut DVO in erster Linie Maßnahmen zur Osteoporose- und Frakturprophylaxe. Neben regelmäßiger körperlicher Aktivität zur Förderung der Muskelkraft, des Gleichgewichtes und der Koordination spielt auch die Vermeidung von Untergewicht, die Durchführung einer Sturzanamnese ab der achten Lebensdekade wie auch die Abwägung eines individuellen NutzenRisiko-Verhältnisses zur Anwendung Osteoporose und/oder Stürze begünstigender Medikamente eine wichtige Rolle (Bolam et al. 2013; Halvarsson et al. 2015; DVO 2017). Empfohlen wird eine psychosoziale Betreuung von Patienten mit bereits stattgehabten Stürzen und/oder Frakturen, um innen die Angst vor erneuten Ereignissen zu nehmen und indirekt einer zunehmenden Immobilisation vorzubeugen (DVO 2017). Generell sollten betroffene Patienten stets auf eine ausreichende Calcium- und Vitamin D-Zufuhr achten und diese gegebenenfalls substituieren (Avenell et al. 2014; DVO 2017).

\subsubsection{Spezifische medikamentöse Therapie}

Ziel der medikamentösen Osteoporose-Therapie ist die Reduktion des erhöhten Frakturrisikos betroffener Patienten. Hinsichtlich der dezidierten Indikationsstellung zur medikamentösen Therapie bei Osteoporose-Patienten sei auf die Leitlinie des DVO verwiesen (DVO 2017). Die nachfolgend genannten Medikamente sind Präparate, deren frakturreduzierende Wirkung für Männer und postmenopausale Frauen belegt ist. Die Osteoporose-Behandlung bei Kindern, Jugendlichen, prämenopausalen Frauen und Patienten mit schwerer Niereninsuffizienz orientiert sich an der Behandlung der jeweiligen Grunderkrankung. Generell unterscheidet man bei den Osteoporose-Medikamenten die Gruppe der antiresorptiven Präparate, wie Bisphosphonate oder Östrogene, die dem Knochenabbau entgegenwirken und den anabolisch wirkenden Mitteln, wie beispielsweise Parathormon-Analoga, die den Knochenaufbau unterstützen. 


\subsection{Bisphosphonate}

Sie gehören zu den antiresorptiven Medikamenten, da sie mit hoher Affinität an der mineralischen Knochenoberfläche - und dort bevorzugt an Stellen mit erhöhter Resorption - binden, von Osteoklasten aufgenommen werden und die Osteoklastenaktivität hemmen (Freissmuth und Böhm 2012). Sie dienen als ErstlinienPräparate sowohl der Prophylaxe als auch der Therapie von Osteoporose (DVO 2017). Von dem DVO empfohlene Präparate sind Alendronat (Liberman et al. 1995; Orwoll et al. 2000), Ibandronat (Delmas et al. 2004), Risedronat (Harris et al. 1999; Zhong und Chen 2009) und Zoledronat (Black et al. 2007; Boonen et al. 2012). Sie reduzieren das Frakturrisiko nachweislich und steigern die Knochenmineraldichte (Liberman et al. 1995; Harris et al. 1999; Black et al. 2007).

\subsection{Denosumab und Romosozumab}

Bei Denosumab handelt es sich um einen humanen monoklonalen Antikörper, der mit hoher Affinität und Spezifität an das Protein RANK-Ligand (RANKL) bindet, was im Folgenden die Differenzierung und Reifung von Osteoklasten hemmt und so deren Funktion in der Knochenresorption unterbindet (Kurth und Lange 2018). Es wird zum einen als Erstlinien-Therapie bei primärer Osteoporose mit hohem Frakturrisiko und bei Patienten, die keine orale Bisphosphonat-Therapie erhalten können eingesetzt und subkutan injiziert (Camacho et al. 2016). Zum anderen findet es begleitend Anwendung bei Frauen mit Brustkrebs unter adjuvanter Therapie mit Aromatase-Hemmern sowie bei Männern mit Prostatakarzinom unter hormonablativer Therapie und erhöhtem Frakturrisiko (Smith et al. 2009). Zahlreiche Studien wie die FREEDOM-Studie konnten eine signifikante Reduktion des Frakturrisikos unter Denosumab belegen (Cummings et al. 2009).

Einen weiteren vielversprechenden Therapieansatz bildet der monoklonale Antikörper Romosozumab, der über die Ausschaltung des Signalproteins Sclerostin den Knochenabbau durch Osteoklasten hemmt. Eine internationale MulticenterStudie konnte nach 12- und 24-monatiger Applikation von Romosozumab bei Frauen mit postmenopausaler Osteoporose und initial deutlich erniedrigter Knochenmineraldichte einen signifikanten Anstieg der BMD verzeichnen. Auch waren Marker des Knochenaufbaus im Blut erhöht und Marker des Knochen- 
abbaus vermindert nachweisbar. Im Verlauf stellte sich insbesondere auch die Kombination mit einer Bisphosphonat-Therapie oder mit Denosumab als förderlich zur Erhaltung der Knochenmineraldichte und zur Senkung des Risikos von Wirbelkörper- und Hüft-Frakturen heraus (McClung et al. 2014; McClung et al. 2018). Romosozumab (Evenity ${ }^{\circledR}$ ) wurde im Frühjahr 2019 in den USA offiziell zur Behandlung der Osteoporose zugelassen. Die deutliche Erhöhung von kardiovaskulären Zwischenfällen verhinderte aber bislang die Zulassung in der EU.

\subsection{Hormon(ersatz)therapie}

Die wohl wichtigste Gruppe der Hormontherapie nehmen die selektiven Östrogenrezeptor-Modulatoren (SERMs) ein. Sie weisen eine agonistisch/antagonistische Wirkung am Östrogenrezeptor auf. Dies bewirkt einen selektiven agonistischen Einfluss auf den Knochen- und Lipidstoffwechsel bei gleichzeitig antagonistischem Effekt am Brustdrüsenparenchym und am Endometrium. Das bedeutet, dass die positive Wirkung des Östrogens am Knochen vorhanden ist, die negative Wirkung durch Erhöhung des Brustkrebsrisikos am Mammaparenchym aber entfällt (Lemmer und Brune 2006). Deshalb wird die Anwendung reiner Östrogenpräparate lediglich auf die Prävention bei postmenopausalen Frauen mit hohem Frakturrisiko beschränkt, die eine Unverträglichkeit oder Kontraindikation für andere Medikamente aufweisen (DVO 2017). Zu den SERMs zählt beispielsweise Raloxifen, dessen Langzeitwirkung in zahlreichen Studien belegt wurde (Siris et al. 2002; Delmas et al. 2003).

Auch Parathormon-Analoga wie Teriparatid werden eingesetzt. Es stimuliert die Osteoblastenaktivität und damit den Knochenaufbau und die Verbesserung der Knochenarchitektur (Lindsay et al. 1997; Neer et al. 2001).

Calcitonin wird heute nur noch als Reservemedikament bei Unverträglichkeiten oder Kontraindikationen gegenüber anderen Medikamenten angewandt. Es ist ein synthetisch hergestelltes Hormon des Calciumstoffwechsels (Trovas et al. 2002).

\subsection{Strontiumsalze}

Strontium gehört zu der Gruppe der Erdalkalimetalle und ist chemisch und physikalisch eng mit Calcium verwandt. Es bedarf einer Kombination mit anderen 
Substanzen, um effektiv vom Darm aufgenommen zu werden. Dies ist beispielsweise durch die Koppelung mit Ranelicsäure zu Strontiumranelat oder mit Citronensäure zu Strontiumcitrat möglich (Bartl 2010). Anders als die übrigen Osteoporose-Medikamente, die entweder antiresorptiv oder osteoanabol arbeiten, bewirkt der Einbau von Strontium in den Knochen beides - sowohl die Knochenneubildung als auch die Hemmung des Knochenabbaus (Geng et al. 2018). Der Wirkmechanismus ist dabei noch nicht vollständig geklärt. Vermutet wird aber, dass es über Calcium-sensitive Rezeptoren und den RANK/RANKL/OPG-Weg auf den Knochen einwirkt (Buehler et al. 2001; Farlay et al. 2005; Choudhary et al. 2007; Bonnelye et al. 2008; Caverzasio 2008; Fonseca 2008; Brennan et al. 2009; Hamdy 2009; Caudrillier et al. 2010; Gallacher und Dixon 2010; Takaoka et al. 2010). Die unmittelbare Wirkung von Strontium am Knochen ist sehr mannigfaltig. So beschleunigt es die Proliferation von Prä-Osteoblasten und deren Differenzierung zu Osteoblasten ebenso wie die Synthese von Kollagen Typ I und die Mineralisation der Knochenmatrix. Außerdem wirkt es inhibierend auf den Knochenabbau, indem es die Differenzierung und Aktivierung von Osteoklasten unterdrückt (Braux et al. 2011; Buache et al. 2012). Damit ähnelt Strontium in seiner Wirkungsweise dem Sexualhormon Östrogen, dessen abfallender Serumspiegel ausschlaggebend für die Entwicklung der postmenopausalen Osteoporose ist.

Zahlreiche Studien konnten nach oraler Applikation von Strontiumranelat eine signifikante Vermehrung der Knochenmasse mit erhöhter Kortikalisdicke und Verbesserung der trabekulären und kortikalen Mikroarchitektur nachweisen, die zu einer verbesserten Knochenqualität und -stärke führten (Ammann et al. 2004; 2007; Kyllönen et al. 2015; Zhao et al. 2015). Dadurch wird eine nachweisliche Erhöhung der Knochenmineraldichte erreicht (Deeks und Dhillon 2010a; Marie et al. 2011; Boivin et al. 2012; Tenti et al. 2014) und das Frakturrisiko für vertebrale und nicht vertebrale Frakturen signifikant reduziert (Nielsen et al. 1999; Meunier et al. 2004; Reginster et al. 2005; 2008; Roux et al. 2008; Reginster et al. 2012; Abboskhujaeva et al. 2014; Iñiguez-Ariza und Clarke 2015). Die Wirkung auf die Knochenmineraldichte wurde in gleicher Weise auch bei Osteoporose-betroffenen Männern nachgewiesen (Kaufman et al. 2013).

Anders als Bisphosphonate, die durch Hemmung des Knochenumbaus eine Frakturheilung verzögern können, zeigten Strontium-Verbindungen im Tiermodell 
einen positiven Effekt auf die Heilung von Frakturen und die damit verbundene Ausreifung von neu gebildetem Kallus (Cao et al. 2002; Habermann et al. 2010; Li YF et al. 2010; Ozturan et al. 2011; Komrakova et al. 2015; Hegde et al. 2016). Auch beim Menschen scheint dieser Effekt auf komplizierte Frakturheilungen vorhanden zu sein (Tarantino et al. 2010; Alegre et al. 2012).

$\mathrm{Zu}$ den Nebenwirkungen, die während der Strontiumranelat-Applikation beim Menschen beobachtet wurden zählen venöse Thrombembolien, Myokardinfarkte, Unwohlsein, Durchfälle, Übelkeit, Hypersensitivitätsreaktionen, Dermatitis, Ekzeme sowie neurologische Nebenwirkungen wie Kopfschmerzen oder Schwindel (Das und Crockett 2013; Komm et al. 2015; Reginster et al. 2015). Sie führten zunächst zur Beschränkung des Anwendungsgebietes von Strontiumranelat (z. B. Protelos ${ }^{\circledR} /$ Osseor $^{\circledR}$ von Servier Deutschland $\mathrm{GmbH}$ oder BERAGENA Arzneimittel $\mathrm{GmbH}$ ), weshalb die Produktion für den Haupt-Hersteller Servier Deutschland $\mathrm{GmbH}$ immer weniger rentabel war und schließlich eingestellt wurde.

Auf dem Hintergrund des großen Potentials, das Strontium bereits gezeigt hatte, werden aber auch weiterhin Studien mit Strontium-Verbindungen durchgeführt und neue Anwendungsgebiete erforscht. Scardueli et al. (2018) wiesen erst kürzlich unter systemischer Strontium-Therapie ein optimiertes Einwachsen von osteosynthetischen Titanimplantaten und eine Verbesserung der periprothetischen Knochenqualität nach. Auch bei der Behandlung der Osteoarthritis existieren Therapiestudien, die die Wirksamkeit von Strontium belegen (Pelletier et al. 2013). Verbindungen, die in diesem Zusammenhang bereits angewendet werden sind Strontiumchlorid und Strontiummalonat (Dahl et al. 2001; Raffalt et al. 2008) sowie Strontiumcitrat, das wie Strontiumranelat eine vergleichbar rasche Erhöhung des Strontium-Gehaltes im Knochen von Probanden bewirkt und als Nahrungsergänzungsmittel frei zu erwerben ist (Moise et al. 2012; Wohl et al. 2013; Moise et al. 2014). 


\subsection{Die Ratte als Versuchsmodell}

Sowohl bei Menschen als auch bei Tieren ist Östrogen ein wichtiger Faktor zur Erhaltung der Knochenvitalität und bei der Unterdrückung der Apoptose von Osteozyten und Osteoblasten (Bonewald 2004).

Bei der Auswahl eines geeigneten Tiermodells zur Erforschung der Osteoporose ist die wichtigste Frage, inwieweit die Vorgänge im Tierskelett hinsichtlich Aktivierung, Resorption und Aufbau den Vorgängen im menschlichen Skelett ähneln, die durch einen ständigen Knochenumbau charakterisiert sind. Das Ratten-Skelett zeigt im Lebensverlauf des Tieres einen allmählichen Übergang vom reinen Knochenaufbau (Modelling) in den später vorherrschenden Knochenumbau (Remodelling) und ähnelt damit den Vorgängen im alternden menschlichen Skelett (Dennison et al. 2005). Diese Veränderungen können beispielsweise am Corpus vertebrae ab dem dritten Lebensmonat der Ratte beobachtet werden und sind meist um den zwölften Lebensmonat abgeschlossen. Dann herrscht wie beim Menschen der Knochenumbau vor (Erben 1996; Iwaniec und Turner 2008).

Bereits zahlreiche Tierversuchsstudien mit Ratten konnten nachweisen, dass eine beidseitige Ovariektomie mit resultierendem Östrogenmangel zu einer Osteopenie der Versuchstiere führt, die mit der postmenopausalen Situation bei Frauen vergleichbar ist (Abb. 2) (Jee und Yao 2001; Li N et al. 2009; El-Khayat et al. 2010; Mohamed und Omar 2010; Naim 2011; Wei et al. 2015; Safty et al. 2018). Da Ratten bereits wenige Wochen nach Ovariektomie eine Osteopenie entwickeln, sind drei Monate alte Ratten ein geeigneten und inzwischen vielfältig angewendetes Tiermodell, um strukturelle Veränderungen der Knochensubstanz bei Osteoporose und medikamentöse Effekte im Rahmen einer Therapie zu evaluieren (Kalu 1991). Giro et al. (2008) wiesen beispielsweise bereits kurz nach Ovariektomie einen rapiden Verlust an spongiöser Knochenmasse und Widerstandsfähigkeit der Knochen der Versuchstiere nach. Ein signifikanter Knochensubstanzverlust am Corpus vertebrae war bei Lelovas et al. (2008) nach ca. 60 Tagen zu beobachten. Untersuchungen an der Lendenwirbelsäule als einem der Hauptmanifestationsorte der Osteoporose wurden in unserer Arbeitsgruppe der Universität Göttingen bereits mehrfach durchgeführt (Erren 2007; Döll 2010; Grüger 2011; Fürst 2014; Genotte 2016; Hofmann 2017; Sturm 2018) und 
publiziert (Sehmisch et al. 2009; Komrakova et al. 2014; 2015; Hoffmann et al. 2017).
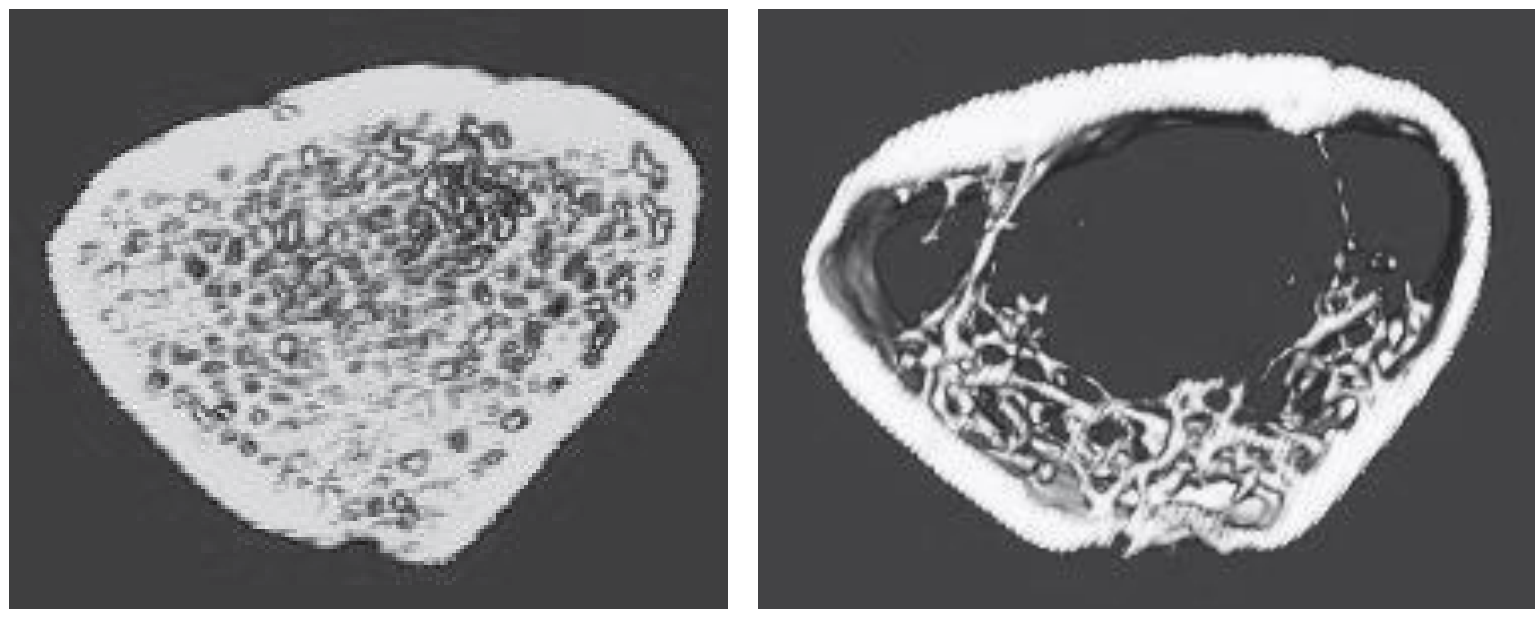

Abb. 2: Beispiel eines gesunden Knochens (links) und eines

osteoporotischen Knochens (rechts) anhand von zwei-dimensionalen Mikro-CTBildern der axial angeschnittenen distalen Femora bei Versuchsratten ohne (links) und mit Ovariektomie (rechts); basierend auf (Saul et al. 2018b), Verwendung mit freundlicher Genehmigung des Journal of Applied Physiology

Um eine Osteopenie in weiblichen oder männlichen Ratten zu induzieren existieren verschiedene Möglichkeiten. Dazu zählen hormonelle Eingriffe durch chirurgische Interventionen wie Ovariektomie oder Orchiektomie, die pharmazeutische Induktion durch Östrogenrezeptor-Antagonisten oder Glukokortikoide, die diätische Variante mit niedrigerer Calciumzufuhr oder auch der Alkoholabusus und die Immobilisation (Lelovas et al. 2008). Auch die Möglichkeiten zur Evaluation der induzierten Osteopenie sind sehr vielfältig. Nicht invasive Methoden schließen die Messung biochemischer Marker wie Calcium und Phosphat im Serum und Urin oder auch von Markern des Knochenumbaus wie Proteinen, die von Osteoblasten oder Osteozyten gebildet werden ein. Die Messung erfolgt mittels Chromatographie oder Radio-Immunassay (Loeb und Quimby 1999; Seibel 2000). Densometrische Verfahren haben sich besonders zur Evaluation der BMD etabliert und erfolgen über die herkömmliche Osteodensitometrie mit spezieller Software für Kleintiere (Cavolina et al. 1997; Turner et al. 2001) oder auch mittels peripherer quantitativer Computertomografie (pQCT), die eine seperate Betrachtung von spongiösem und kortikalem Knochen ermöglicht, eine Untersuchung auf Trabekelebene aber ausschließt (Gasser 1995). Das 
Mikro-CT stellt dagegen eine hochauflösende, drei-dimensionale Bildgebung der Knochen mit der Möglichkeit von Untersuchungen auf Trabekelebene dar. Zusätzlich können damit Parameter evaluiert werden, die eine Aussage über den histomorphologischen Status der Knochen zulassen und damit auch frühe Veränderungen der Knochenarchitektur darstellen können (Jiang et al. 2005; Lelovas et al. 2008). Mittels MR-Mikroskopie ist eine Darstellung von Fett- und Wasseranteilen im Knochen möglich. Sie gewährleistet eine Abbildung des trabekulären Knochens als eine Art Negativbild (Genant und Jiang 2006).

Demgegenüber stehen invasive Methoden zur Detektion und Evaluation der Osteopenie. Bei der Histomorphometrie werden die Knochen histologisch aufgearbeitet und hinsichtlich Zellzahlen analysiert. Gleichzeitig ist auch die Untersuchung der Knochenarchitektur und die Evaluation von Zeichen der knöchernen Fragilität möglich (Dalle Carbonare et al. 2005; Lelovas et al. 2008). Der mechanische Bruchtest mit eigens dafür konzipierten Prüfgeräten stellt eine Methode zur Beurteilung der Widerstandskraft der Knochen dar.

Beim Vergleich osteopenischer Knochen von Ratten und Menschen sollte berücksichtigt werden, dass die Knochen von Ratten unter Umständen auch einem längerfristigen longitudinalen Wachstum mit stetiger Knochenneubildung unterstehen können, was am Corpus vertebrae unter Umständen bis zum 21. Lebensmonat der Tiere anhalten kann (Jee und Yao 2001). Die Ratten der vorliegenden Studie waren zum Studienende etwa 16 Wochen alt und befanden sich demnach noch in einem Stadium mit potentiell persistierendem Knochenaufbau (Erben 1996; Lelovas et al. 2008).

Ein Nachteil, der bei Ratten im Vergleich zum Menschen beobachtet wurde, ist die fehlende Fähigkeit der Tiere zum sogenannten Havers-Umbau, bei dem im menschlichen Skelett minderwertiger, aber schnell verfügbarer Geflechtknochen durch biomechanisch wertvolleren lamellären Knochen ersetzt wird. Ein Fehlen dieses Vorganges begünstigt zwar die Entwicklung der kortikalen Porosität (Heberer et al. 1983), spielt bei der Entwicklung der humanen Osteoporose aber nur eine untergeordnete Rolle, sodass das Fehlen des Vorganges keine größere Bedeutung hat (Turner et al. 2001; Iwaniec und Turner 2008). 
Auch ein weiterer wichtiger Faktor der menschlichen Osteoporose konnte bisher in keinem Tiermodell reproduziert werden: spontane Frakturen und Mikrofrakturen (Frost und Jee 1992).

Auf dem Hintergrund der WHO-Definition der Osteoporose (bei einer BMD unter 2,5 SD unter einem jungen Referenzkollektiv) ist die Ratte dennoch ein geeignetes Modell zur Erforschung der Osteoporose - auch im Vergleich zu anderen Tiermodellen wie Hunden oder Primaten. Ergebnisse sollten auf dem Hintergrund Spezies-spezifischer Unterschiede dennoch immer differenziert betrachtet werden. 


\section{Material und Methoden}

\subsection{Versuchsaufbau}

Nach Ankunft und einwöchiger Akklimatisation der Versuchstiere in der tierexperimentellen Einrichtung des Universitätsklinikum Göttingen erfolgte zunächst die Aufteilung in fünf Gruppen zu je zwölf Ratten (Tabelle 2): NON-OVX - die Kontrollgruppe, die nicht ovariektomiert wurde und dementsprechend keine Osteopenie entwickelte. OVX mit Versuchstieren, die bis auf eine Ovariektomie keine weitere Behandlung erhielten. OVX + SR-Therapie (SR th) mit ovariektomierten Tieren, die zusätzlich eine medikamentöse Therapie mit Strontiumranelat nach Entwicklung einer Osteopenie erhielten. OVX + SR-Prophylaxe (SR pr) - die Versuchsgruppe, die ovariektomiert wurde und sofort eine medikamentöse Prophylaxe mit Strontiumranelat erhielt und die fünfte Gruppe, der nach der Ovariektomie sowohl eine Prophylaxe als auch eine Therapie mit Strontiumranelat zugeführt wurde (SR pr+th).

Im Rahmen dieser Einteilung erhielten die Ratten in der SR th-Gruppe in den ersten acht Wochen nach Ovariektomie kein Medikament und dann für fünf Wochen (Studienwoche 8-13) die medikamentöse SR-Therapie. Tiere in der SR pr-Gruppe bekamen demgegenüber sofort nach $\mathrm{OP}$ für die ersten acht Wochen eine SR-Prophylaxe und anschließend keine weitere Therapie (Studienwoche 0-8). Die Ratten der Prophylaxe- und Therapie-Gruppe (SR pr+th) erhielten während der gesamten 13 Versuchswochen Strontiumranelat (Studienwoche 0-13). Dieses wurde der Nahrung der Versuchstiere in einer Konzentration von 10,52 g/kg Futter beigemengt. Dabei wurden aufgenommene Futtermenge und Gewicht der Tiere einmal wöchentlich dokumentiert. Ein freier Futterzugang ermöglichte eine SR-Tagesdosis von etwa $625 \mathrm{mg} / \mathrm{kg}$ Körpergewicht, was zu einer annähernd vergleichbaren Serumkonzentration wie der im menschlichen Blut nach SR-Einnahme führt (Bain et al. 2009; Habermann et al. 2010; Li YF et al. 2010; Weidemann 2013; Komrakova et al. 2015; 2016).

Der Versuch endeten 13 Wochen nach Ovariektomie mit der Obduktion der Versuchstiere. 


\subsection{Versuchstiere und Tierhaltung}

Die Untersuchungen erfolgten an 60 weiblichen, initial drei Monate alten Ratten vom Sprague-Dawley-Stamm (Zuchtanstalt Winkelmann, Borken, Deutschland) mit einem durchschnittlichen Gewicht von 263,84 g \pm 6,49 g (SD). Die Tiere waren während der gesamten Untersuchungszeit in der Zentralen Tierexperimentellen Einrichtung (ZTE) der Universität Göttingen in $20^{\circ} \mathrm{C}$ temperierten Makrolon ${ }^{\circledR}$ Typ IV-Käfigen bei $55 \%$ Luftfeuchtigkeit untergebracht. Die Käfigaufteilung entsprach der jeweiligen Gruppenzugehörigkeit zu je vier Ratten pro Käfig (Tabelle 2). Zur Erhaltung des Tag-Nacht-Rhythmus erfolgten Hell-DunkelPerioden in zwölf-stündigem Abstand. Soja-freies Futter (ssniff SM R/M; 10 mmPellets; ssniff Spezialdiäten $\mathrm{GmbH}$, Soest, Deutschland) und Wasser standen jederzeit zur freien Verfügung.

Haltung und Experimente erfolgten unter streng ethischen Standards und wurden gemäß dem §8 des Tierschutzgesetzes von der Bezirksregierung Braunschweig genehmigt (G 11.560).

Tabelle 2: Einteilung der Versuchstiere in die Untersuchungsgruppen

\begin{tabular}{|c|c|c|c|}
\hline Gruppennummer & Tieranzahl & $\begin{array}{c}\text { Bezeichnung } \\
\text { (Gruppenkürzel) }\end{array}$ & $\begin{array}{c}\text { Behandlungs- } \\
\text { regime }\end{array}$ \\
\hline $\mathbf{1}$ & 12 & NON-OVX & Kontrollgruppe \\
\hline $\mathbf{2}$ & 12 & OVX & Ovariektomie \\
\hline $\mathbf{3}$ & 12 & SR th & $\begin{array}{c}\text { Ovariektomie }+ \\
\text { Strontiumranelat- } \\
\text { Therapie }\end{array}$ \\
\hline $\mathbf{4}$ & 12 & SR pr & $\begin{array}{c}\text { Ovariektomie + } \\
\text { Strontiumranelat- } \\
\text { Prophylaxe }\end{array}$ \\
\hline $\mathbf{5}$ & 12 & SR pr+th & $\begin{array}{c}\text { Ovariektomie + } \\
\text { Strontiumranelat- } \\
\text { Prophylaxe + } \\
\text { Strontiumranelat- } \\
\text { Therapie }\end{array}$ \\
\hline
\end{tabular}




\subsection{Ovariektomie}

Die Ovariektomie erfolgte in der vorliegenden Studie unter einer intraperitonealen Ketamin-Xylazin-Anästhesie (115 mg und $8 \mathrm{mg} / \mathrm{kg}$ Körpergewicht i.p.).

Zunächst wurden die Ratten zwischen den Rippenbogen und den Hinterläufen rasiert und ausgiebig mit Betaisodona (Mundipharma GmbH, Frankfurt am Main, Deutschland) desinfiziert. Dann wurden Inzisionen an beiden Seiten des Abdomens durchgeführt. Es folgte eine Eröffnung bis zum Peritoneum und eine Präparation der Tubae uterinae sowie der umliegenden Gefäße. Anschließend wurden die Eileiter beidseits abgesetzt und geclipt. Nach Peritoneal- und Muskelnaht mit 4.0 Vicrylfäden (Ethicon, Johnson \& Johnson, Norderstedt, Deutschland) wurden die Wunden mittels Klammernaht verschlossen (Michel wound brackets; 7,5 x 1,75 mm; Gebrüder Martin GmbH \& Co.KG, Tuttlingen, Deutschland).

Zur späteren korrekten Zuordnung der Tiere erhielt jedes Versuchstier eine Nummer sowie einen subcutan (s.c.) im Nacken platzierten elektronischen Chip (UNO Micro ID 12 mm ISO Transponder, UNO BV Zevenaar, Niederlande).

Bis zum Erwachen der Tiere aus der Narkose wurden sie in einem gewärmten Käfig überwacht. Um einer operationsbedingten Dehydrierung vorzubeugen, erhielten sie s.c. jeweils $3 \mathrm{ml}$ isotone Kochsalzlösung.

Der dargestellte Operationsablauf wurde bereits in mehreren anderen Studien durchgeführt und beschrieben (Döll 2010; Stürmer et al. 2010; Eimer 2014; Komrakova et al. 2014; 2015; Hofmann 2017). Während der operativen Eingriffe verstarb ein Tier aus der SR-Therapie-Gruppe, sodass sich die Gesamtzahl der Versuchstiere auf 59 dezimierte.

\subsection{Osteotomie}

Um die Auswirkungen der medikamentösen Prophylaxe und Therapie mit Strontiumranelat auf die Frakturheilung untersuchen zu können, wurden alle Versuchstiere acht Wochen nach Ovariektomie einer bilateralen Osteotomie der metaphysären Tibiae unterzogen. Die Auswertungen dazu waren Bestandteil einer anderen Studie und wurden bereits publiziert (Weidemann 2013; Komrakova et al. 2015). 


\subsection{Obduktion und Präparation der Lendenwirbelkörper}

Nach 13 Studienwochen endete der Versuch mit der Obduktion der Ratten. Zur Gewinnung der Lendenwirbelkörper für Analyseprotokolle dieser Studie erfolgte zunächst die Längsinzision der Haut über den Proccesus spinosi mit anschließender Entfernung der paraspinalen Muskulatur und der Sehnen. Eine Abgrenzung der Lendenwirbelsäule war dabei durch Ertasten der Rippen und Beckenknochen problemlos möglich. Die LWS wurde mittels scharfer Zange vom Rest der Wirbelsäule und dem Becken getrennt und herausgelöst. Im Folgenden wurden die Wirbelkörper nochmals gründlich von Muskel- und Sehnenresten befreit, von den Bandscheiben gelöst und bis zur weiteren Verwendung bei $-20^{\circ} \mathrm{C}$ gelagert (Döll 2010; Fürst 2014).

Zusätzlich zu den Lendenwirbelkörpern wurden die Tibiae, die Femora, zahlreiche Muskeln, der Uterus und Blutserum für Untersuchungen im Rahmen weiterer Studien entnommen, die aber nicht Teil der vorliegenden Arbeit waren.

\subsection{Biomechanischer Kompressionstest}

\subsubsection{Prinzip und Versuchsdurchführung}

Der biomechanische Kompressionstest ist ein nach Sehmisch et al. (2009) standardisierter Test zur Prüfung der Stabilität und Widerstandskraft der Knochen und wurde bereits in zahlreichen Studien durchgeführt (u.a. Daub 2010; Döll 2010; Hofmann 2017; Sturm 2018). Der Test erfolgte unter Verwendung einer Wertstoffprüfmaschine der Firma Zwick (Typ 145660 Z020/TND Zwick/Roell, Ulm, Deutschland) und einer eigens angefertigten, der Anatomie des Wirbelkörpers angepassten Aluminiumplatte, die sich fest mit der Prüfmaschine verbinden ließ.

Der Kompressionstest wurde am vierten Lendenwirbelkörper der Versuchstiere durchgeführt. Vor Beginn des Tests wurden die Wirbelkörper bei Raumtemperatur über etwa 30 Minuten aufgetaut und dann auf der Aluminiumplatte befestigt. Durch die anatomische Anpassung der Platte ist eine ausreichende Fixation des LWK in der Belastungsphase der Untersuchung gewährleistet ohne inn zusätzlich zu stabilisieren und dadurch gegebenenfalls die Testergebnisse $\mathrm{zu}$ beeinflussen. Anschließend wurde der Wirbelkörper über einen Stempel, der orthogonal zur 
Grundplatte des LWK auf den Knochen drückt eingespannt und mit einer Vorkraft von $1 \mathrm{~N}$ komprimiert. Nach abschließender Kontrolle der korrekten Lage des Wirbelkörpers startete der Versuch über die spezielle, mit dem Prüfgerät verbundene Software "testXpert®“ (Zwick/Roell, Ulm, Deutschland). Diese dokumentierte die über die Maschine verrichtete Arbeit mittels Kraft-Weg-Diagramm während der zunehmenden Kompression des Wirbelkörpers mit einer Geschwindigkeit von $50 \mathrm{~mm} / \mathrm{min}$ (Dokumentation alle 0,1 mm) (Abb. 3). Der Versuch wurde automatisch beendet, sobald im Kraft-Weg-Diagramm ein Abfall von mehr als $10 \mathrm{~N}$ gemessen wurde.

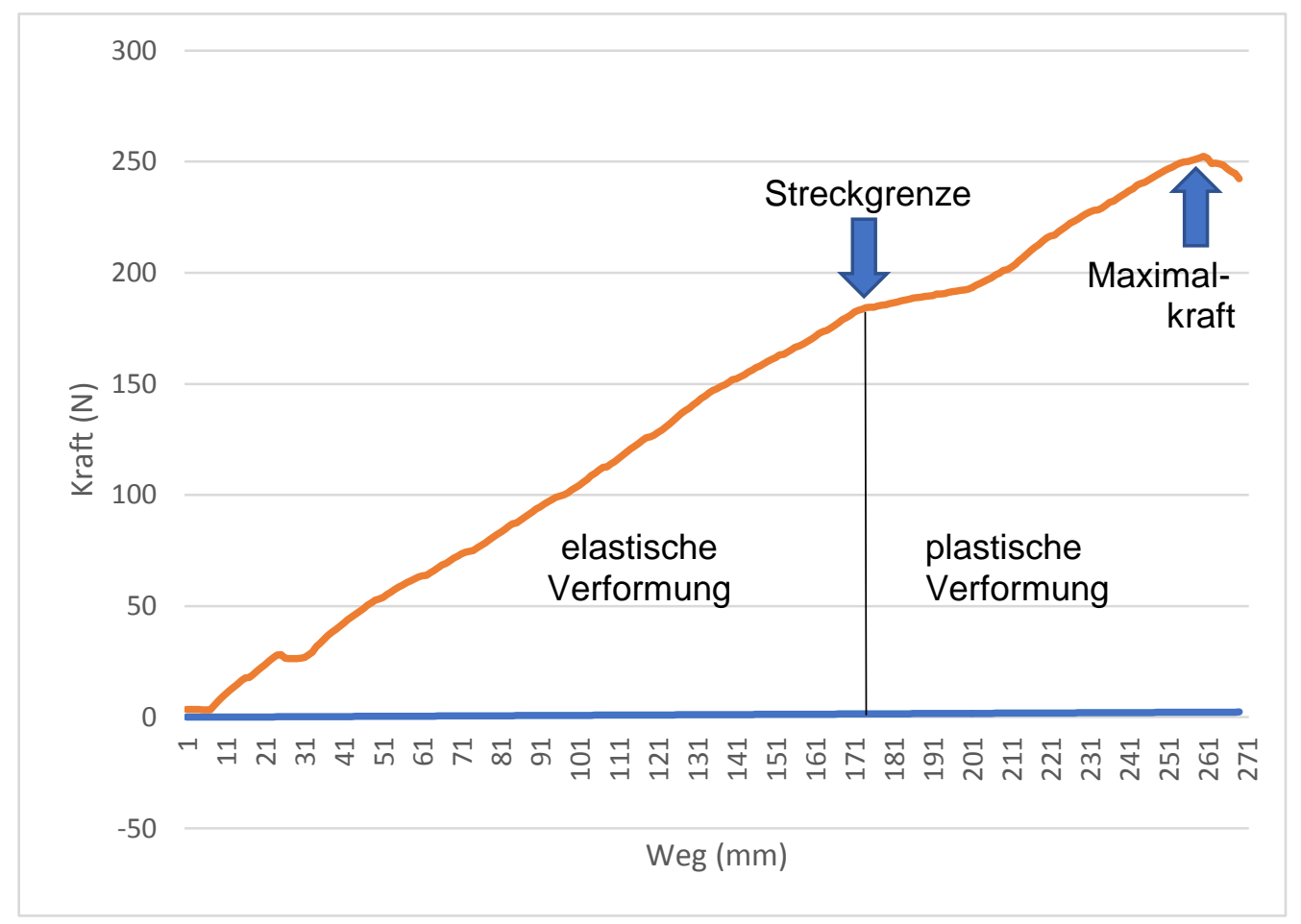

Abb. 3: Beispiel eines Kraft-Weg-Diagramms

\subsubsection{Messparameter}

\subsubsection{Maximale Kraft $\left(F_{\max }\right)$}

Sie entspricht dem höchsten Kraftwert, dem der Knochen standhalten kann, ohne sich vollständig plastisch zu verformen. In der vorliegenden Arbeit entspricht das dem Punkt, an dem die Deckplatte des Wirbelkörpers in den Knochen einbricht (Stürmer et al. 2006). Sie wird in Newton (N) angegeben. 


\subsubsection{Streckgrenze (yield load)}

Die Streckgrenze (engl. yield load) beschreibt den Übergang von der elastischen zur plastischen Verformung - also den Punkt, an dem der Knochen beginnt, nachzugeben und sich irreversibel zu verformen. Im Kraft-Weg-Diagramm entspricht dies dem Graphenabschnitt, an dem die lineare Steigung unterbrochen wird und der Kurvenverlauf abflacht (Sehmisch et al. 2009). Zur Objektivierung wurde aus den Werten des linearen Graphenanstiegs eine Regressionsrate mit Standardabweichung berechnet. Der yield load entspricht dem Punkt, an dem die Steigung (Elastizität) um mehr als die doppelte Standardabweichung abnimmt (Stürmer et al. 2006). Die Streckgrenze entspricht wie $F_{\max }$ einer Krafteinheit und wird in Newton (N) angegeben.

\subsubsection{Elastizität (Steifigkeit)}

Sie beschreibt die knöcherne Flexibilität der Wirbelkörper unter Krafteinwirkung und entspricht im Kraft-Weg-Diagramm dem linearen Anstieg bis zur Streckgrenze (Sehmisch et al. 2009). Je höher die Elastizität eines Knochens, desto widerstandsfähiger ist er. Die Elastizität wird in $\mathrm{N} / \mathrm{mm}$ angegeben.

\subsubsection{Validierung}

Zur Objektivierung der formalen Genauigkeit des Testverfahrens und gleichzeitiger Minimierung des Untersucher-spezifischen Einflusses auf die Testergebnisse erfolgte vor Durchführung des eigentlichen Tests eine Validierung. Da der dafür üblicherweise verwendete Rechts-Links-Vergleich (Stürmer et al. 2006) an der Wirbelsäule aber nicht durchführbar ist, wurden analog zu vorangegangenen Studien der vierte und fünfte LWK von zehn Testratten, die in Größe und Gewicht den eigentlichen Versuchstieren ähnelten in gleicher Art - also hinsichtlich maximaler Kraft, Streckgrenze und Elastizität untersucht (Sehmisch et al. 2009). Die interindividuellen Unterschiede konnten dann, analog eines Rechts-LinksVergleiches, mittels t-Test für unverbundene Stichproben ermittelt werden. Dabei wurde eine Abweichung von bis zu $15 \%$ (SD $\pm 3 \%$ ) zwischen LWK 4 und LWK 5 
hinsichtlich ihrer biomechanischen Beschaffenheit als physiologisch angesehen (Fisk und Baigent 1975; Budsberg et al. 1993; Döll 2010; Sturm 2018).

\subsection{Mikro-Computertomographie}

\subsubsection{Prinzip und Versuchsdurchführung}

Die Evaluation der knöchernen Mikrostruktur der Wirbelkörper war mittels MikroComputertomographie (kurz Mikro-CT) möglich. Dieses Untersuchungsverfahren wurde bereits in zahlreichen anderen Studien ausführlich beschrieben (Döll 2010; Weidemann 2013; Fürst 2014; Komrakova et al. 2015) und ist der herkömmlichen CT im klinischen Altag ähnlich. Allerdings ist der Mikro-Computertomograph deutlich kleiner und besitzt ein höheres örtliches Auflösungsvermögen. Zudem befinden sich die gegenüberliegende Röntgeneinheit und der Detektor in Ruhe und nur das zu untersuchende Objekt rotiert im Zentrum um die eigene Achse, wodurch die Berechnung von Schnittbildern und drei-dimensionalen Rekonstruktionen möglich ist. Wie in herkömmlichen Scannern erfolgt in der Röntgeneinheit die Erzeugung von Röntgenstrahlung durch mittels Hochspannung beschleunigte Elektronen, die aus der Glühkathode austreten und auf die gegenüberliegende Anode prallen. Das Untersuchungsobjekt im Zentrum des Scanners wird so durchleuchtet.

In der vorliegenden Arbeit erfolgten die Untersuchungen durch das Mikro-CT eXplore Locus SP (GE Healthcare, Ontario, Kanada) am dritten LWK der Versuchstiere. Das Scanprotokoll umfasste dabei folgende Messparameter: Röhrenspannung: $72 \mathrm{kVp}$, Röhrenstrom: $90 \mu \mathrm{A}$, Belichtungszeit am Detektor: $1600 \mathrm{~ms}$, Scanmodus: $360^{\circ}$-Rotation, Anzahl der Projektionen bei einem $360^{\circ}$ Scan: 900, Detektorbinning: $2 \times 2$ und Pixelgröße: 0,029 mm.

Zu Beginn wurden die Wirbel über etwa 30 Minuten bei Raumtemperatur aufgetaut. Pro Durchgang konnten sechs Wirbel gleichzeitig gescannt werden. Dazu wurden die Knochen mit den Processus spinosi nach unten in einer Kunststoffröhre gelagert, die aus drei Kammern bestand. In einer Kammer fanden jeweils zwei Wirbel übereinander Platz. Durch diese Einteilung und eine zusätzliche Beschriftung war eine spätere Zuordnung der LWK zum jeweiligen Versuchs- 
tier möglich. Um ein Verrutschen der Wirbel während der Rotation zu verhindern, wurden sie mit ausreichend Schaumstoff in der Röhre fixiert.

Vor dem eigentlichen Scan erfolgte eine etwa 15-minütige „Aufwärmphase" des Tomographen zur Gewährleistung der optimalen physikalischen Voraussetzungen für die anschließenden Messungen. Zusätzlich musste vor jeder Messung eine Kalibrierung des Gerätes mit jeweils fünf Luft- und Dunkelaufnahmen durchgeführt werden. Neben den sechs Wirbeln wurde auch ein Phantom aus Hydroxylapatit mit fünf verschiedenen, dem System bekannten Dichtewerten gemessen. Dieses diente später als Referenz zur korrekten Übertragung der gemessenen Werte in die Knochenmineraldichte. Alle akquirierten Bilddaten wurden für die anschließende Bearbeitung und Analyse an einen Computer übertragen.

\subsubsection{Bildbearbeitung}

Um die Aufnahmen der einzelnen Knochen auswerten zu können, wurde zunächst jeder Wirbel aus dem Gesamtbild der sechs LWK ausgeschnitten und den jeweiligen Versuchstieren zugeordnet. Danach fand die Bildbearbeitung in zwei Schritten statt: Zuerst wurden die CT-Daten - sowohl der Wirbel, als auch des Phantoms - mittels filtered-back-projection-Algorithmus drei-dimensional rekonstruiert. Dazu kam die Software Micro View (Version 2.1.2) von GE Healthcare zum Einsatz. Die anschließende Analyse dieser 3D-Datensätze hinsichtlich der Volumina, der Knochendichte und der einzelnen Knochenbestandteile fand im Programm 3D-OsteoAnalyze (Version 1.000.4) (Sehmisch et al. 2015) gemäß den Kriterien der American Society for Bone and Mineral Research (ASBMR) statt (Parfitt et al. 1987; Bouxsein et al. 2010). Für die Analysen wurden lediglich die Wirbelkörper betrachtet, die dafür in der 3D-Darstellung per Hand umrandet und ausgeschnitten wurden (Abb. 4). Schließlich standen zur Auswertung die 3DModelle der Wirbelkörper wie auch zwei-dimensionale Schnittbilder zur Verfügung. 

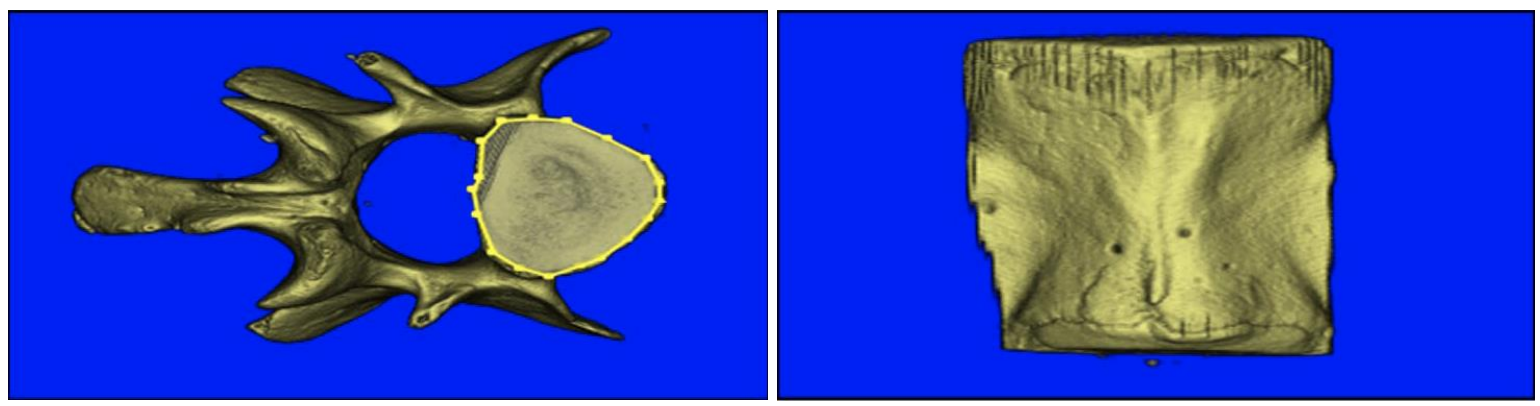

Abb. 4: Umrandung und Ausschnitt eines Corpus vertebrae in einer 3DRekonstruktion. Links: gelb umrandeter Wirbelkörper, Ansicht von kranial. Rechts: ausgeschnittener Wirbelkörper, Ansicht von ventral.

Um für spätere Auswertungen eine valide Aussage über die Knochendichte der Wirbelkörper treffen zu können, wurde die Schwächung der Röntgenstrahlen beim Durchtritt durch den Knochen in einem Grauwert-Histogramm dargestellt. Die xAchse entspricht dabei der zunehmenden Röntgenschwächung, die sich bekanntermaßen aus der Absorption und Streuung der Röntgenstrahlen beim Durchtritt durch einen Stoff zusammensetzt. Die Röntgenschwächung ist dabei maßgeblich von der Ordnungszahl und der Dichte des durchdrungenen Stoffes abhängig (Guhrauer et al. 1929). Die y-Achse gibt die Anzahl der Pixel in den jeweiligen Graustufen an (Abb. 5). Um eine quantitative Aussage über den Knochenmineralgehalt anhand der ermittelten Röntgenschwächung machen zu können, musste eine Kalibrierung mit einem sogenannten Knochenmineralstandard erfolgen (Kurth et al. 2013). Der in dieser Studie verwendete Knochenmineralstandard war ein Phantom aus Hydroxylapatit mit fünf Einschlüssen unterschiedlicher, aber bekannter Dichte.

Jedem Grauwertbereich im Histogramm konnte so ein oberer und unterer Schwellenwert zugeordnet werden. Dies bildete die Grundlage für die computerbasierte Berechnung der Knochenmineraldichte.

Bei den übrigen 2D- und 3D-Analysen erfolgte die Einstellung der optimalen Darstellung von Mikrostrukturen wie Trabekeln und Kortikalis optisch (Abb. 6). 


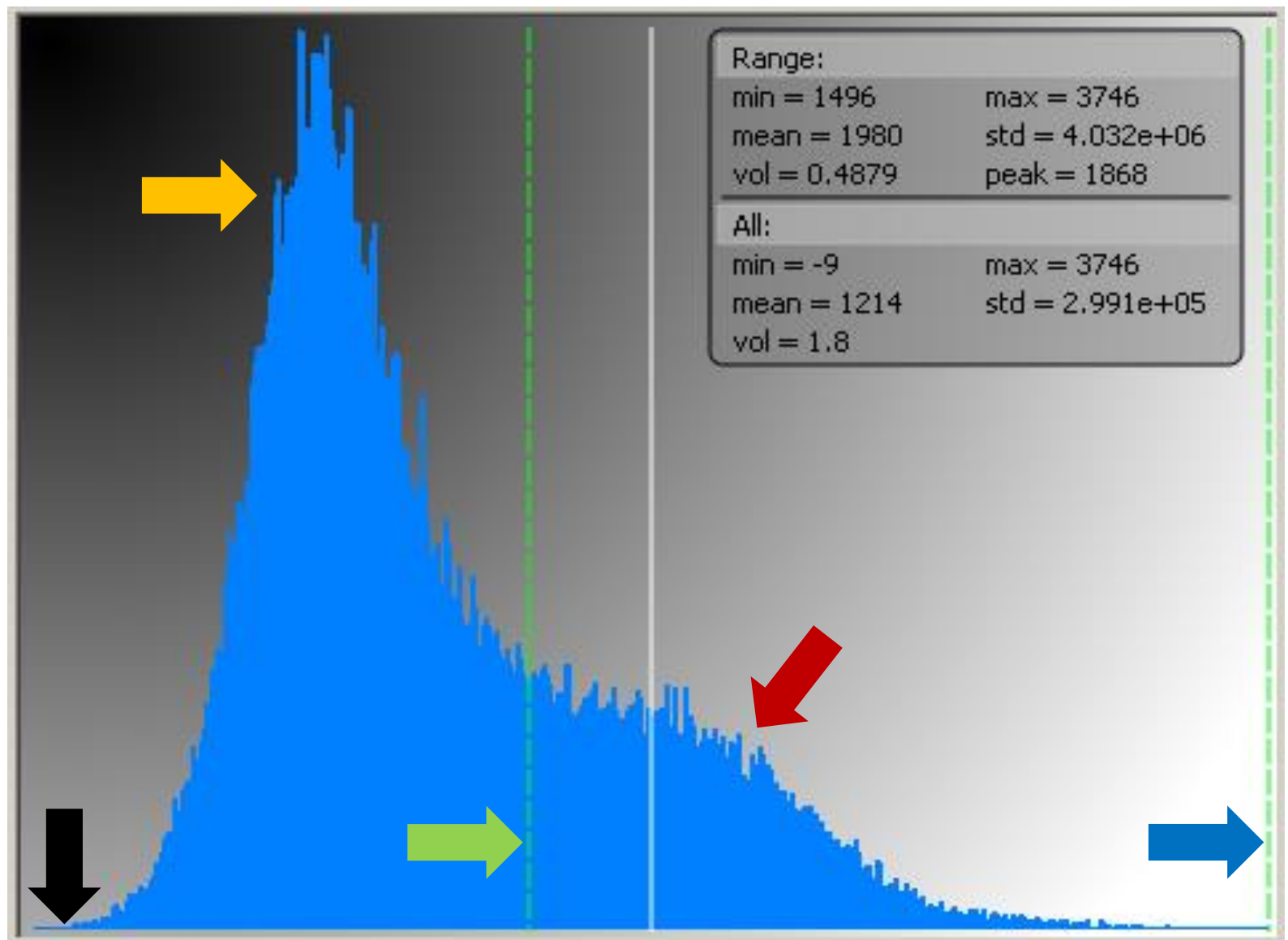

Abb. 5: Beispiel eines Grauwerthistogramms

Schwarzer Pfeil: minimal gemessene Dichte, gelber Pfeil = 1. Peak: Dichte von Weichgewebe, roter Pfeil $=2$. Peak: Dichte von Knochen, grüner Pfeil: unterer Schwellenwert zur Eingrenzung der Knochendichte, blauer Pfeil: maximal gemessene Dichte: oberer Schwellenwert zur Eingrenzung der Knochendichte Der Bereich zwischen den grünen Linien (oberer und unterer Schwellenwert) entspricht dem untersuchten Grauwertbereich unter Ausschluss der Weichgewebe (Range in der Ergebnisübersicht rechts oben).
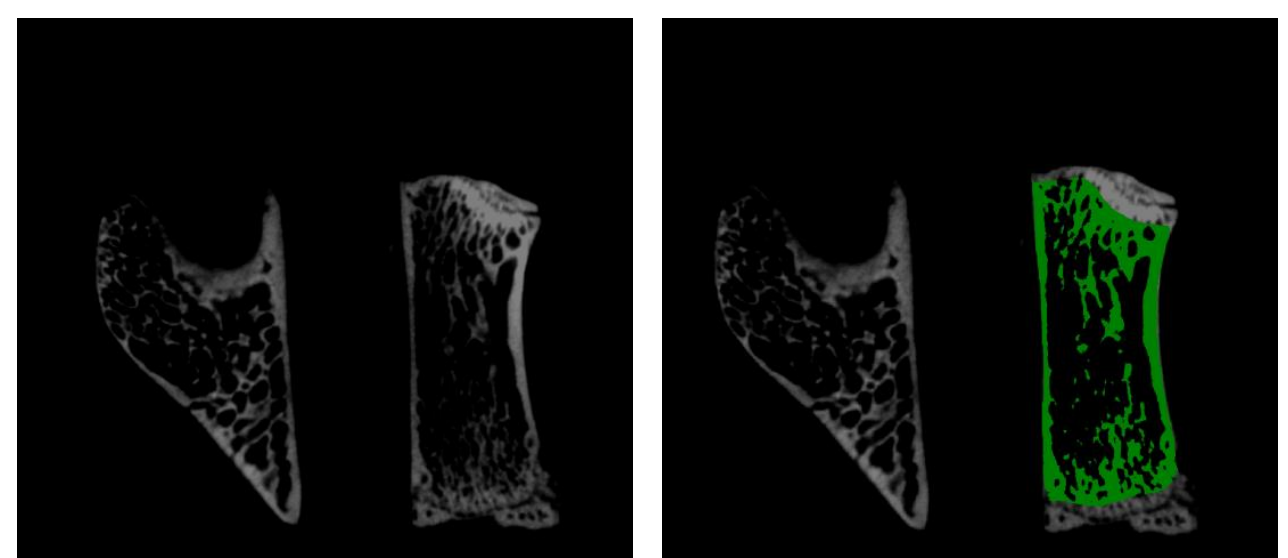

Abb. 6: Optimale Darstellung von Trabekelstrukturen und Kortikalis in der 2D-Analyse mit den optisch eingestellten und grün hinterlegten Schwellenwerten 


\subsubsection{Auswertung der Mikro-CT-Ergebnisse}

Mithilfe der Programme 3D-OsteoAnalyze und MetaMorph Basic Acquisition Software konnten am 3D- und 2D-Modell die im Folgenden genannten Messparameter ermittelt werden. Die Auswertung fand unter Berücksichtigung der Volumina sowie der Kortikalis- und Trabekelstrukturen statt und wurde analog den Kriterien der ASBMR (Parfitt et al. 1987; Dempster et al. 2013; Hoffmann et al. 2016) definiert.

\subsubsection{3D-Analysen im Mikro-CT}

\subsection{Bestimmung des Wirbelkörper-Volumens}

Um mögliche Unterschiede in den Versuchsgruppen hinsichtlich des WirbelkörperVolumens beurteilen zu können, wurden die Volumina mithilfe folgender Formel am 3D-Modell berechnet:

$$
V=\pi r^{2} h
$$

Der Radius ( $r$ ) ergab sich aus dem Mittelwert der Quer- und Längsdurchmesser des Wirbelkörpers, die Höhe (h) entspricht der kraniokaudalen Ausdehnung. Die Kreiszahl $(\pi)$ gibt das Verhältnis des Umfanges eines Kreises zu seinem Durchmesser an und stellt eine mathematische Konstante mit dem gerundeten Wert 3,14 dar (Fürst 2014; Hofmann 2017).

\subsection{Bestimmung der BV/TV und der bone mineral density (BMD)}

Die Volumenbestimmungen fanden am 3D-Modell der Wirbelkörper statt. Zunächst wurden wieder Transparenz und Kontrast angepasst. Um die Trabekelstrukturen zur Bestimmung von Knochendichte optimal abzubilden, erfolgte eine erneute manuelle Anpassung, sodass die Knochensubstanz optimal grün hinterlegt war und offensichtliche Weichteilstrukturen nicht maskiert wurden. Mithilfe des vom Computer errechneten Gesamtvolumens (TV) des Knochens und des eigentlichen Knochenvolumens (BV) konnte der Anteil an mineralisiertem Knochen im Wirbelkörper (BV/TV) anhand folgender Formel bestimmt werden (Hofmann 2017): 


\section{$\mathrm{BV} / \mathrm{TV}=$ Knochenvolumen/Gesamtvolumen des WK $\times 100 \%$}

Neben den Volumina wurde auch die Knochenmineraldichte (bone mineral density) untersucht. Analog der TV und BV wurden die Total BMD, also die Gesamtdichte des Knochens mit Weichgewebe, Knochenmark, Osteoid und mineralisiertem Knochen und die Bone BMD betrachtet, die nur mineralisierte Knochensubstanz beinhaltet. Die vom Mikro-CT detektierten Grauwerte (grey values = GVal) mussten dafür in Dichtewerte der Einheit $\mathrm{mg} / \mathrm{cm}^{3}$ überführt werden. Dies geschah mithilfe des mitgescannten Hydroxylapatit-Phantoms. Die Einstellungen dafür fanden unter Zuhilfenahme des Grauwerthistogramms statt. Um die Total BMD berechnen zu können, musste der Schwellenwert so angeglichen werden, dass das gesamte Untersuchungsvolumen berücksichtigt, also grün hinterlegt war. Für die Berechnung der Bone BMD wurde der Regler zur Schwellenwertbestimmung so verschoben, dass die Weichgewebe nicht hinterlegt und nur noch die Kortikalis und Trabekel gut sichtbar waren (Weidemann 2013; Fürst 2014; Hofmann 2017).

Zunächst wurden die Phantomabschnitte mit Einschlüssen unterschiedlicher, bekannter Mineraldichte (angegeben in $\mathrm{mg} / \mathrm{cm}^{3}$ ) computerbasiert in Grauwerte (GVal) überführt (Tabelle 3).

Tabelle 3: Phantomdichten mit den ermittelten Dichtewerten in GVal (Weidemann 2013; Hofmann 2017)

\begin{tabular}{|c|c|}
\hline Dichte in $\mathbf{~ m g / \mathbf { c m } ^ { 3 }}$ & Dichte in GVal \\
\hline 200 & 807 \\
\hline 400 & 1677 \\
\hline 600 & 2441 \\
\hline 800 & 3134 \\
\hline 1000 & 3850 \\
\hline
\end{tabular}

Nach Übertragung der Grauwertdaten des Phantoms in ein Punktdiagramm (Abb. 7) konnte - analog früherer Studien mit ähnlichem Studiendesign (Weidemann 2013; Hofmann 2017) - mithilfe einer linearen Regression die Knochenmineraldichte in $\mathrm{mg} / \mathrm{cm}^{3}$ berechnet werden. 
Dazu wurde folgende Formel verwendet:

$$
\begin{array}{ll}
\mathbf{y = m} & \bullet \text { GVal }+\mathbf{b} \\
\mathrm{y} & =\text { bone mineral density in } \mathrm{mg} / \mathrm{cm}^{3} \\
\mathrm{~m} & =0,2646 \\
\text { GVal } & =\text { Grauwerte aus der Knochenanalyse } \\
\mathrm{b} & =-30,2
\end{array}
$$

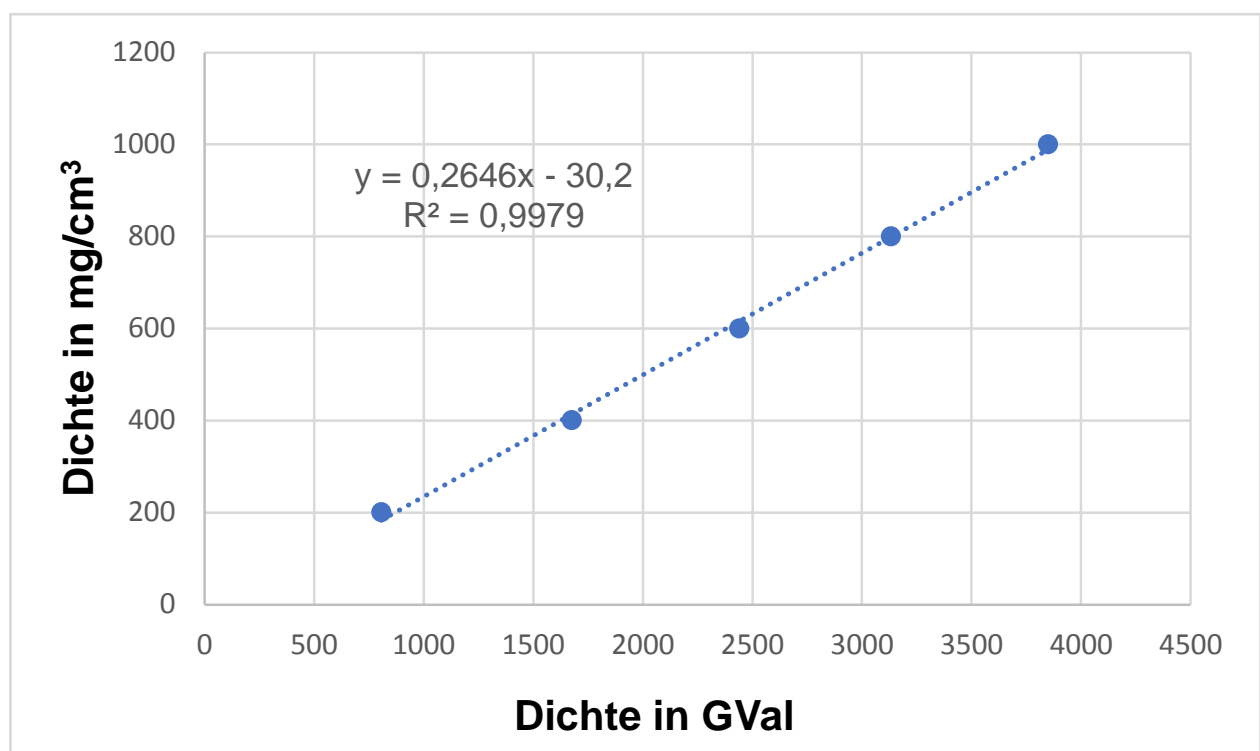

Abb. 7: Graphische Darstellung der linearen Regression von Dichte in $\mathrm{mg} / \mathrm{cm}^{3}$ zu Dichte in GVal unter Angabe der Regressionsformel und des Bestimmtheitsmaßes $\mathrm{R}^{2}$

\subsubsection{2D-Analysen im Mikro-CT}

\subsection{Bestimmung der Kortikalisparameter}

Die Kortikalisdicke wurde an einem vertikalen Medianschnitt durch den dreidimensional rekonstruierten Wirbel bestimmt (Abb. 8). Dazu erfolgten Messungen an fünf verschiedenen, gleichmäßig über die ventrale und dorsale Kortikalis verteilten Punkten aus denen dann jeweils ein Mittelwert gebildet wurde (Fürst 2014; Hofmann 2017). 


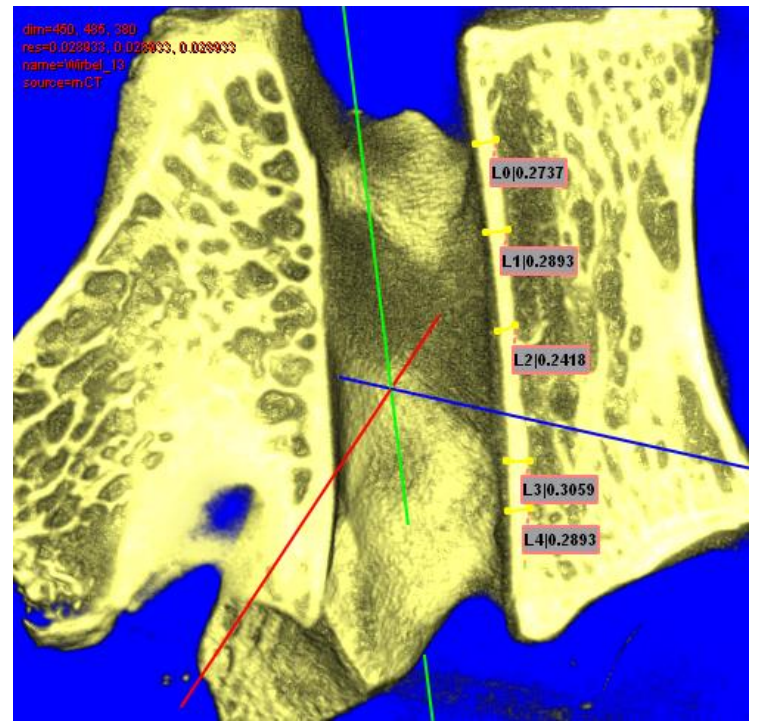

\section{Abb. 8: Bestimmung der Kortikalisdicke anhand von fünf Referenzmessungen}

Unter Verwendung der Software 3D-OsteoAnalyze wurden außerdem die Kortikalisfläche und die Kortikalisdichte bestimmt.

\subsection{Bestimmung der Trabekelstruktur}

Um im Rahmen osteopenischer Veränderungen den spongiösen Knochen betrachten zu können, wurden weitere Analysen hinsichtlich der Trabekelstruktur durchgeführt. Dazu stand die Software MetaMorph Basic Acquisition Software (Leica Microsystems Vertrieb GmbH, Wetzlar, Deutschland) zur Verfügung. Auch diese Analysen fanden an 2D-Modellen statt (Abb. 9). Die Auswertungen erfolgten unter Angabe der Trabekeldichte, der mittleren Trabekeldicke, der Trabekelfläche, der Anzahl der Trabekelkreuzungen (N.Nd) und der trabekulären Konnektivität (N.Nd/mm²). 

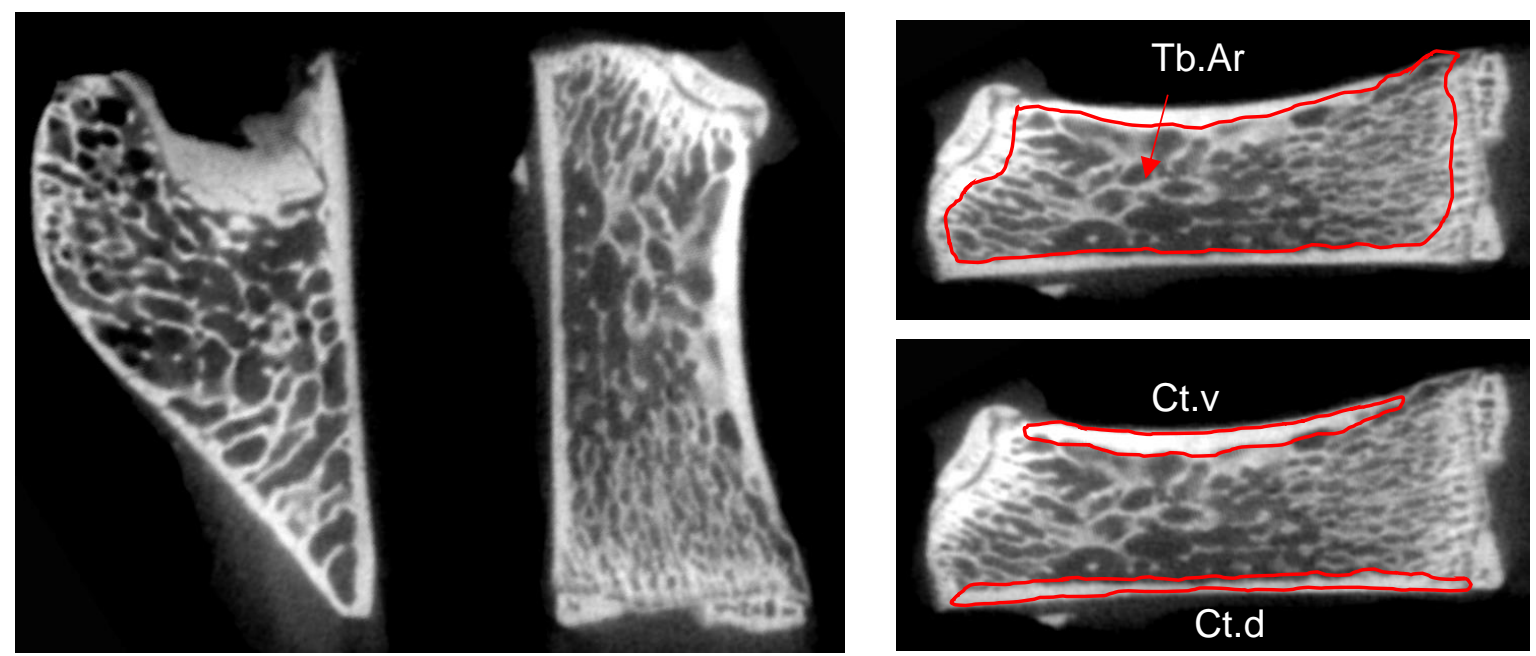

Abb. 9: 2D-Bilder für die Trabekelanalyse, links: Schnittbilder eines Lendenwirbels mit Ansicht von lateral, rechts oben: Corpus vertebrae mit Areal für die Trabekelanalyse (Tb.Ar, Pfeil), rechts unten: Corpus vertebrae mit Arealen der ventralen (Ct.v) und dorsalen Kortikalis (Ct.d), Beispiel aus der Gruppe NON-OVX

\subsubsection{Validierung}

Um Untersucher-spezifische Messabweichungen in den Ergebnissen vernachlässigbar gering zu halten, wurde die Versuchsdurchführung zuerst mit fünf zufällig ausgewählten Wirbeln trainiert. Die Ergebnisse durften im direkten Vergleich nicht maßgeblich voneinander abweichen (SD $\pm 5 \%$ ).

\subsection{Veraschung}

Zur Quantifizierung der organischen Knochenmatrix, des anorganischen Mineralsalzgehaltes sowie des Calcium- und Phosphatgehaltes der Knochen wurde als letzte Versuchsreihe eine sogenannte Veraschung an den zweiten Lendenwirbelkörpern der Versuchsratten durchgeführt. Auch dieses Testverfahren wurde bereits zahlreich angewendet und publiziert (u.a. Döll 2010; Eimer 2014; Fürst 2014; Komrakova et al. 2015). 


\subsubsection{Bestimmung der organischen und anorganischen Knochensubstanz}

Zur Bestimmung der organischen und anorganischen Knochensubstanz wurden die Wirbel zunächst wieder über etwa 30 Minuten bei Raumtemperatur aufgetaut und in einem Muffelofen über einen Tag bei $110^{\circ} \mathrm{C}$ getrocknet. Zur exakten Berechnung der Knochensubstanz-Anteile wurde das genaue Gewicht der Wirbel vor und nach Veraschung benötigt. Dazu wurde zunächst das Leergewicht eines Porzellangefäßes bestimmt, in dem die Veraschung stattfand. Dann konnten die getrockneten Wirbel im Gefäß analytisch gewogen werden. Unter Abzug des Gefäßgewichtes erhielt man das Ausgangsgewicht der Knochen. Die Veraschung fand bei $750^{\circ} \mathrm{C}$ im Porzellangefäß statt. Der so entstandene Glührückstand wurde in einem Exsikkator über Kieselgel abgekühlt, um die Ablagerung von Kondensationswasser zu vermeiden. Der übrig gebliebene Rückstand entspricht dem anorganischen Anteil der Knochensubstanz und besteht hauptsächlich aus Hydroxylapatit. Auch dieser Rückstand wurde analytisch im Porzellangefäß gewogen (Döll 2010; Fürst 2014; Komrakova et al. 2015; Schwedt et al. 2016).

Unter Verwendung folgender Formeln konnten die prozentualen Anteile an organischer und anorganischer Masse im Wirbel berechnet werden (Döll 2010; Eimer 2014; Hofmann 2017):

- Organischer Anteil:

$\%$ organisch $=\left(\left(m_{\text {vor Veraschung }}-m_{\text {nach Veraschung }}\right) \bullet 100\right) / m_{\text {vor Veraschung }}$

- Anorganischer Anteil:

$$
\% \text { anorganisch }=100-\% \text { organisch }
$$




\subsubsection{Versuchsdurchführung zur Bestimmung des Calcium- und Phosphatgehalts}

Um den Calcium- und Phosphatgehalt der Knochen bestimmen zu können, musste das eigentlich wasserunlösliche Hydroxylapatit zunächst in eine wasserlösliche Form überführt werden. Hierzu erfolgt ein sogenannter Säureaufschluss mit zehn prozentiger Salpetersäure als Aufschlussmittel (Jander und Blasius 1995). Der Glührückstand wurde mit Mörser und Stößel zu einem homogenen Pulver verarbeitet. Davon wurden $50 \mathrm{mg}$ des Pulvers analytisch abgewogen, mit $200 \mathrm{ml}$ zehn prozentiger Salpetersäure in einem Rundkolben versetzt, mit einem Rückflusskühler versehen und über eine halbe Stunde auf Siedetemperatur (hier $150^{\circ} \mathrm{C}$ ) erhitzt. Die daraus entstandene klare Aufschlusslösung wurde dann in einen Messkolben überführt und mit $1000 \mathrm{ml}$ destilliertem Wasser aufgefüllt. Um für die folgenden Analysen eine Lösungskonzentration im Vertrauensbereich des jeweiligen Messverfahrens zu erhalten, erfolgte eine abschließende Verdünnung mit destilliertem Wasser um den Faktor 1:20. Der Vertrauensbereich für Calcium lag dabei bei 0,1-5,0 mg/l und für Phosphat bei 0,1-1,5 mg/l (Eimer 2014; Fürst 2014; Sturm 2018).

\subsubsection{Bestimmung des Calciumgehalts}

Mit Hilfe eines Atomabsorptionsspektrometers (AAS, DIN EN ISO 7980:2000, FIAS 4100, Perkin-Elmer, Deutschland) wurde der Calciumgehalt der Proben ermittelt. Unter Zugabe von Lanthanchlorid erfolgte zunächst eine Maskierung des in der Probe befindlichen Phosphats. Anschließend wurde die Lösung in die Analyseeinheit des Atomabsorptionsspektrometers gegeben. Im Inneren des Gerätes befindet sich eine Atomisiereinheit mit einer Flamme aus einem AcetylenLuft-Gemisch und einem Zerstäuber, der die Analyselösung in die Flamme zerstäubt und so in ihre atomaren, anregbaren Teilchen überführt. Die Flamme wird dadurch verfärbt. Eine Hohlkathodenlampe emittiert nun Licht mit einer definierten Frequenz in die Flamme. Ein gegenüberliegender Detektor analysiert die Intensität des durch die Atomwolke geschwächten eintreffenden Lichtstrahls. Diese Schwächung wird als Extinktion bezeichnet (Welz und Sperling 2012). Entsprechend des Lambert-Beer'schen Gesetzes steigt die Extinktion des 
Lichtstrahls proportional zur Konzentration des Analytikums (in diesem Fall Calcium) in der Atomwolke (Lambert 1760; Bouguer 1923). Sie wurde anhand einer entsprechenden Verdünnungsreihe kalibriert und an einer CalciumEmissionsbande von 422,8 nm gemessen (Döll 2010; Fürst 2014; Hofmann 2017).

\subsubsection{Bestimmung des Phosphatgehalts}

Der Phosphatgehalt wurde durch spektrale Photometrie (DIN EN ISO 6879/2004, DM4, Zeiss, Deutschland) mittels Phosphor-Molybdänblau-Komplex bestimmt. Dazu wurde ein Phosphat-Reagenz - bestehend aus $25 \mathrm{ml}$ Schwefelsäure, $15 \mathrm{ml}$ Ascorbinsäure-Lösung, 7,5 ml Ammoniummolybdat-Lösung und 2,5 ml Kaliumantimonoxidtartrat - benötigt (Döll 2010; Fürst 2014; Hofmann 2017). 10 ml der zuvor hergestellten Analyselösung wurden mit $2 \mathrm{ml}$ des Phosphat-Reagenz in einem Messkolben versetzt und für zehn Minuten ruhen gelassen. Anschließend erfolgte die spektrometrische Messung der Extinktion mittels $10 \mathrm{~mm}$ dicker Küvette und einer Messwellenlänge von $690 \mathrm{~nm}$ in einem direkten Vergleich zu einer Blindprobe aus destilliertem Wasser (Harris 1998). Die Kalibrierung fand dabei durch die Messung der Extinktion einer Verdünnungsreihe einer Phosphat-StandardLösung im Vertrauensbereich des Messverfahrens statt (Vgl. 2.8.2.1). Um während des Vorganges einer Komplexbildung aus Haptomolybdat und Phosphat und damit einer Verfälschung der spektrometrischen Messung durch Ausbildung einer Eigenfarbe dieses Komplexes vorzubeugen, wurde die Lösung während der Analyse dauerhaft gekühlt (Döll 2010; Fürst 2014; Hofmann 2017). 


\subsection{Statistik}

Die statistischen Analysen und graphischen Darstellungen der Ergebnisse fanden mit der Software GraphPad Prism (Version 5.04, GraphPad Software, Inc. San Diego, CA) statt.

Die Gauß'sche Normalverteilung wurde für alle Daten mittels KolmogorovSmirnov-Test, D'Agostino-and-Pearson-Omnibus-Test oder Shapiro-Wilk-Test untersucht.

Alle normalverteilten Daten wurden mittels one-way analysis of variance (ANOVA), der einfaktoriellen Varianzanalyse auf signifikante Unterschiede zwischen den Versuchsgruppen getestet, welche dann mit Hilfe des Tukey-Kramer-post-hocTest spezifiziert werden konnten. Das Signifikanzniveau wurde dafür auf $p<0,05$ festgelegt.

Für nicht normalverteilte Daten kamen der Kruskal-Wallis-Test sowie der Dunnmultiple-comparison-Test (kurz Dunn's Test) zur Anwendung. Auch hierfür lag das festgelegte Signifikanzniveau bei $p<0,05$.

Die ermittelten Daten wurden hinsichtlich ihrer Mittelwerte und Mediane sowie der Standardabweichungen in den Versuchsgruppen verglichen. Mithilfe von BoxplotDiagrammen konnten die Ergebnisse graphisch dargestellt werden. 


\section{Ergebnisse}

Nachfolgend werden die Ergebnisse der vorliegenden Studie präsentiert. Dabei werden zuerst die Gewichtsentwicklung der Versuchstiere und deren Futteraufnahme während der ersten 13 Versuchswochen sowie die abschließend gemessenen Uterusgewichte dargestellt. Diese Ergebnisse wurden bereits in einer anderen Dissertation veröffentlicht (Weidemann 2013).

Im zweiten Teil erfolgt die Abbildung der Ergebnisse des biomechanischen Kompressionstests am vierten Lendenwirbelkörper, der Mikro-Computertomographie am dritten LWK und des Veraschungs-Versuches am zweiten Lendenwirbelkörper der Versuchstiere. Die graphische Darstellung der signifikanten Testergebnisse erfolgt anhand von Boxplot-Diagrammen, zu denen die Signifikanzen und der jeweils verwendete statistische Test angegeben sind. Alle Ergebnisse werden tabellarisch unter Angabe der Mittelwerte, Mediane und Standardabweichungen aufgeführt.

Zur vereinfachten Darstellung werden die verschiedenen Signifikanzniveaus wie folgt bezeichnet:

Tabelle 4: Symbolische Darstellung der Signifikanzen

\begin{tabular}{|c|c|}
\hline Symbol & Bedeutung \\
\hline$a$ & signifikant zu OVX \\
\hline$b$ & signifikant zu SR th \\
\hline$c$ & signifikant zu SR pr \\
\hline$d$ & signifikant zu NON-OVX \\
\hline$e$ & signifikant zu allen anderen \\
& Gruppen \\
\hline${ }^{*} p<0,05$ & signifikant \\
\hline${ }^{* *} p<0,01$ & hoch signifikant \\
\hline${ }^{* * *} p<0,001$ & höchst signifikant \\
\hline
\end{tabular}




\subsection{Charakteristika der Versuchstiere}

\subsubsection{Gewicht der Versuchstiere}

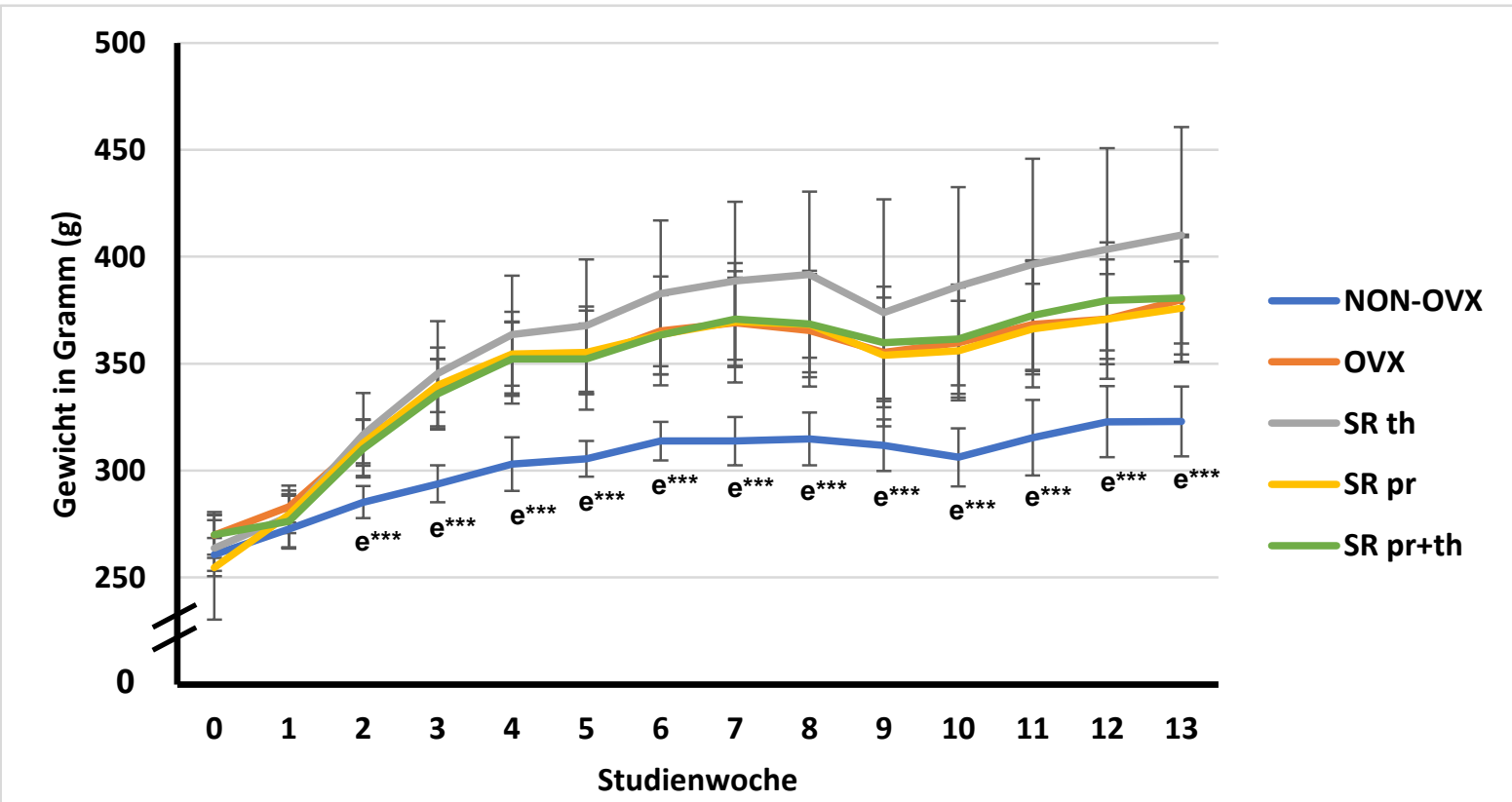

Abb. 10: Gewichtsentwicklung der Versuchstiere innerhalb der Versuchsgruppen in Gramm; Angabe der Mittelwerte \pm Standardabweichung, e = signifikant zu allen anderen Gruppen, ${ }^{* * *} p<0,001$, Tukey-Kramer-Test

Das Körpergewicht der Versuchstiere war zu Studienbeginn in den einzelnen Gruppen annähernd gleich. Nach Ovarektomie (Studienwoche 0) in den Gruppen OVX, SR th, SR pr und SR pr+th nahmen die Tiere dieser Versuchsgruppen deutlich mehr an Gewicht zu als die nicht ovariektomierten Tiere der Vergleichsgruppe (NON-OVX). Diese Entwicklung war ab der zweiten Studienwoche bis zum Versuchsende höchst signifikant (Abb. 10 und Tabelle A1 im Anhang, S. 77). Eine kurzzeitige Gewichtsabnahme in Woche neun und zehn war bei allen Gruppen zu beobachten und folgte auf die Osteotomie in Studienwoche acht. Insbesondere Tiere der SR th-Gruppe nahmen hier ab, was im Vergleich zu den anderen Versuchsgruppen aber nicht signifikant war.

Das Endgewicht der Ratten differierte ebenfalls deutlich. Auch hier wogen die Tiere der Kontrollgruppe am wenigstens. Tiere der SR th-Gruppe zeigten dagegen ein höheres mittleres Gewicht gegenüber den anderen Gruppen, was aufgrund großer Standardabweichungen aber nicht signifikant war. 


\subsubsection{Futteraufnahme}

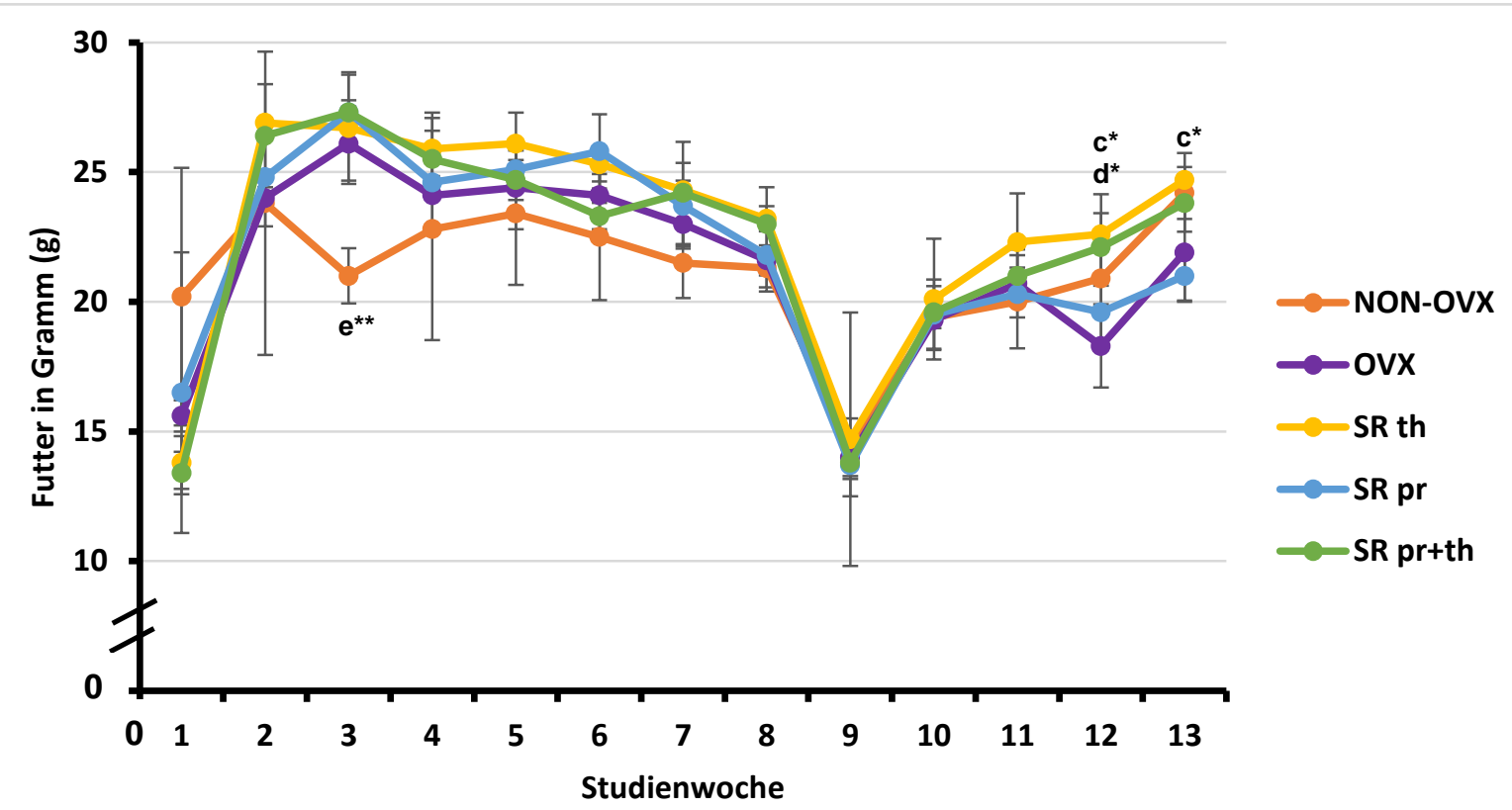

Abb. 11: Mittlere tägliche Futteraufnahme pro Tier und Studienwoche in den Versuchsgruppen; Angabe der Mittelwerte \pm Standard-abweichung; $c=$ signifikant zu SR pr, $d$ = signifikant zu NON-OVX, e = signifikant zu allen anderen Gruppen, ${ }^{*} p<0,05,{ }^{* *} p<0,01$, Tukey-Kramer-Test

Die mittlere tägliche Futteraufnahme war zu Versuchsbeginn, unmittelbar nach Ovariektomie bei allen Versuchstieren vergleichsweise hoch (Abb. 11 und Tabelle A2 im Anhang, S. 78). Erste Unterschiede waren in Versuchswoche drei zu beobachten. Hier nahmen die Tiere der NON-OVX-Gruppe hoch signifikant weniger Futter auf als Tiere der anderen Versuchsgruppen. Auch im Verlauf zeigte die Kontrollgruppe eine geringere, aber zu den anderen Gruppen nicht signifikante Nahrungsaufnahme. In Woche neun nach Osteotomie (in Studienwoche acht) war die Futteraufnahme im Vergleich zu den vorherigen und den nachfolgenden Testwochen bei allen Versuchstieren deutlich reduziert. Gegen Studienende war in Studienwoche zwölf bei der SR th-Gruppe eine signifikant höhere Nahrungsaufnahme gegenüber der NON-OVX- und der SR pr-Gruppe zu beobachten, die sich in Woche 13 mit einer ebenfalls signifikant erhöhten Futteraufnahme der SR th-Gruppe im Vergleich zur SR pr-Gruppe fortsetzte.

Entsprechend der schwankenden Futteraufnahme unterlag auch die mit dem Futter aufgenommene Menge an Strontiumranelat Schwankungen. Durchschnittlich nahmen die Versuchstiere $654 \pm 132 \mathrm{mg} \mathrm{SR} / \mathrm{kg} / \mathrm{Tag}$ auf. Dabei lag das 
Minimum bei einer Strontiumranelat-Aufnahme von $295 \mathrm{mg} / \mathrm{kg} / \mathrm{Tag}$ und das Maximum bei $948 \mathrm{mg} / \mathrm{kg} / \mathrm{Tag}$.

\subsubsection{Uterusgewicht}

Alle ovariektomierten Versuchstiere der Gruppen OVX, SR th, SR pr und SR pr+th zeigten ein signifikant bis höchst signifikant reduziertes Uterusgewicht gegenüber Tieren der nicht ovariektomierten Kontrollgruppe NON-OVX (Abb. 12 und Tabelle A3 im Anhang, S. 78).

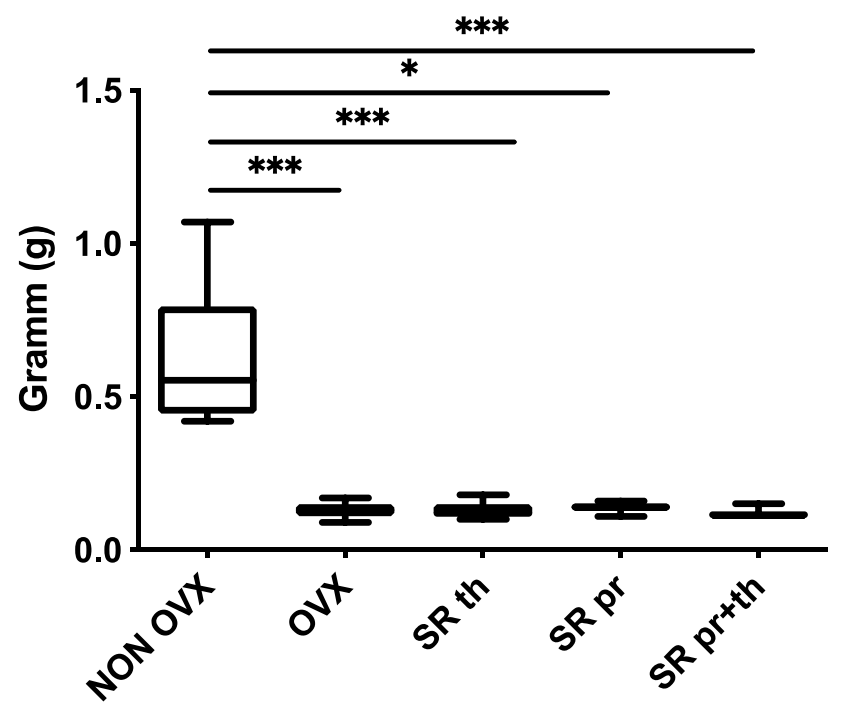

Abb. 12: Uterusgewicht in den Versuchsgruppen

(Dunn's Test)

${ }^{*} p<0,05,{ }^{* * *} p<0,001$

\subsubsection{Zusammenfassung der Versuchstier-Charakteristika}

Die nicht ovariektomierten Tiere (NON-OVX) nahmen im Vergleich zu allen anderen, ovariektomierten Gruppen (OVX, SR th, SR pr und SR pr+th) teils signifikant weniger Futter zu sich. Dies spiegelte sich auch in der Gewichtsentwicklung der Tiere wieder. Zudem waren die Uterusgewichte der ovariektomierten Ratten gegenüber der Kontroll-Gruppe (NON-OVX) signifikant geringer. 


\subsection{Ergebnisse des biomechanischen Kompressionstests}

Die Ergebnisse der Messparameter Maximalkraft, Streckgrenze und Elastizität sind im Folgenden graphisch und tabellarisch aufgezeigt. Mithilfe eines repräsentativen Kraft-Weg-Diagramms und einer Zusammenfassung werden die Versuchsergebnisse am Ende des Kapitels nochmals dargestellt.

\subsubsection{Maximale Kraft $\left(F_{\max }\right)$ und Streckgrenze (yield load)}

Bezüglich der Maximalkraft zeigten sich signifikant höhere Werte in der SR pr+thGruppe im Vergleich zu den Gruppen OVX, SR th und SR pr (Abb. 13 und Tabelle 5). Bei der Streckgrenze waren signifikante Unterschiede zwischen den Gruppen SR pr+th und OVX sowie SR pr+th und SR pr nachweisbar (Abb. 14 und Tabelle 5).
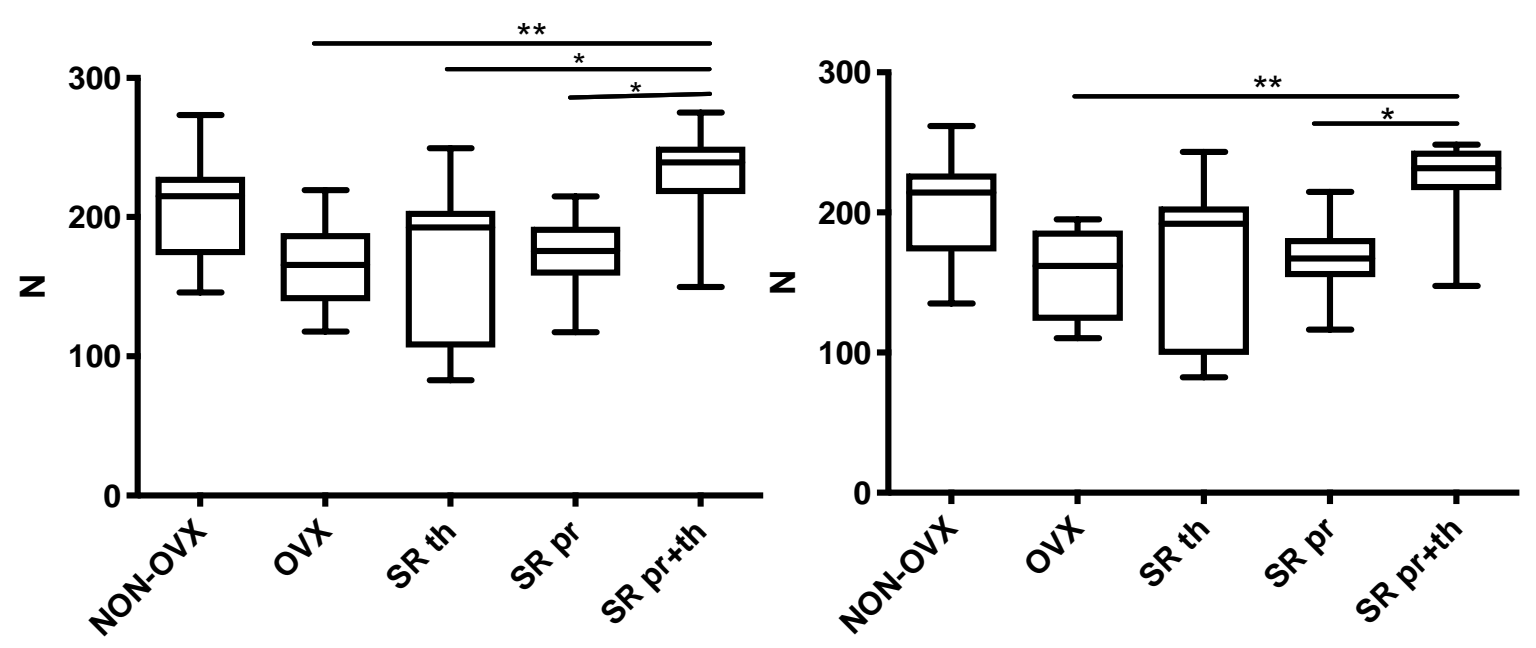

Abb. 13: Ergebnisse der Maximalkraft (Tukey-Kramer-Test)

${ }^{*} p<0,05$

Abb. 14: Ergebnisse der Streckgrenze (Dunn's Test)

** $p<0,01$ ${ }^{*} p<0,05$

${ }^{* *} p<0,01$ 


\subsubsection{Elastizität}

Die Elastizität war in der ovariektomierten Gruppe (OVX) signifikant reduziert gegenüber den nicht ovariektomierten Ratten (NON-OVX) (Abb. 15 und Tabelle 5). Bei den Gruppen mit Strontiumranelat-Prophylaxe und/oder -Therapie ergab sich kein signifikanter Unterschied.

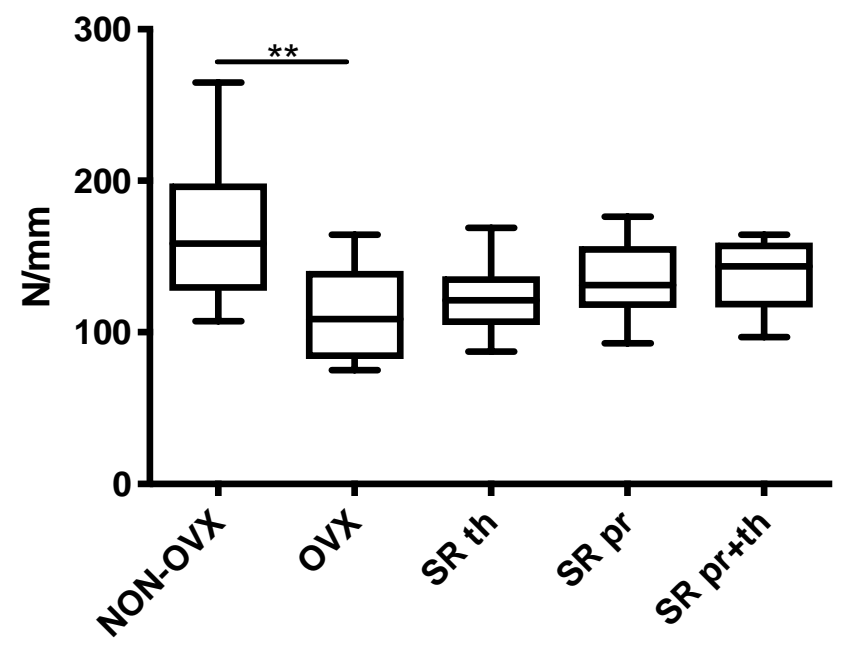

Abb. 15: Ergebnisse der Elastizität

(Tukey-Kramer-Test)

$$
\text { ** } p<0,01
$$

Tabelle 5: Ergebnisse des biomechanischen Tests in den Versuchsgruppen; Darstellung der Mittelwerte/Mediane \pm Standardabweichung

\begin{tabular}{|c|c|c|c|c|c|}
\hline $\begin{array}{l}\text { Gruppen } \\
\text { Parameter }\end{array}$ & NON-OVX & ovX & SR th & SR pr & SR pr+th \\
\hline $\begin{array}{c}\mathbf{F}_{\max } \\
(\mathbf{N})\end{array}$ & $\begin{array}{r}207,07 \\
215,08 \\
\pm 37,37 \\
\end{array}$ & $\begin{array}{r}166,50 \\
165,70 \\
\pm 30,74\end{array}$ & $\begin{array}{r}169,65 \\
192,61 \\
\pm 58,07\end{array}$ & $\begin{array}{r}173,59 \\
175,58 \\
\pm 26,44 \\
\end{array}$ & $\begin{array}{c}229,90 \\
239,30 \\
\pm 35,58 \\
\left(\mathbf{a}^{\star \star}, \mathbf{b}^{\star}, \mathbf{c}^{\star}\right)\end{array}$ \\
\hline $\begin{array}{c}\text { Streckgrenze } \\
\text { (N) }\end{array}$ & $\begin{array}{l}202,41 \\
214,19 \\
\pm 37,94\end{array}$ & $\begin{array}{r}157,90 \\
161,80 \\
\pm 32,28\end{array}$ & $\begin{array}{c}164,73 \\
192,0 \\
\pm 60,11\end{array}$ & $\begin{array}{c}167,34 \\
166,94 \\
\pm 26,27\end{array}$ & $\begin{array}{c}223,0 \\
231,60 \\
\pm 30,99 \\
\left(a^{\star *}, c^{\star}\right)\end{array}$ \\
\hline $\begin{array}{c}\text { Elastizität } \\
(\mathrm{N} / \mathrm{mm})\end{array}$ & $\begin{array}{c}165,78 \\
158,51 \\
+48,58\left(a^{\star \star}\right)\end{array}$ & $\begin{array}{r}112,50 \\
108,80 \\
\pm 32,78\end{array}$ & $\begin{array}{r}122,81 \\
121,16 \\
\pm 24,66\end{array}$ & $\begin{array}{l}133,74 \\
130,97 \\
\pm 26,0\end{array}$ & $\begin{array}{r}136,97 \\
143,68 \\
\pm 24,94\end{array}$ \\
\hline
\end{tabular}

$\mathrm{a}=$ signifikant zu OVX, b = signifikant zu SR th, c = signifikant zu SR pr, ${ }^{*} p<0,05,{ }^{* *} p<0,01$ 


\subsubsection{Repräsentatives Kraft-Weg-Diagramm}

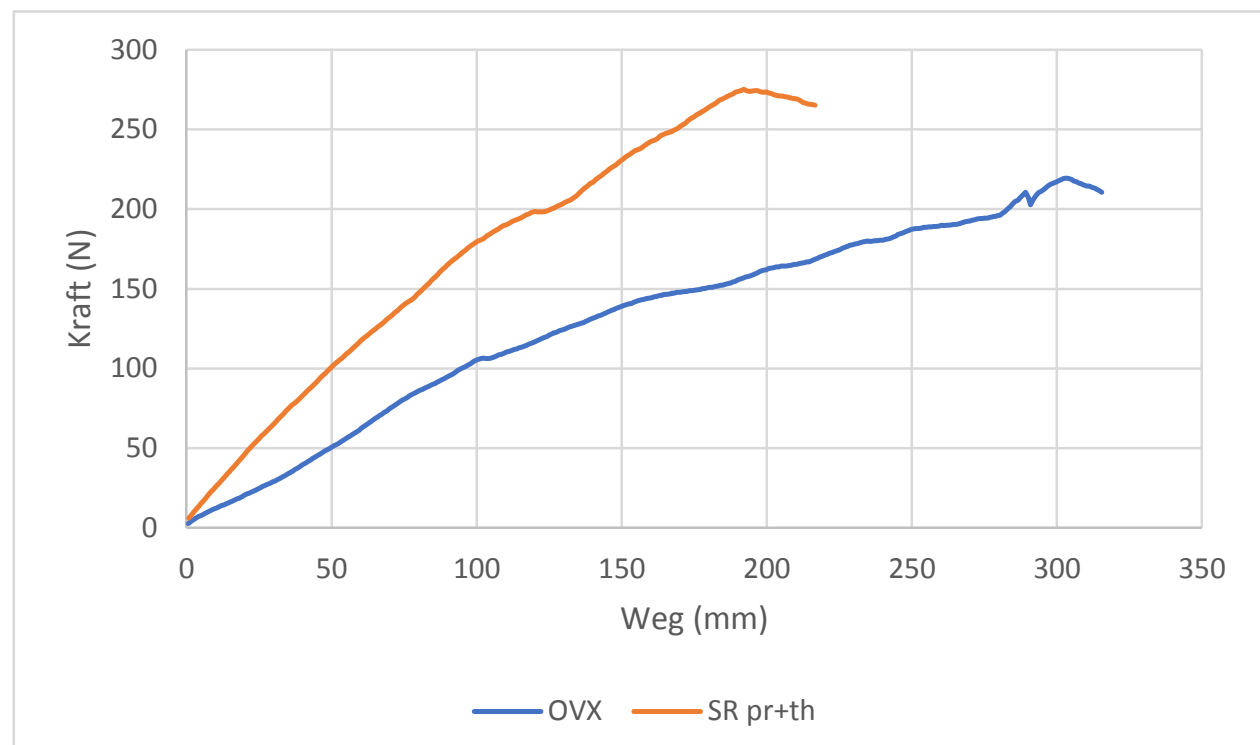

Abb. 16: Kraft-Weg-Diagramm aus den Gruppen „OVX“ und „SR pr+th“

Anhand des oben dargestellten Kraft-Weg-Diagramms (Abb. 16) sind die statistisch signifikanten Unterschiede zwischen der rein ovariektomierten Versuchsgruppe (OVX) und der ovariektomierten Gruppe, die sowohl eine Prophylaxe als auch eine Therapie mit Strontiumranelat erhielt (SR pr+th) ersichtlich. Die maximal anwendbare Kraft vor vollständigem Einbruch des Wirbelkörpers lag bei der SR pr+th-Ratte bei $275,17 \mathrm{~N}$, bei der OVX-Ratte dagegen nur bei $219,29 \mathrm{~N}$. Auch die Streckgrenze von der elastischen zur plastischen Verformbarkeit des Knochens differierte hier deutlich von 248,35 N bei der Ratte mit Strontiumranelat-Prophylaxe und -Therapie gegen 195,02 N bei der ovariektomierten Ratten ohne Therapie oder medikamentöse Prophylaxe. Der flachere Kurvenverlauf der OVX-Ratte (Elastizität 107,17 N/mm) gegenüber der SR pr+th-Ratte (Elastizität 161,35 N/mm) repräsentiert eine geringere Flexibilität des Knochens der OVX-Ratte, was im vorliegenden Gruppenvergleich (OVX versus SR pr+th) jedoch nicht statistisch signifikant war (Abb. 15 und Tabelle 5). 


\subsubsection{Zusammenfassung der Ergebnisse des biomechanischen Kompressionstests}

Die Wirbelkörper von Tieren der Gruppe SR pr+th zeigten gegenüber denen der Gruppen OVX, SR th und SR pr eine signifikant höhere Maximalkraft vor der plastischen Verformung sowie eine höhere Streckgrenze im Vergleich zu Ratten der OVX-Gruppe und der SR pr-Gruppe. Die Elastizität der Knochen war dagegen in den Strontium-behandelten Gruppen nicht signifikant beeinflusst.

\subsection{Ergebnisse der Mikro-Computertomographie}

Nachfolgend werden die Ergebnisse der mittels Mikro-CT erhobenen Daten aufgeteilt in Volumenanalysen, die Knochenmineraldichte, Kortikalisparameter und die Trabekelanalysen - dargestellt. Eine Zusammenfassung veranschaulicht am Ende des Kapitels die Ergebnisse nochmals übersichtlich.

\subsubsection{Volumenanalysen}

Hinsichtlich des gemessenen Wirbelkörper-Volumens $(p=0,156)$, des ermittelten Gesamtvolumens (TV, $p=0,348$ ), des reinen Knochenvolumens (BV, $p=0,480$ ), wie auch der prozentualen Anteile an mineralisiertem Knochen am Gesamtvolumen der Wirbelkörper (BV/TV, $p=0,261$ ) ergaben sich keine statistisch signifikanten Unterschiede im Gruppenvergleich (Tabelle A4 im Anhang, S. 79). Der höchste prozentuale Anteil an mineralisiertem Knochengewebe fand sich bei Ratten der NON-OVX- und SR pr+th-Gruppe (bis 44,9\%), der niedrigste Anteil war in der OVX-Gruppe mit 26,3\% nachweisbar. 


\subsubsection{Auswertungsergebnisse der Knochenmineraldichte (BMD)}

Bei den Auswertungen der Total BMD und der Bone BMD ergaben sich signifikant höhere Gesamtdichtewerte (Total BMD) in den Gruppen SR pr+th und NON-OVX im Vergleich zu OVX (Abb. 17 und Tabelle 6).

Hinsichtlich der Bone BMD zeigten sich in den Gruppenvergleichen keine signifikanten Unterschiede $(p=0,120)$ (Tabelle 6). Die niedrigsten Werte wurden in der OVX-Gruppe mit minimal $435,5 \mathrm{mg} / \mathrm{cm}^{3}$ gegenüber dem höchsten Wert in der SR pr+th-Gruppe mit $768,1 \mathrm{mg} / \mathrm{cm}^{3}$ erreicht.

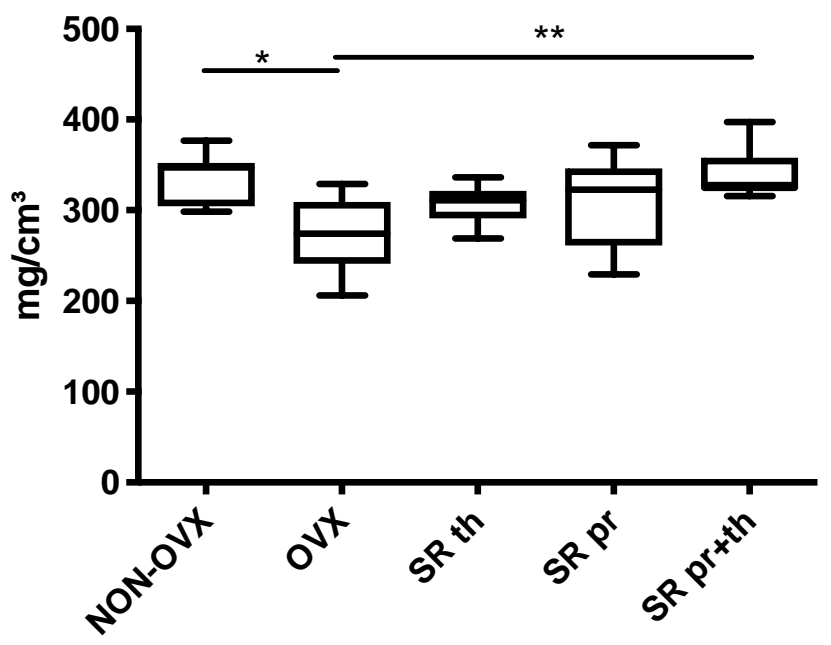

$$
\begin{gathered}
\text { Abb. 17: Ergebnisse der Total BMD } \\
\text { (Dunn's Test) } \\
{ }^{*} p<0,05,{ }^{* *} p<0,01
\end{gathered}
$$

Tabelle 6: Ergebnisse der gesamten Mineraldichte (Total BMD) und der Knochenmineraldichte (Bone BMD) in den Versuchsgruppen; Darstellung der Mittelwerte/Mediane \pm Standardabweichung

\begin{tabular}{|c|c|c|c|c|c|}
\hline $\begin{array}{c}\text { Gruppen } \\
\text { Parameter }\end{array}$ & NON-OVX & OVX & SR th & SR pr & SR pr+th \\
\hline $\begin{array}{c}\text { Total BMD } \\
\left(\mathbf{m g} / \mathbf{c m}^{3}\right)\end{array}$ & 334,7 & 272,4 & 307,2 & 310,4 & 339,8 \\
& $\pm 27,01\left(\mathbf{a}^{\star}\right)$ & $\pm 41,39$ & $\pm 21,11$ & $\pm 48,42$ & $\pm 28,77\left(\mathbf{a}^{\star \star}\right)$ \\
\hline Bone & 667,6 & 617,1 & 638,8 & 664,9 & 684,7 \\
BMD & 665,2 & 629,1 & 653,5 & 665,2 & 665,2 \\
$\left(\mathbf{m g} / \mathbf{c m}^{3}\right)$ & $\pm 37,17$ & $\pm 74,43$ & $\pm 34,63$ & $\pm 39,44$ & $\pm 49,67$ \\
\hline
\end{tabular}

$a=$ signifikant zu OVX, * $p<0,05,{ }^{* *} p<0,01$, Dunn's Test 


\subsubsection{Kortikalisparameter}

\subsubsection{Kortikalisfläche}

Im Gruppenvergleich zeigte sich eine signifikant erhöhte Gesamtfläche der Kortikalis in den ovariektomierten Versuchsgruppen, die eine Prophylaxe mit Strontiumranelat erhielten (SR pr) gegenüber der OVX-Gruppe (Abb. 18 und Tabelle 7).

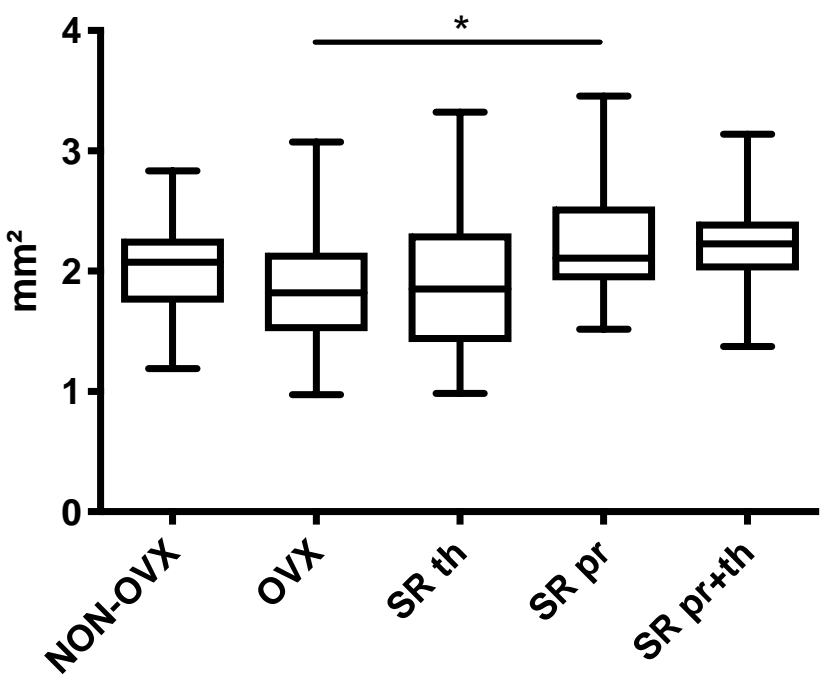

Abb. 18: Ergebnisse der Gesamtfläche der Kortikalis (Tukey-Kramer-Test)

$$
{ }^{*} p<0,05
$$

Tabelle 7: Ergebnisse der Kortikalisfläche in den Versuchsgruppen; Darstellung der Mittelwerte/Mediane \pm Standardabweichung

\begin{tabular}{|c|c|c|c|c|c|}
\hline $\begin{array}{c}\text { Gruppen } \\
\text { Parameter }\end{array}$ & NON-OVX & OVX & SR th & SR pr & SR pr+th \\
\hline $\begin{array}{c}\text { Kortikalis- } \\
\text { fläche } \\
\left(\mathbf{m m}^{2}\right)\end{array}$ & $\begin{array}{c}1,99 / 2,08 \\
\pm 0,39\end{array}$ & $\begin{array}{c}1,84 / 1,82 \\
\pm 0,50\end{array}$ & $\begin{array}{c}1,92 / 1,85 \\
\pm 0,67\end{array}$ & $\begin{array}{c}2,23 / 2,11 \\
\pm 0,43\left(\mathbf{a}^{\star}\right)\end{array}$ & $\begin{array}{c}2,17 / 2,23 \\
\pm 0,41\end{array}$ \\
\hline
\end{tabular}

$\mathrm{a}=$ signifikant zu OVX, * $\mathrm{p}<0,05$, Tukey-Kramer-Test 


\subsubsection{Kortikalisdicke}

Bei Betrachtung der Kortikalisdicke zeigten sich keine signifikanten Unterschiede zwischen den mit Strontiumranelat behandelten Tieren und der OVX-Gruppe. Am ventralen Wirbelkörper war die Kortikalisdicke in der NON-OVX-Gruppe signifikant höher als in der OVX- und SR th-Gruppe (Abb. 19 und Tabelle 8). Bei Betrachtung des dorsalen Wirbelkörpers fielen signifikante Unterschiede zwischen der NONOVX-Gruppe und allen weiteren Versuchsgruppen auf (Abb. 20 und Tabelle 8).

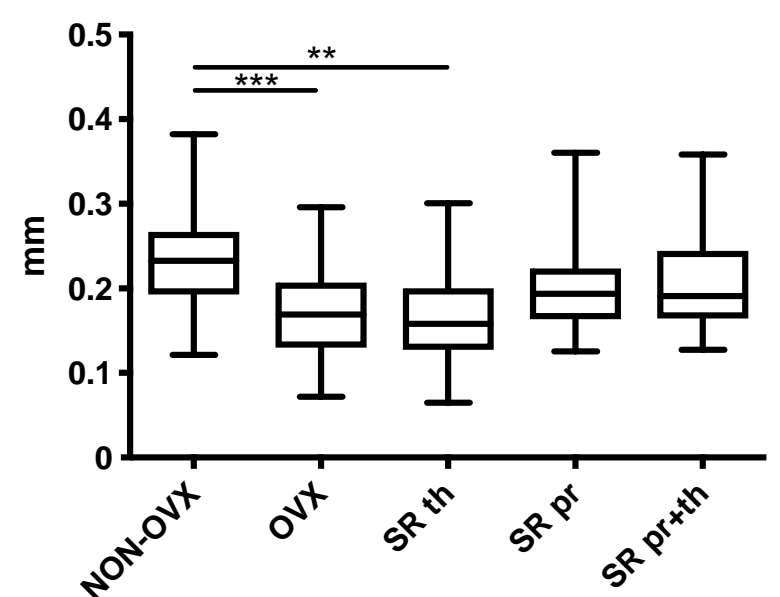

Abb. 19: Ergebnisse der Kortikalisdicke am ventralen WK

(Tukey-Kramer-Test)

${ }^{* *} p<0,01$

${ }^{* * *} p<0,001$

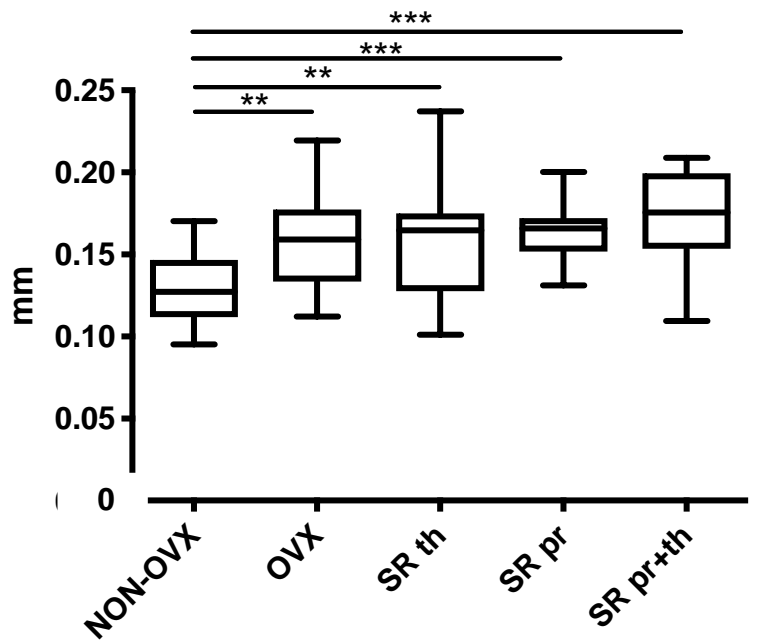

Abb. 20: Ergebnisse der Kortikalisdicke am dorsalen WK (Tukey-Kramer-Test)

** $p<0,01$

${ }^{* * *} p<0,001$

Tabelle 8: Ergebnisse der Kortikalisdicke am ventralen und dorsalen WK in den Versuchsgruppen; Darstellung der Mittelwerte/Mediane \pm Standardabweichungen

\begin{tabular}{|c|c|c|c|c|c|}
\hline $\begin{array}{c}\text { Gruppen } \\
\text { Parameter }\end{array}$ & NON-OVX & OVX & SR th & SR pr & SR pr+th \\
\hline $\begin{array}{c}\text { Kortikalis- } \\
\text { dicke ventral } \\
(\mathbf{m m})\end{array}$ & $\begin{array}{c}0,23 / 0,23 \\
\pm 0,06 \\
\left(\mathbf{a}^{\star *}, \mathbf{b}^{\star \star}\right)\end{array}$ & $\begin{array}{c}0,17 / 0,16 \\
\pm 0,06\end{array}$ & $\begin{array}{c}0,17 / 0,16 \\
\pm 0,06\end{array}$ & $\begin{array}{c}0,20 / 0,19 \\
\pm 0,05\end{array}$ & $\begin{array}{c}0,21 / 0,19 \\
\pm 0,06\end{array}$ \\
\hline $\begin{array}{c}\text { Kortikalis- } \\
\text { dicke dorsal } \\
(\mathbf{m m})\end{array}$ & $\begin{array}{c}0,13 / 0,13 \\
\pm 0,02 \\
\left(\mathbf{e}^{\star *}, \mathbf{e}^{\star \star *}\right)\end{array}$ & $\begin{array}{c}0,16 / 0,16 \\
\pm 0,03\end{array}$ & $\begin{array}{c}0,16 / 0,16 \\
\pm 0,03\end{array}$ & $\begin{array}{c}0,16 / 0,17 \\
\pm 0,02\end{array}$ & $\begin{array}{c}0,17 / 0,18 \\
\pm 0,03\end{array}$ \\
\hline
\end{tabular}

$\mathrm{a}=$ signifikant $\mathrm{zu}$ OVX, $\mathrm{b}=$ signifikant $\mathrm{zu}$ SR th, e = signifikant zu allen anderen Gruppen, ${ }^{* *} p<0,01,{ }^{* * *} p<0,001$, Tukey-Kramer-Test 


\subsubsection{Kortikalisdichte}

Eine signifikant erhöhte Dichte der Kortikalis konnte bei den SR pr+th-Tieren im Vergleich zur OVX-Gruppe nachgewiesen werden (Abb. 21 und Tabelle 9). Auch im Vergleich zur reinen SR-Therapie zeigten sich signifikant erhöhte Dichtewerte beim kombinierten Regime aus SR-Prophylaxe und -Therapie. Die Kortikalisdichte der nicht ovariektomierten Tiere (NON-OVX) war ebenfalls signifikant höher als die der OVX- Tiere oder derer, die eine reine zusätzliche SR-Therapie erhielten.

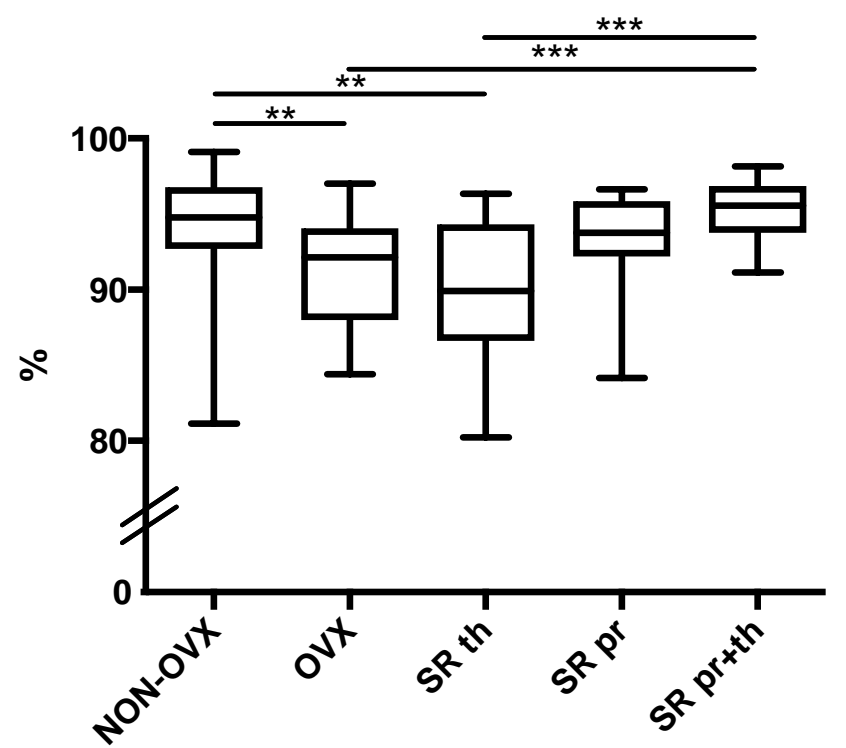

\section{Abb. 21: Ergebnisse der Kortikalisdichte}

(Dunn's Test)

${ }^{* *} p<0,01 ;{ }^{* * *} p<0,001$

Tabelle 9: Ergebnisse der kortikalen Knochendichte in den Versuchsgruppen; Darstellung der Mittelwerte/Mediane \pm Standardabweichung

\begin{tabular}{|c|c|c|c|c|c|}
\hline $\begin{array}{c}\text { Gruppen } \\
\text { Parameter }\end{array}$ & NON-OVX & ovX & SR th & SR pr & SR pr+th \\
\hline $\begin{array}{l}\text { Kortikalis- } \\
\text { dichte } \\
(\%)\end{array}$ & $\begin{array}{c}94,32 \\
94,79 \\
\pm 3,57 \\
\left(\mathbf{a}^{\star *}, \mathbf{b}^{\star *}\right)\end{array}$ & $\begin{array}{l}91,16 \\
92,14 \\
\pm 3,81\end{array}$ & $\begin{array}{r}90,28 \\
89,92 \\
\pm 4,80 \\
\end{array}$ & $\begin{array}{r}93,49 \\
93,77 \\
\pm 2,87 \\
\end{array}$ & $\begin{array}{c}95,13 \\
95,55 \\
\pm 2,03 \\
\left(\mathbf{a}^{\star \star \star}, \mathbf{b}^{\star \star \star}\right)\end{array}$ \\
\hline
\end{tabular}

Test 


\subsubsection{Ergebnisse der Trabekelanalysen}

\subsubsection{Trabekeldichte und mittlere Trabekeldicke}

Bei der Betrachtung der Trabekeldichte der einzelnen Versuchsgruppen fällt bereits in den makroskopischen medianen Sagittalschnitten der Mikro-CT-Bilder eine deutlich reduzierte Trabekeldichte in der OVX-Gruppe im Vergleich zur SR pr+th-Gruppe auf. Im direkten Vergleich zu den Versuchstieren ohne Osteopenie (NON-OVX) erscheinen morphologisch alle ovariektomierten und Strontiumbehandelten Versuchsgruppen hinsichtlich trabekulärer Dichte und Dicke reduziert (Abb. 22).

\section{NON-OVX}

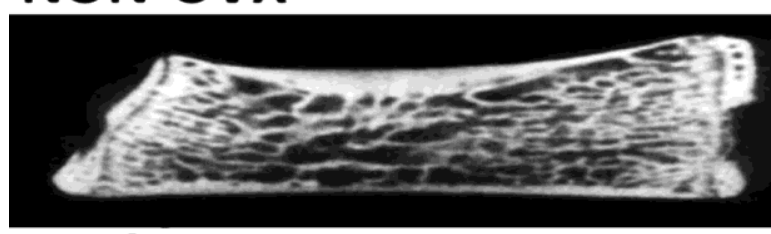

\section{SR th}

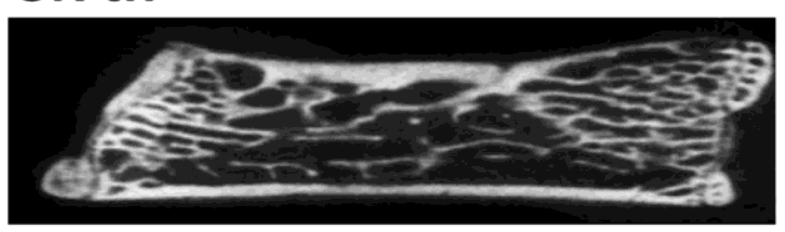

\section{SR th+pr}

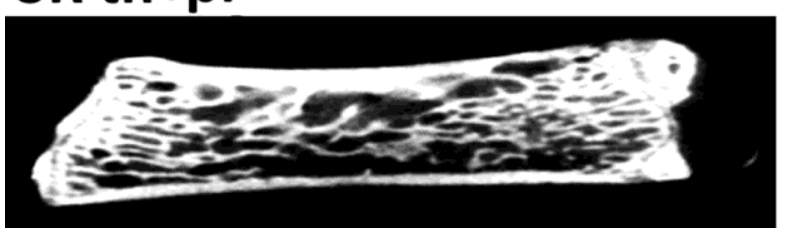

\section{OVX}

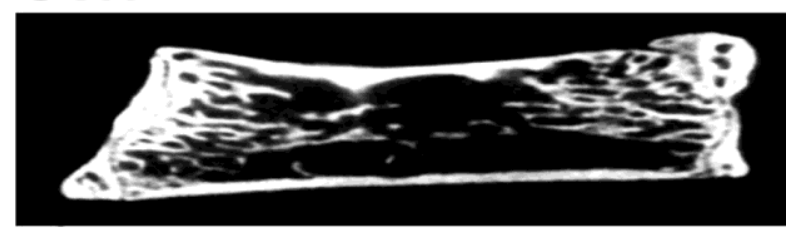

SR pr

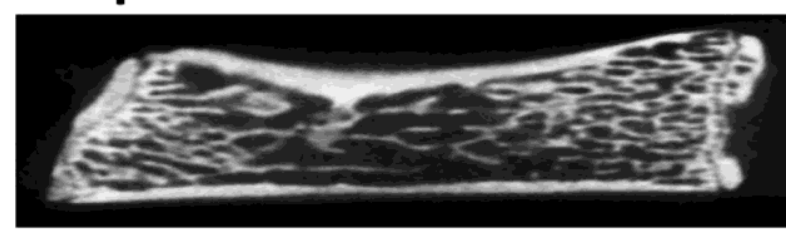

Abb. 22: Eigene 2D-Bilddaten aus Mikro-CT-Scans der Corpora vertebrae jeder Versuchsgruppe; nach Saul et al. 2018a, Verwendung mit freundlicher Genehmigung des Verlages Springer Nature

Diese makroskopischen Ergebnisse ließen sich auch statistisch belegen (Abb. 23 und 24 sowie Tabelle 10). Die Trabekeldichte war bei den nicht ovariektomierten Tieren (NON-OVX) noch am höchsten, gefolgt von den SR pr+th-Tieren im Vergleich zu den restlichen Versuchsgruppen.

Auch die mittlere Trabekeldicke war in der Gruppe NON-OVX signifikant erhöht. Eine Behandlung aus SR-Prophylaxe und -Therapie war der OVX-Gruppe wie auch den Einzelregimes (SR th und SR pr) überlegen. 


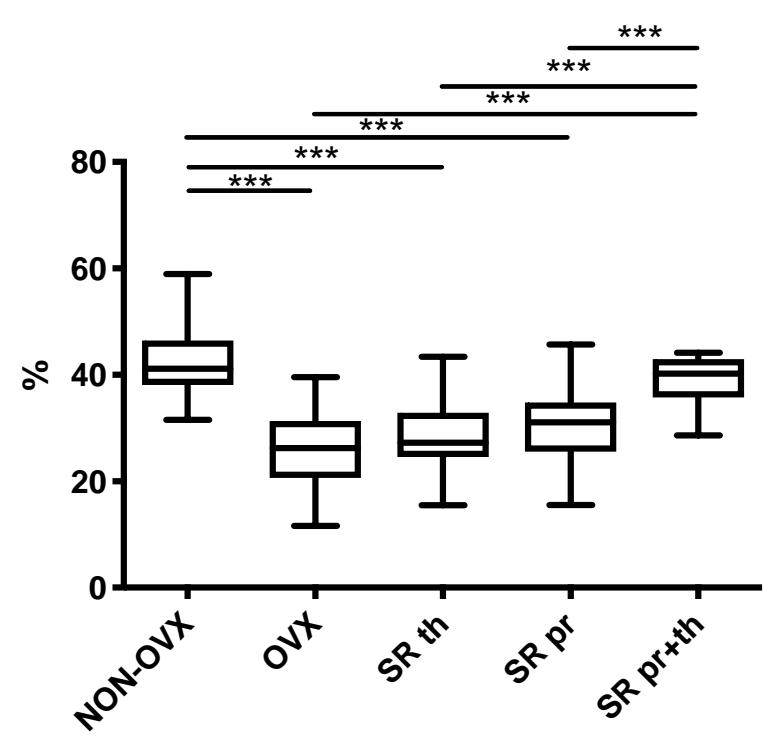

Abb. 23: Ergebnisse der Trabekeldichte der Wirbelkörper

(Tukey-Kramer-Test)

${ }^{* * *} p<0,001$

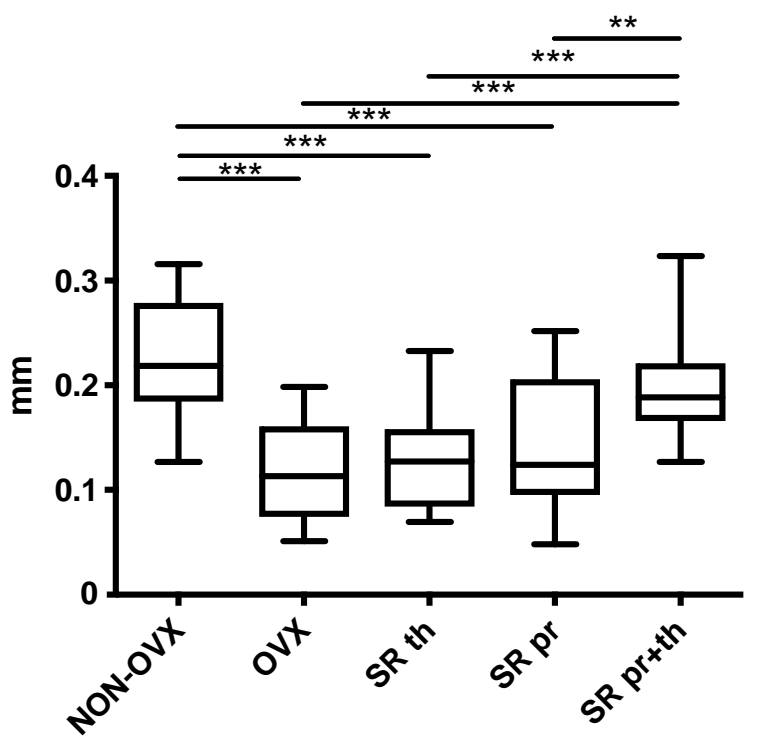

Abb. 24: Ergebnisse der mittleren Trabekeldicke der Wirbelkörper (Tukey-Kramer-Test)

${ }^{* *} p<0,01$

$* * *<<0,001$

Tabelle 10: Ergebnisse der Trabekeldichte und mittleren Trabekeldicke in den Versuchsgruppen; Darstellung der Mittelwerte/Mediane \pm Standardabweichung

\begin{tabular}{|c|c|c|c|c|c|}
\hline $\begin{array}{l}\text { Gruppe } \\
\text { Parameter }\end{array}$ & NON-OVX & OVX & SR th & SR pr & SR pr+th \\
\hline \multirow{4}{*}{$\begin{array}{c}\text { Trabekel- } \\
\text { dichte } \\
(\%)\end{array}$} & 42,52 & & & & 39,05 \\
\hline & 41,15 & 25,78 & 28,64 & 30,52 & 40,21 \\
\hline & $\pm 6,40$ & 26,23 & 27,24 & 31,13 & $\pm 4,49$ \\
\hline & $\begin{array}{c}\left(\mathbf{a}^{\star \star \star}, \mathbf{b}^{\star \star \star \star}\right. \\
\left.\mathbf{c}^{\star \star \star}\right)\end{array}$ & $\pm 7,30$ & $\pm 7,01$ & $\pm 7,14$ & $\begin{array}{c}\left(\mathbf{a}^{\star \star \star}, \mathbf{b}^{\star \star \star \star}\right. \\
\left.\mathbf{c}^{\star \star \star}\right)\end{array}$ \\
\hline \multirow{3}{*}{$\begin{array}{l}\text { Mittlere } \\
\text { Trabekel- } \\
\text { dicke } \\
(\mathbf{m m})\end{array}$} & 0,23 & & & & 0,19 \\
\hline & 0,22 & 0,12 & 0,13 & 0,14 & 0,19 \\
\hline & $\begin{array}{c} \pm 0,05 \\
\left(\mathbf{a}^{\star \star \star}, \mathbf{b}^{* \star *}\right. \\
\left.\mathbf{c}^{\star \star \star}\right)\end{array}$ & $\begin{array}{c}0,11 \\
\pm 0,04\end{array}$ & $\begin{array}{c}0,13 \\
\pm 0,05\end{array}$ & $\begin{array}{c}0,12 \\
\pm 0,06\end{array}$ & $\begin{array}{c} \pm 0,05 \\
\left(\mathbf{a}^{\star \star \star *}, \mathbf{b}^{\star \star \star \star}\right. \\
\left.\mathbf{c}^{\star \star}\right)\end{array}$ \\
\hline
\end{tabular}

$\mathrm{a}=$ signifikant zu OVX, b = signifikant zu SR th, $\mathrm{C}=$ signifikant zu SR pr, ${ }^{* *} \mathrm{p}<$ $0,01,{ }^{* \star *} p<0,001$, Tukey-Kramer-Test 


\subsubsection{Trabekelfläche}

Analog zur Trabekeldichte und mittleren Trabekeldicke war auch die Gesamtfläche der Trabekel in der NON-OVX-Gruppe signifikant höher als in den übrigen Versuchsgruppen außer SR pr+th. Auch zwischen der SR pr+th-Gruppe und der rein ovariektomierten Versuchsgruppe (OVX) sowie der SR th-Gruppe war ein signifikanter Unterschied nachweisbar (Abb. 25 und Tabelle 11). Zwischen der NONOVX- und der SR pr+th-Gruppe ergab sich keine signifikante Differenz.

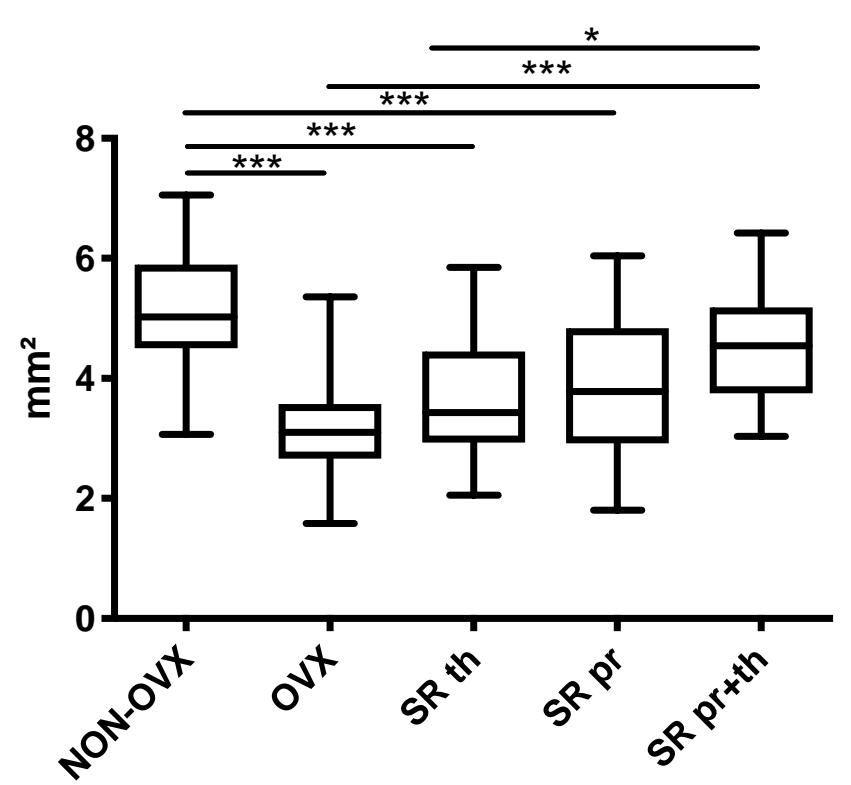

Abb 25: Ergebnisse der Gesamtfläche der Trabekel

(Tukey-Kramer-Test)

${ }^{*} p<0,05,{ }^{* * *} p<0,001$

Tabelle 11: Ergebnisse der Gesamtfläche der Trabekel in den Versuchsgruppen; Darstellung der Mittelwerte/Mediane \pm Standardabweichung

\begin{tabular}{|c|c|c|c|c|c|}
\hline $\begin{array}{c}\text { Gruppen } \\
\text { Parameter }\end{array}$ & NON-OVX & OVX & SR th & SR pr & SR pr+th \\
\hline $\begin{array}{c}\text { Trabekel- } \\
\text { fläche } \\
\left(\mathbf{m m}^{\mathbf{2}}\right)\end{array}$ & $\begin{array}{c}5,09 / 5,03 \\
\pm 1,01 \\
\left(\mathbf{a}^{\star \star \star}, \mathbf{b}^{\star \star \star}\right. \\
\left.\mathbf{c}^{\star \star \star}\right)\end{array}$ & $\begin{array}{c}3,18 / 3,10 \\
\pm 0,91\end{array}$ & $\begin{array}{c}3,66 / 3,43 \\
\pm 1,10\end{array}$ & $\begin{array}{c}3,78 / 3,78 \\
\pm 1,18\end{array}$ & $\begin{array}{c}4,51 / 4,54 \\
\pm 0,89 \\
\left(\mathbf{a}^{\star \star \star}, \mathbf{b}^{\star}\right)\end{array}$ \\
\hline
\end{tabular}

$\mathrm{a}=$ signifikant zu OVX, b = signifikant zu SR th, c = signifikant zu SR pr, ${ }^{*} \mathrm{p}<$ $0,05,{ }^{* * *} p<0,001$, Tukey-Kramer-Test 


\subsubsection{Trabekelkreuzungen und trabekuläre Konnektivität}

Im direkten Vergleich der Anzahl der Trabekelkreuzungen (N.Nd) ergaben sich keine signifikanten Unterschiede zwischen den Vergleichsgruppen $(p=0,253)$ (Tabelle 12). Die höchste, aber gleichzeitig auch die niedrigste Anzahl an Trabekelknoten fand sich in der OVX-Gruppe zwischen 23 und 85. Die Dichte der Trabekelkreuzungen pro $\mathrm{mm}^{2}$ (N.Nd/mm²) war dagegen in der NON-OVX-Gruppe signifikant reduziert gegenüber den Gruppen OVX, SR th und SR pr. Auch die SR pr+th-Gruppe wies eine signifikant geringere Dichte an Trabekelknoten pro $\mathrm{mm}^{2}$ im Vergleich zur OVX-Gruppe auf (Abb. 26 und Tabelle 12).

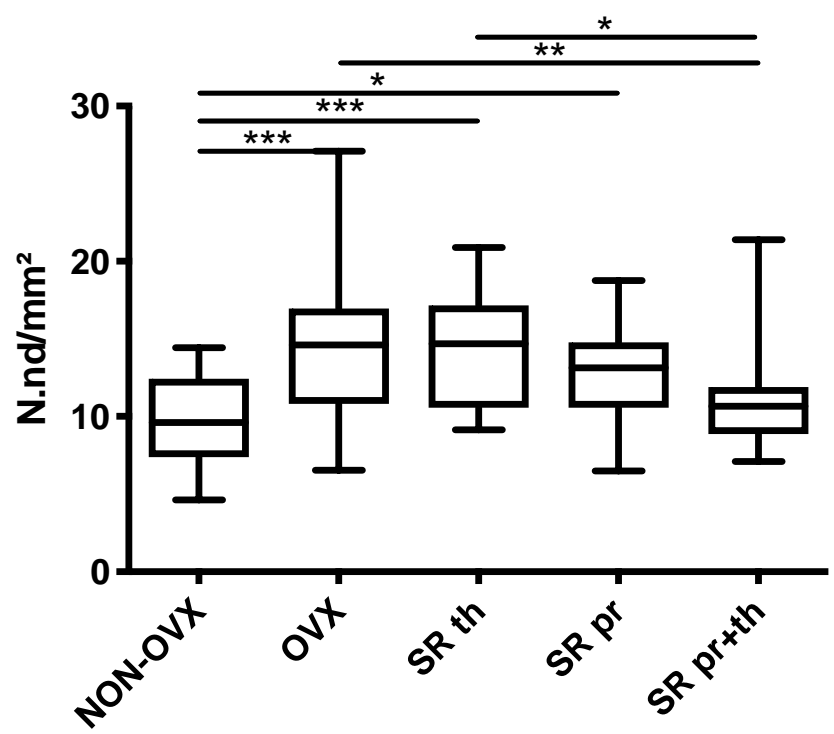

Abb. 26: Ergebnisse der trabekulären Konnektivität (Tukey-Kramer-Test)

${ }^{*} p<0,05,{ }^{* *} p<0,01,{ }^{* * *} p<0,001$ 
Tabelle 12: Ergebnisse der Trabekelknotenanzahl und der trabekulären Konnektivität in den Versuchsgruppen; Darstellung der Mittelwerte/Mediane \pm Standardabweichung

\begin{tabular}{|c|c|c|c|c|c|}
\hline $\begin{array}{l}\text { Gruppen } \\
\text { Parameter }\end{array}$ & NON-OVX & ovx & SR th & SR pr & SR pr+th \\
\hline \multirow{3}{*}{$\begin{array}{l}\text { Anzahl der } \\
\text { Trabekel- } \\
\text { kreuzungen }\end{array}$} & 46,93 & 43,07 & 48,76 & 45,22 & 48,48 \\
\hline & 45,00 & 42,50 & 52,00 & 42,00 & 49,00 \\
\hline & $\pm 9,20$ & $\pm 13,89$ & $\pm 11,11$ & $\pm 11,38$ & $\pm 10,93$ \\
\hline \multirow{3}{*}{$\begin{array}{l}\text { Trabekuläre } \\
\text { Konnektivität } \\
\left(\mathrm{N} . \mathrm{nd} / \mathrm{mm}^{2}\right)\end{array}$} & $\begin{array}{l}9,67 \\
961\end{array}$ & 14,16 & 13,99 & 12,63 & 10,96 \\
\hline & $\pm 2,86$ & 14,61 & 14,69 & 13,14 & 10,65 \\
\hline & $\begin{array}{c}\left(\mathbf{a}^{\star \star \star}, \mathbf{b}^{\star \star \star}\right. \\
\left.\mathbf{c}^{\star}\right)\end{array}$ & $\pm 4,62$ & $\pm 3,74$ & $\pm 3,12$ & $\begin{array}{c} \pm 2,77 \\
\left(\mathbf{a}^{\star \star}, \mathbf{b}^{\star}\right)\end{array}$ \\
\hline
\end{tabular}

$\mathrm{a}=$ signifikant gegen OVX, b = signifikant zu SR th, $c=$ signifikant zu SR pr, ${ }^{*} p<0,05,{ }^{* *} p<0,001$, Tukey-Kramer-Test

\subsubsection{Zusammenfassung der Ergebnisse im Mikro-CT}

Bei den Auswertungen der Ergebnisse des Mikro-CT fiel die Wichtung vor allem auf Unterschiede zwischen den Gruppen NON-OVX und SR pr+th gegenüber OVX, SR th und SR pr auf. So zeigten Tiere der NON-OVX-/SR pr+th-Gruppen eine gesteigerte totale BMD, Kortikalisdichte, Trabekeldichte, mittlere Trabekeldicke und Trabekelfläche im Vergleich zu den anderen Versuchsgruppen. Dagegen war die gesamte Kortikalisfläche bei Ratten der SR pr-Gruppe größer als die der OVX- und SR th-Gruppe. Eine medikamentöse Prophylaxe oder Therapie mit Strontiumranelat hatte keinen signifikanten Einfluss auf die Kortikalisdicke der Wirbelkörper-Vorder- oder -Hinterkanten. 


\subsection{Ergebnisse der Veraschung}

Im Folgenden werden die Ergebnisse des Veraschungsversuches demonstriert. Die erhobenen Daten werden am Ende des Kapitels zusammengefasst.

\subsubsection{Organische und anorganische Knochensubstanz}

Beim Vergleich der Anteile an organischer und anorganischer Knochensubstanz war ein signifikant reduzierter Anteil an anorganischer Substanz in der SR pr+thund der OVX-Gruppe gegenüber NON-OVX nachweisbar (Abb. 27 und Tabelle 13). Entsprechend zeigten Tiere der SR pr+th- und der OVX-Gruppe einen signifikant höheren Anteil an organischer Substanz (Abb. 28 und Tabelle 13).
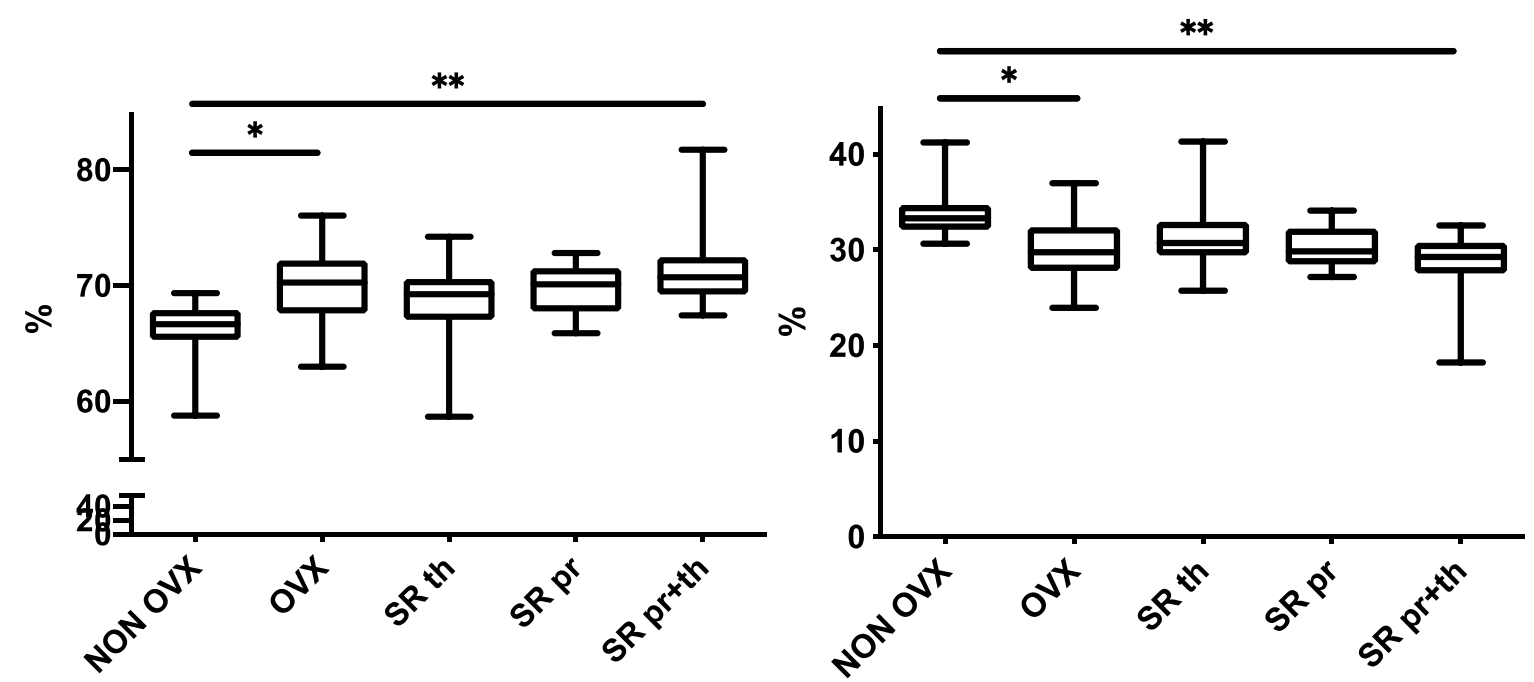

Abb. 27: Ergebnisse Anteil organische Knochensubstanz

(Tukey-Kramer-Test)

Abb. 28: Ergebnisse Anteil anorganische Knochensubstanz (Dunn's Test)

${ }^{*} p<0,05$

${ }^{*} p<0,05$

${ }^{* *} p<0,01$

${ }^{* *} p<0,01$ 
Tabelle 13: Ergebnisse der Anteile an organischer und anorganischer Knochensubstanz in den Versuchsgruppen; Darstellung der Mittelwerte/Mediane \pm Standardabweichung

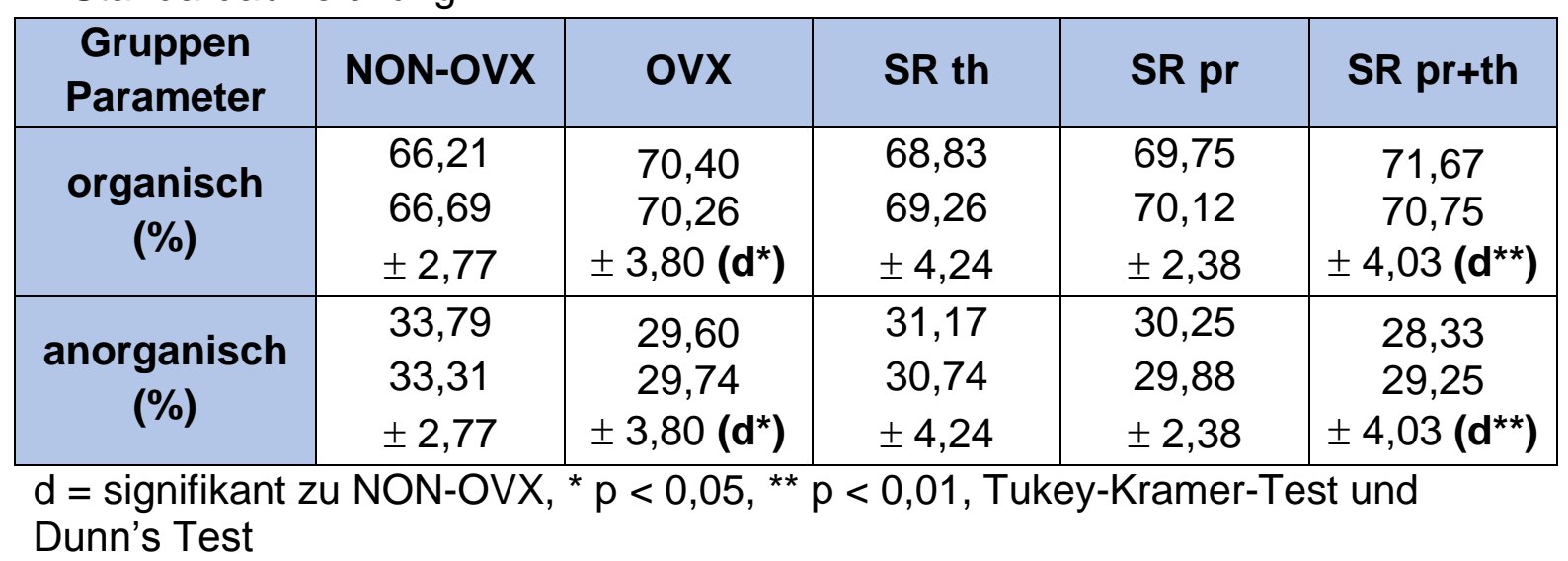

\subsubsection{Phosphatgehalt der Knochen}

Beim Vergleich des Phosphatgehalts der anorganischen Knochensubstanz zeigten sich keine signifikanten Gruppenunterschiede $(p=0,230)$ (Tabelle 14).

Den höchsten Phosphatanteil im Knochen zeigten Tiere der NON-OVX-Gruppe mit bis zu 74,27\%, den niedrigsten Phosphatanteil hatten Knochen der Gruppe SR pr+th mit $48,67 \%$.

Tabelle 14: Ergebnisse des Phosphatgehalts in den Versuchsgruppen; Darstellung der Mittelwerte/Mediane \pm Standardabweichung

\begin{tabular}{|c|c|c|c|c|c|}
\hline $\begin{array}{c}\text { Gruppen } \\
\text { Parameter }\end{array}$ & NON-OVX & OVX & SR th & SR pr & SR pr+th \\
\hline $\begin{array}{c}\text { Phosphatgehalt } \\
\text { (\%) }\end{array}$ & 56,00 & 53,89 & 53,94 & 54,10 & 52,18 \\
& $\pm 6,96$ & 53,52 & 53,39 & 54,23 & 52,67 \\
$\pm 1,29$ & $\pm 2,23$ & $\pm 0,42$ & $\pm 2,32$ \\
\hline
\end{tabular}

Keine signifikanten Unterschiede, $p>0,05$, Dunn's Test 


\subsubsection{Calciumgehalt der Knochen}

Auch hinsichtlich des Calciumgehalts ergaben sich keine signifikanten Unterschiede zwischen den Versuchsgruppen $(p=0,051)$ (Tabelle 15). Den höchsten Anteil an Calcium hatten Tiere der OVX- und SR th-Gruppe (bis 40,73\%). Den geringsten Anteil zeigten Ratten der NON-OVX- und SR pr+th-Gruppe (bis $33,39 \%)$.

Tabelle 15: Ergebnisse des Calciumgehalts in den Versuchsgruppen; Darstellung der Mittelwerte/Mediane \pm Standardabweichung

\begin{tabular}{|c|c|c|c|c|c|}
\hline $\begin{array}{c}\text { Gruppen } \\
\text { Parameter }\end{array}$ & NON-OVX & OVX & SR th & SR pr & SR pr+th \\
\hline Calciumgehalt & 36,18 & 37,09 & 36,98 & 37,14 & 35,71 \\
$(\%)$ & 36,03 & 36,96 & 36,72 & 37,20 & 36,15 \\
& $\pm 1,53$ & $\pm 1,42$ & $\pm 1,21$ & $\pm 0,27$ & $\pm 0,44$ \\
\hline
\end{tabular}

Keine signifikanten Unterschiede, $p>0,05$, Dunn's Test 


\subsubsection{Verhältnis von Calcium zu Phosphat}

Beim Vergleich des Verhältnisses an Calcium zum Phosphatgehalt der anorganischen Knochensubstanz war das $\mathrm{Ca}^{2+} / \mathrm{PO}_{4}{ }^{3-}-$ Verhältnis bei der $\mathrm{SR}$ pr+thGruppe gegenüber allen anderen Gruppen höchst signifikant reduziert (Abb. 29 und Tabelle 16). Die reine Ovariektomie (OVX) hatte keinen signifikanten Einfluss auf den Calcium-Phosphat-Gehalt im Vergleich zur nicht operierten Kontrollgruppe (NON-OVX).

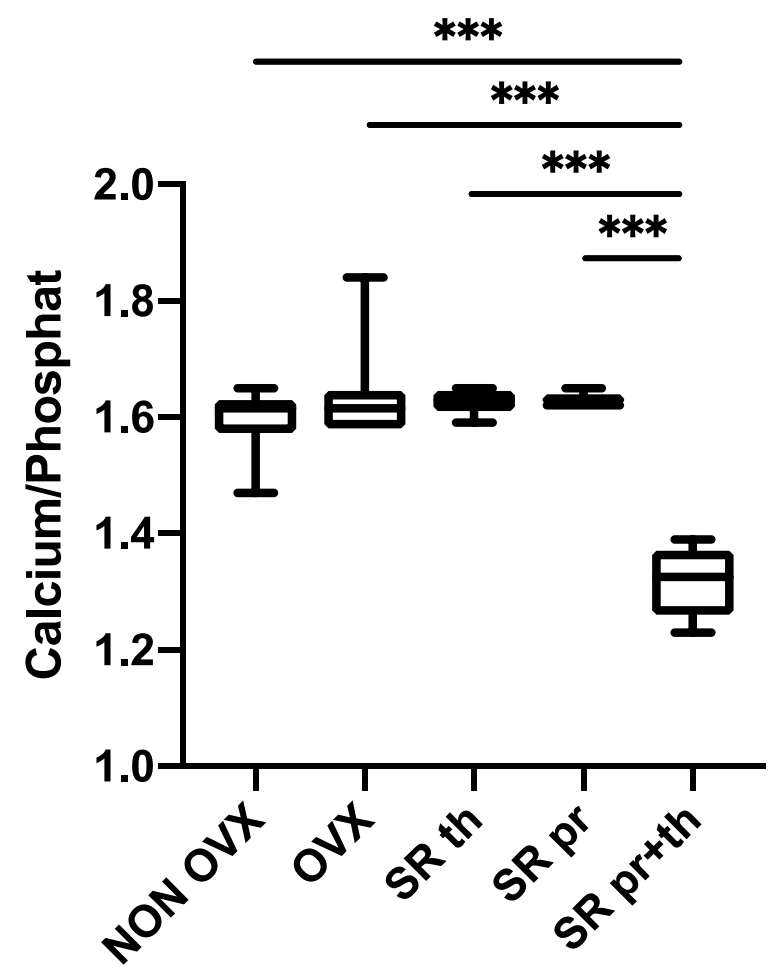

Abb. 29: Ergebnisse des Calcium-Phosphat-Verhältnisses

(Tukey-Kramer-Test)

${ }^{* * *} p<0,0001$

Tabelle 16: Ergebnisse des Calcium-Phosphat-Verhältnisses in den Versuchsgruppen; Darstellung der Mittelwerte/Mediane \pm Standardabweichung

\begin{tabular}{|c|c|c|c|c|c|}
\hline $\begin{array}{c}\text { Gruppen } \\
\text { Parameter }\end{array}$ & NON-OVX & OVX & SR th & SR pr & SR pr+th \\
\hline $\mathbf{C a}^{2+} / \mathbf{P O}_{4}{ }^{3-}$ & $\begin{array}{c}1,55 / 1,60 \\
\pm 0,13\end{array}$ & $\begin{array}{c}1,62 / 1,61 \\
\pm 0,07\end{array}$ & $\begin{array}{c}1,63 / 1,63 \\
\pm 0,02\end{array}$ & $\begin{array}{c}1,63 / 1,62 \\
\pm 0,01\end{array}$ & $\begin{array}{c}1,33 / 1,33 \\
\pm 0,05 \\
\left(\mathbf{e}^{\star \star \star}\right)\end{array}$ \\
\hline
\end{tabular}

$\mathrm{e}=$ signifikant $z u$ allen anderen Gruppen, ${ }^{* * *} p<0,001$, Tukey-Kramer-Test 


\subsubsection{Zusammenfassung der Veraschungsergebnisse}

Zusammenfassend zeigte sich ein deutlich reduzierter Anteil an anorganischer Substanz mit entsprechend erhöhtem Anteil an organischer Knochensubstanz bei Ratten der OVX-Gruppe im Vergleich zur nicht operierten Kontroll-Gruppe (NONOVX). Bei Strontium-behandelten Tieren zeigte sich bis auf die SR pr+th-Gruppe kein Effekt auf die organische/anorganische Knochenmatrix. Die Wirbelkörper der SR pr+th-Ratten wiesen jedoch ebenfalls einen höheren Gehalt von organischer und einen geringeren Anteil an anorganischer Substanz auf.

Signifikante Gruppenunterschiede des Calcium- oder Phosphatgehaltes im Knochen fanden sich nicht. Dafür war der Calcium-Phosphat-Index - also das Verhältnis von Calciumgehalt zum Phosphatanteil im Knochen - bei Tieren der SR pr+th-Gruppe gegenüber Tieren aller anderer Gruppen deutlich reduziert. 


\section{Diskussion}

\subsection{Futteraufnahme, Körper- und Uterusgewicht der Ratten}

In unserer Studie haben wir beobachtet, dass bis zur dritten Studienwoche alle Versuchstiere annähernd die gleiche Futtermenge zu sich nahmen und eine entsprechend gleiche Gewichtsentwicklung zeigten, was der physiologischen Entwicklung von Ratten entspricht (Berg und Harmison 1957; Komrakova et al. 2009). Ab der zweiten Studienwoche bis Studienende nahmen die Tiere aller Gruppen außer NON-OVX mehr an Gewicht zu. In dieser Gruppe war die Futteraufnahme auch niedriger als bei den anderen Versuchsgruppen. Studien belegen den Zusammenhang zwischen Östradiol - der wirksamsten Form des Östrogens, das in den Follikeln der Eierstöcke gebildet wird - und seiner Appetitzügelnden Wirkung, was die vorliegende Konstellation stützen würde (Mela et al. 2016). Lyons et al. (1989) wiesen in diesem Zusammenhang eine signifikant verminderte Nahrungsaufnahme bei jungen, gesunden Frauen in der präovulären Phase nach, in der die Serumkonzentration an Östradiol am höchsten ist. Die Blockade von Östrogenrezeptoren kann diesen Appetit-zügelnden Effekt vollständig aufheben (Mela et al. 2016). Ein Wegfall der Östrogenwirkung durch die Ovariektomie bewirkt bei wachsenden weiblichen Ratten zudem eine Zunahme des Körpergewichtes durch vermehrten Muskelaufbau und Einlagerung von Fettgewebe (Toth et al. 2001; Komrakova et al. 2009; Saul et al. 2019).

Die Futter- und Körpergewichtsabnahme nach der Osteotomie (in Studienwoche acht) kann durch postoperative Effekte erklärt werden. Die Narkose und postoperativen Schmerzen haben trotz adäquater Schmerztherapie Einfluss auf diese Parameter, was bereits in früheren, ähnlich durchgeführten Studien unserer Arbeitsgruppe beobachtet wurde (Komrakova et al. 2009; 2018).

Die Strontium-behandelten Tiere (SR th, SR pr, SR pr+th) zeigten weder untereinander, noch im Vergleich zur OVX-Gruppe hinsichtlich Futteraufnahme und Gewichtsentwicklung relevante Unterschiede. Ratten aller Gruppen außer NONOVX nahmen im Verlauf annähernd gleiche Futtermengen auf und hatten ein höheres Körpergewicht gegenüber NON-OVX-Tieren. Unter Strontium-Behandlung ist kein unmittelbarer Effekt auf die Nahrungsaufnahme und die damit ver- 
bundene Gewichtszunahme von Versuchsratten bekannt. Als Nebenwirkung von Strontium-Behandlungen wird aber die Einlagerung von Wasser im Sinne von peripheren Ödemen beschrieben (Mendoza et al. 2013; Drago et al. 2016), was eventuell zur Gewichtszunahme der Tiere, die Strontiumranelat erhalten hatten beigetragen haben kann.

Alle ovariektomierten Tiere zeigten ein signifikant reduziertes Uterusgewicht im Vergleich zur nicht ovariektomierten Versuchsgruppe NON-OVX. Das hier noch wirksame Östradiol hat einen stimulierenden Effekt auf das endometriale Uterusgewebe, sodass die Östrogexposition den Uterus in physiologischer Weise beeinflusst und stabilisiert (Hinson et al. 2018). Der Wegfall der Östrogenwirkung nach Ovariektomie bewirkt hingegen die Uterusatrophie (Sehmisch et al. 2009; Komrakova et al. 2014; 2015), was in der vorliegenden Studie als Zeichen der erfolgreichen Ovariektomie gewertet wurde. Das Uterusgewicht macht dennoch nur einen Bruchteil des gesamten Körpergewichtes aus, sodass diese Veränderungen keinen Einfluss auf das Gesamtgewicht der Tiere hatten.

Die Strontium-Aufnahme wurde über die Beimengung zum Futter gewährleistet und erfolgte in drei unterschiedlichen Regimes - nur als Prophylaxe, nur als Therapie oder kombiniert in Prophylaxe und Therapie. Dabei imitiert die StrontiumProphylaxe die Situation, in der Patienten pathologische Frakturen erleiden, während sie mit Strontium behandelt werden (Komrakova et al. 2015). Die Strontiumranelat-Prophylaxe erhielten die Tiere unmittelbar nach Ovariektomie, die Therapie nach Ovariektomie fand mit einer Latenzzeit von acht Wochen über die restlichen fünf Wochen der Studie statt. Laut einer Studie von Dahl et al. (2001) erreicht der Einbau von Strontium in den Knochen bei Ratten sein Plateaulevel bereits nach vier Wochen dauerhafter Medikation. Die Tiere der vorliegenden Studie erhielten also 5, 8 oder 13 Wochen Strontiumranelat, was auf dem Hintergrund der Studienlage ausreichen müsste, um genügend Strontium in die Knochenmatrix zu integrieren (Deeks und Dhillon 2010b). Die dabei täglich aufgenommene Menge an $625 \mathrm{mg}$ Strontium pro kg Körpergewicht entsprach durchschnittlich auch der Serumkonzentration von Strontium im menschlichen Blut nach prophylaktischer Einnahme von Strontiumranelat (Bain et al. 2009; Habermann et al. 2010; Li YF et al. 2010; Komrakova et al. 2015; 2016). Eine Studie mit unterschiedlichen täglichen Dosen an Strontiumranelat $(225 \mathrm{mg}, 450 \mathrm{mg}$ und 900 mg pro kg Körpergewicht) konnte nachweisen, dass bereits geringe tägliche 
Dosen dazu führen, die intrinsische Knochenqualität und damit die Widerstandskraft der Knochen ihrer Versuchsratten positiv zu beeinflussen (Ammann et al. 2007). Andere Studien zeigten aber auch, dass zu hohe Dosen an Strontiumranelat sogar einen destruierenden Effekt auf den Knochen haben können, was in erster Linie durch die Beeinflussung der Calciumhomöostase und die damit verbundene geringere Produktion an Vitamin $D_{3}$ erklärt wurde und dementsprechend auch von der zusätzlichen individuellen Calciumzufuhr der Testratten abhängig war (Grynpas und Marie 1990; Grynpas et al. 1996).

\subsection{Diskussion der Ergebnisse des biomechanischen Kompressionstests}

Die Bedeutung der mechanischen Widerstandskraft eines Knochens wurde größer, als Studien zeigten, dass die reine Erhöhung der Knochenmasse nicht gleichbedeutend mit einer Verringerung des Frakturrisikos ist. Erst das richtige Verhältnis von organischer und anorganischer Knochensubstanz macht die Elastizität und damit die Belastbarkeit eines Knochens aus (Bartl und Bartl 2004). Diese wird maßgeblich von Kollagen und insbesondere dem in der organischen Knochenmatrix vorherrschenden Kollagen Typ I beeinflusst, dessen Bildung und Differenzierung sowohl von Östrogen als auch von Strontium gefördert wird (Braux et al. 2011). Eine Messung der mechanischen Widerstandkraft von Knochen erfolgt ex vivo anhand von Drei- und Vier-Punkt-Biegungs- und Torsionsversuchen oder mittels Kompressionstests (Turner et al. 1987; Jee und Yao 2001; Stürmer et al. 2006). In dieser Arbeit wurde eine durch unsere Arbeitsgruppe konzipierte Methode für den Kompressionstest von Wirbelkörpern angewandt (Erren 2007; Sehmisch et al. 2009).

Die Behandlung mit Strontiumranelat über 13 Wochen (SR pr+th) verbesserte die Biomechanik der untersuchten Wirbelkörper hinsichtlich Maximalkraft und Streckgrenze signifikant gegenüber anderen Gruppen ohne Strontium (OVX) oder nur verkürzter Strontium-Gabe ( $S R$ th, $S R$ pr). Auch die Elastizität und damit Flexibilität der Wirbelkörper von Tieren der SR pr+th-Gruppe war gegenüber den anderen Versuchsgruppen (OVX, SR th, SR pr) tendenziell erhöht. Gleichzeitig war die Knochenelastizität bei Ratten der OVX-Gruppe gegenüber Tieren der NON-OVX-Gruppe signifikant reduziert. Ausschlaggebend wird dafür der Wegfall 
der Östrogenwirkung auf die Kollagenproduktion sein, die - wie bereits erwähnt essentiell für die Knochenelastizität ist. Die längerfristige Gabe von Strontium schien in unserer Studie die Widerstandkraft der osteopenischen Knochen positiv zu beeinflussen. Hintergrund ist der Einbau von Strontium anstelle von Calcium in die mineralische Knochensubstanz und die verbesserte Mikroarchitektur unter Strontium-Wirkung. $99 \%$ des aufgenommenen Strontiums liegen im Körper knöchern gebunden vor. Es ist bevorzugt in trabekelreichen Knochen wie Wirbelkörpern, Beckenkamm und Femumetaphyse zu finden und wird dort im Rahmen der mineralischen Knochenneubildung anstelle von Calcium eingebaut (Dahl et al. 2001; Li C et al. 2010; Oliveira et al. 2012). Da der Knochenumbau im trabekulären Knochen nachweislich höher ist als in kortikalen Knochenregionen, ist der Strontium-Anteil in der Spongiosa von neu gebildeten Knochen bis zu viermal höher als in altem Knochen (Verberckmoes et al. 2003; Farlay et al. 2005). Wu et al. (2013) verabreichten Ratten über 16 Wochen täglich $308 \mathrm{mg}$ Strontiumranelat pro kg Körpergewicht und wiesen anschließend einen erhöhten Strontium-Einbau an der Trabekeloberfläche und den vertebralen Grund- und Deckplatten nach Regionen mit erhöhter Knochenumsatzrate. Insbesondere die gleichzeitige Gabe von Strontium und Calcium scheint die Expression osteogenetischer Gene und damit die Knochenneubildung zu fördern (Li Z et al. 2009).

Eine kürzere Applikationszeit von Strontium über fünf oder acht Wochen hatte in den Gruppen SR th und SR pr keinen signifikanten Effekt auf die Biomechanik der Wirbelkörper. Die Ergebnisse decken sich mit Resultaten einer ähnlich durchgeführten Studie von Ammann et al. (2007). Vegger et al. (2016) konnten nach der Applikation von $900 \mathrm{mg}$ Strontiumranelat pro $\mathrm{kg}$ Körpergewicht über einen Zeitraum von drei bis acht Wochen ebenfalls keinen Effekt auf die Studien biomechanischen Eigenschaften rodenter Knochen nachweisen. Auch frühere Ergebnisse unserer Arbeitsgruppe erzielten beispielsweise unter sechs-wöchiger Strontium-Gabe keine signifikante Verbesserung der vertebralen oder femoralen Biomechanik (Hoffmann et al. 2017). Selbst unter zusätzlicher Vibrationstherapie ergab die sechs-wöchige Strontium-Gabe nach Osteotomie und Knochenheilung keine Verbesserung der Biomachanik der untersuchten Tibiae (Komrakova et al. 2016). 


\subsection{Diskussion der Mikro-CT-Ergebnisse}

Die Knochenmineraldichte hat sich in den letzten Jahrzehnten als wichtiges diagnostisches Mittel zur Beurteilung der individuellen Knochendichte etabliert. Zahlreiche Studien konnten ein steigendes Frakturrisiko bei Patienten belegen, deren BMD nachweislich vermindert war (Cummings et al. 1993; Marshall et al. 1996; EPOS Group 2002; Miller et al. 2002). Weitere Studien zeigten auch, dass die Gabe von antiresorptiven Medikamenten bei betroffenen Patienten zwar das Risiko für Frakturen deutlich senken konnte, gleichzeitig aber keinen relevanten Einfluss auf die BMD der Knochen hatte, was die Vermutung nahe legt, dass die Bestimmung der BMD allein nicht ausreicht, um die Knochenqualität und Widerstandskraft und damit auch das Frakturrisiko ausreichend beurteilen zu können (Cummings et al. 1998; 2002; Lane 2006). Laut Ammann und Rizzoli (2003) gibt die BMD Auskunft über etwa 60-70 \% der Gesamtknochen-Stärke. Die restlichen 30-40\% werden von weiteren Parametern bestimmt, die eine Beurteilung der knöchernen Widerstandskraft zulassen. Dazu gehören die Knochengeometrie, die Mikroarchitektur und die intrinsische Knochenqualität, sodass die Erhebung dieser Parameter neben der Bestimmung der BMD essentiell ist. Die Beurteilung der BMD, der Knochenvolumina und der Mikroarchitektur war in dieser Studie mittels Mikro-CT möglich.

Es konnte eine signifikante Erhöhung der totalen BMD, der Kortikalisdichte, der Trabekeldichte, der mittleren Trabekeldicke und der Trabekelfläche bei Tieren der Gruppe SR pr+th mit einer Strontium-Applikationszeit von 13 Wochen nachgewiesen werden. Eine reine Prophylaxe oder Therapie (SR pr oder SR th) mit Strontiumranelat hatte kaum einen Effekt auf die Mikroarchitektur. Lediglich die Gesamtfläche der Kortikalis war bei prophylaktischer Strontium-Gabe gegenüber der OVX-Gruppe signifikant erhöht. Analog dazu beschrieben Chen et al. (2013) in einer Studie mit Ratten nach SR-Gabe von 500 mg pro kg Körpergewicht pro Tag über einen Zeitraum von zwölf Wochen einen Anstieg der BMD, der Trabekelanzahl und -dicke sowie der Festigkeit der Knochen der Versuchstiere. Demgegenüber waren bei Hoffmann et al. (2017) mit einer Applikation von $600 \mathrm{mg}$ pro $\mathrm{kg}$ Körpergewicht über sechs Wochen nur die Kortikalisdicke der untersuchten lumbalen Wirbel positiv beeinflusst. Eine signifikante Änderung trabekulärer Parameter zeigte sich bei dieser Studie nicht (Hoffmann et al. 2017). 
Hinsichtlich der Volumina BV, TV und BV/TV ergaben sich keine signifikanten Unterschiede. Dies deckt sich mit früheren Ergebnissen unserer Arbeitsgruppe (Hofmann 2017). Ammann et al. (2004) konnten dagegen nach einer längeren Strontium-Gabe über zwei Jahre eine signifikante Zunahme der WirbelkörperVolumina der Versuchsratten nachweisen.

Bei Betrachtung der BMD war bei Ratten mit der längsten Applikationszeit von Strontium (SR pr+th über 13 Wochen) und bei gesunden NON-OVX-Tieren im Vergleich zur OVX-Gruppe eine signifikant erhöhte totale BMD nachweisbar. Die reine Bone BMD war in denselben Gruppen tendenziell erhöht, erreichte aber aufgrund hoher Standardabweichungen kein Signifikanzlevel.

Boyd et al. (2011) beschrieben nach einer Strontium-Applikationszeit von 104 Wochen eine Verbesserung der BV/TV und der BMD an Wirbelkörpern von Ratten. Die Total BMD war dagegen bei Hoffmann et al. (2017) bereits nach einer Strontium-Gabe von über sechs Wochen signifikant erhöht, was unsere Ergebnisse hinsichtlich der Total BMD und die positive Tendenz bei Untersuchungen der Bone BMD nach längerer Strontium-Applikation stützt.

Auch die Untersuchungsergebnisse an den Tibiae unserer Versuchstiere ergaben eine Steigerung der BMD in der Versuchsgruppe mit einer Strontium-Applikation über die vollen 13 Versuchswochen gegenüber der ovariektomierten Vergleichsgruppe ohne Strontium-Gabe (Weidemann 2013; Komrakova et al. 2015). Auch die Untersuchung der osteopenischen Femora der Versuchsratten ergab eine verbesserte Mikroarchitektur der Knochen nach Behandlung der Tiere mit Strontiumranelat über 13 Wochen. Dies zeigte sich besonders in einem vermehrten trabekulären Knochen, einer Erhöhung der Anzahl an Trabekelkreuzungen und einer vermehrten Trabekeldichte gegenüber Ratten der Vergleichsgruppe OVX (Köstner 2018). Zudem konnte nachgewiesen werden, dass eine langfristige Applikation von Strontiumranelat unter Auftreten einer Fraktur einen positiven Effekt auf frühe Stadien der Knochenheilung hat (Komrakova et al. 2015). Bei der zusätzlichen Untersuchung der Skelettmuskulatur unserer Versuchstiere konnte kein negativer Einfluss des applizierten Strontiumranelats auf die Muskulatur festgestellt werden (Saul et al. 2018a; Harlass 2019).

Die Kortikalisdichte war bei Tieren der SR pr+th-Gruppe und den NON-OVXRatten gegenüber den anderen Gruppen signifikant erhöht. Bezüglich der 
Kortikalisdicke ergaben sich keine Unterschiede zwischen Tieren der OVX-Gruppe und Strontium-behandelten Ratten. Die ventrale Kortikalisdicke war bei NONOVX-Ratten signifikant höher als bei Ratten der Gruppen OVX und SR th. Die dorsale Kortikalisdicke war bei den NON-OVX-Tieren sogar gegenüber allen anderen Gruppen signifikant erhöht. Eine mögliche Erklärung hierfür liefern Hengsberger et al. (2005), die herausfanden, dass besonders anteriore Regionen der Wirbelkörper von Substanzverlusten nach Ovariektomie betroffen sind. Dazu kommt, dass die Strontium-Wirkung am Knochen besonders die spongiösen Anteile und weniger die Kortikalis betreffen, was sich auch in Ergebnissen der vorliegenden Studie wiederspiegelt und besagte Ergebnisse an der ventralen und dorsalen Kortikalis stützen kann (Farlay et al. 2005).

Dementsprechend zeigten sich in unserer Studie zahlreiche signifikante Ergebnisse auf Trabekelebene. So konnte eine Erhöhung der Trabekeldichte, der Trabekeldicke und der Trabekelfläche bei Ratten der Gruppen NON-OVX und SR pr+th im Vergleich zu den übrigen Versuchsgruppen nachgewiesen werden. Hinsichtlich Trabekelknotenanzahl und trabekulärer Konnektivität ergaben sich unter Strontium-Gabe keine signifikanten Effekte. Auch diese Ergebnisse decken sich wiederum mit früheren Ergebnissen unserer Arbeitsgruppe (Hoffmann et al. 2017). Die Verbesserung der trabekulären Parameter unter Strontium waren in anderen, teils auch klinischen Studien wie beispielsweise von Rizzoli et al. (2010) nachweisbar, die eine erhöhte Trabekeldichte bei postmenopausalen Frauen detektierten, die über zwei Jahr eine orale Strontium-Prophylaxe erhielten. Ammann et al. (2007) beschrieben bei Strontium-behandelten Ratten mit Dosen von 400-900 mg pro kg Körpergewicht eine dosisabhängige und signifikant erhöhte Trabekelanzahl und Trabekeldicke.

Das Mikro-CT ist inzwischen auch in lebenden, narkotisierten Tieren zur Beurteilung mikrostruktureller Knochenveränderungen durchführbar, wodurch die Verlaufskontrolle in einem Individuum möglich ist. Dies gewährleistet eine erhöhte Vergleichbarkeit der Daten (Boyd et al. 2006; Gasser et al. 2006) und könnte in zukünftigen Studien angewendet werden. 


\subsection{Diskussion der Ergebnisse der Veraschung}

Der letzte an den Wirbeln durchgeführte Test, die Veraschung, dient der Quantifizierung von Anteilen an organischer und anorganischer Matrix sowie des Calcium- und Phosphatgehalts der Lendenwirbel. Er lässt dadurch eine Evaluation der intrinsischen Knochenqualität unter Strontium-Gabe zu.

Die Strontium-Gabe über 13 Wochen (SR pr+th) hatte in dieser Studie den Effekt, dass im Vergleich zu allen anderen Versuchsgruppen ein signifikant niedrigeres Calcium-Phosphat-Verhältnis auftrat. Diese Beobachtung wird durch die Erkenntnis gestützt, dass Strontium anstelle von Calcium in den mineralisierten, neu gebildeten Knochen eingebaut wird; das Calcium dort also in gewisser Weise verdrängt und dadurch ein verminderter Calciumgehalt induziert wird (Dahl et al. 2001; Li C et al. 2010; Oliveira et al. 2012). Bei Betrachtung des Calcium- und Phosphatgehaltes der Knochenmatrix konnten allerdings keine signifikanten Unterschiede zwischen den Gruppen festgestellt werden. Hier wäre es interessant, ob sich signifikante Veränderungen nach längerer Applikationszeit (mehr als 13 Wochen) nachweisen ließen, da Tiere der SR pr+th-Gruppe im Vergleich zu Ratten aus den Gruppen SR pr und SR th einen erniedrigten, wenn auch nicht signifikanten Calciumgehalt im Knochen zeigten, was ebenfalls für die Calciumverdrängung durch Strontium sprechen würde. Studien, bei denen Frauen mit Osteoporose über drei Jahre Strontiumranelat verabreicht wurde, konnten nach dieser Zeit allerdings keinen Effekt auf den Gesamtgehalt von Hydroxylapatit, der kristallinen Form des Calciumphosphats nachweisen (Doublier et al. 2011; Boivin et al. 2012).

Gleichzeitig zeigten die Ratten der SR pr+th-Gruppe gegenüber Tieren, die prophylaktisch oder therapeutisch Strontium erhalten hatten (SR pr und SR th) einen geringeren, wenn auch nicht signifikanten Phosphatgehalt im Knochen. Eine mögliche Erklärung hierfür liefern Studien von Wopenka und Pasteris (2005) sowie Querido et al. (2014). Sie wiesen unter Strontium einen Ersatz von Phosphat durch Carbonat im Knochen nach und begründeten dies als mögliche Reaktion auf den abfallenden Calciumspiegel, um die Neutralität im Gitternetz des mineralischen Knochens wiederherzustellen bzw. aufrecht zu erhalten. 
Sowohl Ratten der OVX- als auch Tiere der SR pr+th-Gruppe wiesen einen geringeren Anteil an anorganischer und ein erhöhtes Ausmaß an organischer Knochensubstanz auf. Bei Tieren der SR pr+th-Gruppe wäre dies durch den aktivierenden Effekt von Strontium auf die Kollagenproduktion zu erklären, da Kollagen Typ I den Großteil der organischen Knochenmatrix ausmacht (Braux et al. 2011; Buache et al. 2012). Andererseits beschrieben Meunier et al. (1971) bereits Anfang der 70er Jahre eine Akkumulation von Fettzellen im Knochenmark von Frauen mit Osteoporose, was das Ergebnis der Gruppe OVX erklären könnte. Auch andere Studien wiesen in diesem Zusammenhang einen höheren Fettgehalt im Mark osteoporotischer Knochen bei Frauen in der Postmenopause nach, die zu einem negativen Verhältnis von Knochenmarksfett zur ursprünglichen Knochenmatrix führten (Rozman et al. 1990; Justesen et al. 2001; Verma et al. 2002). Strontium dagegen scheint neben der unmittelbaren Wirkung auf den Knochen auch die Adipogenese des Knochenmarks zu hemmen, was die adipogene Transformation und die damit verbundene Verschlechterung der Knochenqualität behindert (Fournier et al. 2012). Der reine Fettgehalt der Wirbelkörper wurde in der vorliegenden Studie nicht untersucht. Die Ergebnisse lassen aber vermuten, dass die rein ovariektomierten Ratten (OVX) einen erhöhten Fettanteil und die Strontium-behandelten Tiere der Gruppe SR pr+th eine vermehrte Kollagenbildung ihrer organischen Knochenmatrix aufwiesen (Rozman et al. 1990; Justesen et al. 2001; Verma et al. 2002; Braux et al. 2011).

\subsection{Schlussfolgerung}

In der vorliegenden Studie erhielten die Versuchsratten in drei verschiedenen Regimes das Medikament Strontiumranelat über ihre Nahrung - als Prophylaxe über acht Wochen ( $S R$ pr), als Therapie über fünf Wochen ( $S R$ th) oder in Kombination aus Prophylaxe und Therapie über 13 Wochen (SR pr+th). Die Applikation von Strontiumranelat über 13 Studienwochen zeigte bei den osteopenischen Ratten einen positiven Effekt auf den spongiösen und kortikalen Knochen. Der bekanntlich größere Einfluss von Strontium auf die trabekuläre Knochenmatrix im Vergleich zu kortikalen Knochenanteilen (Farlay et al. 2005) hat sich hier ebenfalls bestätigt. Die Hauptwirkung von Strontiumranelat auf die 
Biomechanik, die Trabekelparameter und das Calcium-Phosphat-Verhältnis konnte in der Gruppe SR pr+th (13 Wochen) nachgewiesen werden. Parameter, die die Gesamtheit des Knochens betrachten, wie die Total BMD waren ebenfalls signifikant erhöht. Eine kürzere Applikationszeit in der Prophylaxe- und der Therapiegruppe $(\mathrm{SR}$ pr $=$ acht Wochen und $\mathrm{SR}$ th $=$ fünf Wochen) ergab kaum signifikante Ergebnisse.

Andere Knochenparameter wie die Bone BMD, die Volumina (BV, TV) sowie die Calcium- und Phosphatgehalte waren von den Effekten durch Strontium nicht beeinflusst.

Es zeigte sich ein vermindertes Calcium-Phosphat-Verhältnis bei Ratten der SR pr+th-Gruppe unter der 13-wöchigen Applikation von Strontiumranelat, was andeutungsweise die These stützen, dass Calcium durch Strontium im mineralisierten Knochen verdrängt wird (Dahl et al. 2001; Li C et al. 2010; Oliveira et al. 2012).

Die vermehrte organische Knochensubstanz bei Ratten aus der Gruppe SR pr+th könnte für eine Stimulation der Kollagensynthese durch Strontium sprechen. Hinsichtlich der Biomechanik war bereits ein positiver Einfluss auf die Knochenstabilität unter Strontium-Gabe nachweisbar.

Die Ergebnisse zeigen, dass ein vollständiger Effekt der Strontium-Wirkung erst nach langfristiger Einnahme des Medikamentes - wie hier 13 Studienwochen einsetzt. Kürzere Applikationszeiten und Unterbrechungen der StrontiumEinnahme sind nicht zu empfehlen.

Dies spiegelte sich auch in Ergebnissen weiterer Untersuchungen unserer Arbeitsgruppe am selben Versuchstierkollektiv wieder. Demnach zeigten sich unter der langfristigen Gabe von Strontiumranelat über 13 Wochen positive Effekte auf die Frakturheilung der osteotomierten Ratten-Tibiae und eine verbesserte Mikroarchitektur der Femora der Versuchstiere auf Trabekelebene (Weidemann 2013; Komrakova et al. 2015; Köstner 2018; Saul et al. 2018a). Eine signifikante Auswirkung der Behandlung mit Strontiumranelat auf die Skelettmuskukatur der ovariektomierten Tiere konnte dabei nicht festgestellt werden (Saul et al. 2018a; Harlass 2019). 


\section{Zusammenfassung}

Osteoporose ist eine systemische Knochenerkrankung, von der weltweit schätzungsweise 200 Millionen Menschen und davon vorwiegend Frauen in der Postmenopause betroffen sind. Durch den sinkenden Östrogenspiegel wird das Gleichgewicht zwischen Knochenaufbau und Knochenresorption zugunsten des Knochenabbaus verschoben. Es resultieren eine verminderte Knochendichte sowie eine Verschlechterung der knöchernen Mikroarchitektur, was das Frakturrisiko - insbesondere in prädisponierten Regionen wie den Wirbelkörpern der Brust- und Lendenwirbelsäule - gefährlich erhöht.

Durch die Ähnlichkeit der pathophysiologischen Reaktion des Knochens auf Östrogendefizite sowie deren Ansprechen auf therapeutische Ansätze eignet sich das Tiermodell der Ratte gut zur Erforschung der Osteoporose.

In dieser Studie wurde die Wirkung des Medikaments Strontiumranelat auf den durch Ovariektomie induzierten osteopenischen Knochen von Ratten anhand dreier unterschiedlicher Regimes untersucht: als Prophylaxe (SR pr) in den ersten acht Studienwochen (Woche 0-8), als Therapie (SR th) in den letzten fünf Studienwochen (Woche 9-13) oder kombiniert in Prophylaxe und Therapie (SR pr+th) über den gesamten Studienzeitraum von 13 Wochen (Woche 0-13). Demgegenüber wurden zwei Vergleichsgruppen gestellt, die zum einen nur ovariektomiert, aber nicht mit Strontium behandelt wurden (OVX), zum anderen weder ovariektomiert, noch medikamentös behandelt wurden (NON-OVX). Bei den Versuchstieren handelte es sich um initial drei Monate alte Ratten vom SpragueDawley-Stamm, von denen jeweils zwölf Tiere den fünf genannten Untersuchungsgruppen zugeordnet wurden. Sie erhielten das Strontiumranelat als Nahrungsbeimengung in einer Konzentration von 10,52 g/kg Futter, was einer täglichen Tagesdosis von etwa 625 mg Strontiumranelat pro kg Körpergewicht entsprach.

Mit Strontiumranelat (Protelos ${ }^{\circledR}$ von Servier Deutschland) wurde ein Medikament gewählt, das im Gegensatz zu anderen Osteoporose-Therapien sowohl aktivierend auf den Knochenaufbau als auch hemmend auf den Knochenabbau wirkt. Trotz einiger Nebenwirkungen wie beispielsweise venöse Thrombembolien, Übelkeit oder Durchfälle, die die Anwendung beschränken, dienen Strontiumsalze weiterhin als eine alternative Osteoporose-Behandlung. 
Anhand von drei unterschiedlichen Tests an den Lendenwirbelkörpern der Versuchstiere konnte eine Quantifizierung der mikrostrukturellen Knochenqualität und der Knochenmineraldichte erfolgen - den zwei wesentlichen Faktoren, die die Knochenqualität bestimmen. Dazu wurde die mechanische Widerstandkraft mittels biomechanischem Kompressionstest, die intrinsische Knochenqualität hinsichtlich Knochenmineraldichte, Knochenvolumina sowie Kortikalis- und Trabekelparametern anhand von Mikro-CT-Untersuchungen sowie die Anteile organischer und anorganischer Knochensubstanz und die Calcium- und Phosphatgehalte der Knochen durch Veraschung ermittelt.

Es konnte ein positiver Effekt von Strontiumranelat auf den osteopenischen Knochen der Versuchstiere nachgewiesen werden. Die Hauptwirkung auf die Biomechanik, die Kortikalis- und Trabekelparameter, die Knochenmineraldichte sowie das Calcium-Phosphat-Verhältnis war in der Gruppe SR pr+th mit einer Strontium-Applikationszeit von 13 Wochen nachzuweisen. Eine kürzere Applikationszeit in der Prophylaxe- und Therapiegruppe $(\mathrm{SR} \mathrm{pr}=$ acht Wochen, SR th $=$ fünf Wochen) zeigte wenig Effekt auf die Knochen.

Die erzielten Ergebnisse sprechen insgesamt für eine deutliche Verbesserung der Knochenstruktur und -qualität unter der längerfristigen medikamentösen Behandlung mit Strontium - wie hier 13 Wochen. Zu kurze Applikationszeiten zeigen kaum einen Einfluss auf die Knochen und sind daher nicht zu empfehlen. 


\section{Anhang}

Tabelle A1: Gewichtsentwicklung der Versuchstiere in Gramm; Angabe der Mittelwerte \pm Standardabweichung

\begin{tabular}{|c|c|c|c|c|c|}
\hline $\begin{array}{c}\text { Gruppen } \\
\text { Versuchs- } \\
\text { woche }\end{array}$ & NON-OVX & OVX & SR th & SR pr & SR pr+th \\
\hline 0 & $\begin{array}{r}260,8 \\
\pm 7,63\end{array}$ & $\begin{array}{c}269,9 \\
\pm 10,71\end{array}$ & $\begin{array}{c}263,7 \\
\pm 13,12\end{array}$ & $\begin{array}{c}254,7 \\
\pm 24,38\end{array}$ & $\begin{array}{r}270,1 \\
\pm 9,34\end{array}$ \\
\hline 1 & $\begin{array}{l}272,6 \\
\pm 8,67\end{array}$ & $\begin{array}{l}283,2 \\
\pm 7,48\end{array}$ & $\begin{array}{c}278,5 \\
\pm 14,40\end{array}$ & $\begin{array}{l}279,5 \\
\pm 8,76\end{array}$ & $\begin{array}{c}276,3 \\
\pm 12,73\end{array}$ \\
\hline 2 & $\begin{array}{c}285,3 \\
\pm 7,46\left(\mathrm{e}^{\star \star \star}\right)\end{array}$ & $\begin{array}{c}313,6 \\
\pm 10,09\end{array}$ & $\begin{array}{c}316,9 \\
\pm 19,34\end{array}$ & $\begin{array}{r}313,0 \\
\pm 10,76\end{array}$ & $\begin{array}{c}310,3 \\
\pm 13,59\end{array}$ \\
\hline 3 & $\begin{array}{c}293,8 \\
\pm 8,68\left(\mathrm{e}^{\star \star \star}\right)\end{array}$ & $\begin{array}{c}338,4 \\
\pm 19,19\end{array}$ & $\begin{array}{c}345,3 \\
\pm 24,61\end{array}$ & $\begin{array}{c}339,8 \\
\pm 12,37\end{array}$ & $\begin{array}{c}335,9 \\
\pm 16,16\end{array}$ \\
\hline 4 & $\begin{array}{c}303,0 \\
\pm 12,53\left(\mathbf{e}^{\star \star \star}\right)\end{array}$ & $\begin{array}{c}352,8 \\
\pm 21,40\end{array}$ & $\begin{array}{c}363,6 \\
\pm 27,58\end{array}$ & $\begin{array}{c}354,5 \\
\pm 14,79\end{array}$ & $\begin{array}{c}352,3 \\
\pm 17,36\end{array}$ \\
\hline 5 & $\begin{array}{c}305,5 \\
\pm 8,28\left(\mathrm{e}^{\star \star \star}\right)\end{array}$ & $\begin{array}{c}352,6 \\
\pm 24,13\end{array}$ & $\begin{array}{c}367,8 \\
\pm 30,95\end{array}$ & $\begin{array}{c}355,3 \\
\pm 19,45\end{array}$ & $\begin{array}{r}352,17 \\
\pm 16,52\end{array}$ \\
\hline 6 & $\begin{array}{c}313,8 \\
\pm 9,07\left(\mathrm{e}^{\star \star \star}\right)\end{array}$ & $\begin{array}{c}365,3 \\
\pm 25,40\end{array}$ & $\begin{array}{c}382,8 \\
\pm 34,08\end{array}$ & $\begin{array}{c}363,6 \\
\pm 18,63\end{array}$ & $\begin{array}{c}363,5 \\
\pm 18,43\end{array}$ \\
\hline 7 & $\begin{array}{c}313,8 \\
\pm 11,35\left(\mathbf{e}^{\star \star \star}\right)\end{array}$ & $\begin{array}{c}369,1 \\
\pm 27,86\end{array}$ & $\begin{array}{c}388,7 \\
\pm 36,95\end{array}$ & $\begin{array}{c}369,6 \\
\pm 20,67\end{array}$ & $\begin{array}{c}370,8 \\
\pm 22,39\end{array}$ \\
\hline 8 & $\begin{array}{c}314,8 \\
\pm 12,37\left(\mathrm{e}^{\star \star \star}\right)\end{array}$ & $\begin{array}{c}365,6 \\
\pm 26,21\end{array}$ & $\begin{array}{c}391,7 \\
\pm 38,82\end{array}$ & $\begin{array}{c}368,3 \\
\pm 22,38\end{array}$ & $\begin{array}{c}368,5 \\
\pm 24,91\end{array}$ \\
\hline 9 & $\begin{array}{c}311,8 \\
\pm 12,05\left(\mathrm{e}^{\star \star \star}\right)\end{array}$ & $\begin{array}{r}355,2 \\
\pm 25,64\end{array}$ & $\begin{array}{l}373,8 \\
\pm 53,0\end{array}$ & $\begin{array}{c}353,9 \\
\pm 21,39\end{array}$ & $\begin{array}{c}359,8 \\
\pm 26,18\end{array}$ \\
\hline 10 & $\begin{array}{c}306,2 \\
\pm 13,60\left(\mathbf{e}^{\star \star \star}\right)\end{array}$ & $\begin{array}{c}359,9 \\
\pm 25,71\end{array}$ & $\begin{array}{c}386,2 \\
\pm 46,37\end{array}$ & $\begin{array}{c}356,1 \\
\pm 23,33\end{array}$ & $\begin{array}{c}361,5 \\
\pm 25,53\end{array}$ \\
\hline 11 & $\begin{array}{c}315,4 \\
\pm 17,72\left(\mathrm{e}^{\star \star \star}\right)\end{array}$ & $\begin{array}{c}368,3 \\
\pm 29,39\end{array}$ & $\begin{array}{c}396,5 \\
\pm 49,40\end{array}$ & $\begin{array}{c}366,2 \\
\pm 21,22\end{array}$ & $\begin{array}{c}372,5 \\
\pm 25,93\end{array}$ \\
\hline 12 & $\begin{array}{c}322,8 \\
\pm 16,61\left(\mathrm{e}^{\star \star \star}\right)\end{array}$ & $\begin{array}{c}370,8 \\
\pm 27,90\end{array}$ & $\begin{array}{c}403,4 \\
\pm 47,28\end{array}$ & $\begin{array}{c}370,8 \\
\pm 21,12\end{array}$ & $\begin{array}{c}379,5 \\
\pm 27,25\end{array}$ \\
\hline 13 & $\begin{array}{c}323,0 \\
\pm 16,26\left(\mathrm{e}^{\star \star \star}\right)\end{array}$ & $\begin{array}{c}379,9 \\
\pm 29,22\end{array}$ & $\begin{array}{c}410,1 \\
\pm 50,58\end{array}$ & $\begin{array}{c}376,0 \\
\pm 21,78\end{array}$ & $\begin{array}{c}380,6 \\
\pm 29,76\end{array}$ \\
\hline
\end{tabular}

$\mathrm{e}=$ signifikant $z \mathrm{u}$ allen anderen Gruppen, ${ }^{\star \star *} \mathrm{p}<0,001$, Tukey-Kramer-Test 
Tabelle A2: Darstellung der täglichen Futteraufnahme in Gramm pro Tier in den jeweiligen Versuchsgruppen über die Studienwochen; Angabe der Mittelwerte \pm Standardabweichung

\begin{tabular}{|c|c|c|c|c|c|}
\hline $\begin{array}{c}\text { Gruppen } \\
\text { Versuchs- } \\
\text { woche }\end{array}$ & NON-OVX & ovX & SR th & SR pr & SR pr+th \\
\hline $\mathbf{1}$ & $20,2 \pm 4,96$ & $15,6 \pm 0,61$ & $13,8 \pm 1,02$ & $16,5 \pm 5,41$ & $13,4 \pm 0,82$ \\
\hline $\mathbf{2}$ & $23,8 \pm 5,85$ & $24,0 \pm 1,09$ & $26,9 \pm 0,18$ & $24,8 \pm 0,05$ & $26,4 \pm 1,98$ \\
\hline $\mathbf{3}$ & $\begin{array}{c}21,0 \pm 1,06 \\
\left(\mathbf{e}^{\star *}\right)\end{array}$ & $26,1 \pm 1,43$ & $26,7 \pm 2,15$ & $27,3 \pm 0,47$ & $27,3 \pm 1,45$ \\
\hline $\mathbf{4}$ & $22,8 \pm 4,28$ & $24,1 \pm 1,42$ & $25,9 \pm 1,39$ & $24,6 \pm 0,25$ & $25,5 \pm 1,10$ \\
\hline $\mathbf{5}$ & $23,4 \pm 2,75$ & $24,4 \pm 1,60$ & $26,1 \pm 1,19$ & $25,1 \pm 0,73$ & $24,7 \pm 0,77$ \\
\hline $\mathbf{6}$ & $22,5 \pm 2,43$ & $24,1 \pm 1,40$ & $25,3 \pm 0,66$ & $25,8 \pm 1,43$ & $23,3 \pm 0,51$ \\
\hline $\mathbf{7}$ & $21,5 \pm 1,35$ & $23,0 \pm 0,86$ & $24,3 \pm 0,37$ & $23,7 \pm 1,65$ & $24,2 \pm 1,97$ \\
\hline $\mathbf{8}$ & $21,3 \pm 0,75$ & $21,6 \pm 0,58$ & $23,2 \pm 0,48$ & $21,8 \pm 1,41$ & $23,0 \pm 1,42$ \\
\hline $\mathbf{9}$ & $14,4 \pm 0,42$ & $14,0 \pm 1,50$ & $14,7 \pm 4,88$ & $13,7 \pm 0,53$ & $13,8 \pm 0,52$ \\
\hline $\mathbf{1 0}$ & $19,4 \pm 1,21$ & $19,3 \pm 0,14$ & $20,1 \pm 2,33$ & $19,5 \pm 1,36$ & $19,6 \pm 0,61$ \\
\hline $\mathbf{1 1}$ & $20,0 \pm 1,80$ & $20,7 \pm 1,31$ & $22,3 \pm 1,88$ & $20,3 \pm 0,29$ & $21,0 \pm 0,32$ \\
\hline $\mathbf{1 2}$ & $20,9 \pm 1,21$ & $18,3 \pm 1,60$ & $\begin{array}{c}22,6 \pm 1,55 \\
\left(\mathbf{c}^{*}, \mathbf{d}^{\star}\right)\end{array}$ & $19,6 \pm 1,02$ & $22,1 \pm 1,31$ \\
\hline $\mathbf{1 3}$ & $24,2 \pm 1,00$ & $21,9 \pm 1,86$ & $\begin{array}{c}24,7 \pm 1,04 \\
\left(\mathbf{c}^{\star}\right)\end{array}$ & $21,0 \pm 1,00$ & $23,8 \pm 1,10$ \\
\hline
\end{tabular}

$\mathrm{c}=$ signifikant zu SR pr, $d=$ signifikant zu NON-OVX, e = signifikant zu allen anderen Gruppen, ${ }^{*} p<0,05,{ }^{* *} p<0,01$, Tukey-Kramer-Test

Tabelle A3: Uterusgewicht in Gramm in den Versuchsgruppen; Angabe der Mittelwerte/Mediane \pm Standardabweichung

\begin{tabular}{|c|c|c|c|c|c|}
\hline $\begin{array}{c}\text { Gruppen } \\
\text { Parameter }\end{array}$ & NON-OVX & OVX & SR th & SR pr & SR pr+th \\
\hline $\begin{array}{c}\text { Uterus- } \\
\text { gewicht }(\mathbf{g})\end{array}$ & $\begin{array}{c}0,64 / 0,56 \\
\pm 0,21 \\
\left(\mathbf{c}^{*}, \mathbf{e}^{\star \star \star}\right)\end{array}$ & $\begin{array}{c}0,13 / 0,13 \\
\pm 0,02\end{array}$ & $\begin{array}{c}0,13 / 0,12 \\
\pm 0,03\end{array}$ & $\begin{array}{c}0,14 / 0,14 \\
\pm 0,02\end{array}$ & $\begin{array}{c}0,12 / 0,12 \\
\pm 0,02\end{array}$ \\
\hline
\end{tabular}

$\mathrm{c}=$ signifikant zu SR pr, e = signifikant zu allen anderen Gruppen, ${ }^{*} p<0,05$, ${ }^{* * *} p<0,001$, Dunn's Test 
Tabelle A4: Ergebnisse der Volumenanalysen in den Versuchsgruppen;

Darstellung der Mittelwerte/Mediane \pm Standardabweichung

\begin{tabular}{|c|c|c|c|c|c|}
\hline $\begin{array}{l}\text { Gruppen } \\
\text { Parameter }\end{array}$ & NON-OVX & OVX & SR th & SR pr & SR pr+th \\
\hline \multirow{3}{*}{$\begin{array}{c}\text { WK- } \\
\text { Volumen } \\
\left(\mathrm{mm}^{3}\right)\end{array}$} & 67,80 & 69,94 & 76,15 & 71,60 & 73,66 \\
\hline & 65,47 & 69,18 & 84,24 & 72,44 & 72,84 \\
\hline & $\pm 6,13$ & $\pm 5,04$ & $\pm 14,33$ & $\pm 7,16$ & $\pm 9,63$ \\
\hline \multirow{3}{*}{$\begin{array}{c}\mathrm{TV} \\
\left(\mathrm{mm}^{3}\right)\end{array}$} & 95,28 & 103,80 & 104,50 & 102,50 & 99,37 \\
\hline & 95,77 & 99,82 & 108,70 & 102,00 & 97,68 \\
\hline & $\pm 7,92$ & $\pm 14,89$ & $\pm 12,98$ & $\pm 10,46$ & $\pm 8,33$ \\
\hline \multirow{3}{*}{$\begin{array}{c}\text { BV } \\
\left(\mathrm{mm}^{3}\right)\end{array}$} & 35,70 & 34,88 & 38,10 & 37,64 & 38,19 \\
\hline & 36,05 & 33,99 & 38,09 & 35,79 & 37,84 \\
\hline & $\pm 4,58$ & $\pm 5,50$ & $\pm 5,71$ & $\pm 3,87$ & $\pm 5,22$ \\
\hline \multirow{3}{*}{$\begin{array}{c}\text { BV/TV } \\
(\%)\end{array}$} & 37,53 & 33,80 & 36,42 & 36,88 & 38,38 \\
\hline & 36,66 & 34,88 & 37,31 & 35,66 & 38,24 \\
\hline & $\pm 4,20$ & $\pm 4,35$ & $\pm 3,03$ & $\pm 3,87$ & $\pm 3,67$ \\
\hline
\end{tabular}

Keine signifikanten Unterschiede, $\mathrm{p}>0,05$; TV und BV/TV: Tukey-Kramer-Test, BV und WK-Volumen: Dunn's Test 


\section{$7 \quad$ Literaturverzeichnis}

Abboskhujaeva LS, Ismailov SI, Alikhanova NM (2014): Efficacy of strontium ranelate in combination with a D-hormone analog for the treatment of postmenopausal osteoporosis. Drugs RD 14, 315-324

Adler CP: Knochenkrankheiten: Diagnostik makroskopischer, histologischer und radiologischer Strukturveränderungen des Skeletts. 2. Auflage; Springer-Verlag, Berlin 1998

Alegre DN, Ribeiro C, Sousa C, Correia J, Silva L, de Almeida L (2012): Possible benefits of strontium ranelate in complicated long bone fractures. Rheumatol Int $\underline{32}, 439$ 443

Ammann P, Rizzoli R (2003): Bone strength and its determinants. Osteoporos Int $\underline{14}$ Suppl 3, 13-18

Ammann P, Badoud I, Barraud S, Dayer R, Rizzoli R (2007): Strontium ranelate treatment improves trabecular and cortical intrinsic bone tissue quality, a determinant of bone strength. J Bone Miner Res 22, 1419-1425

Ammann P, Shen V, Robin B, Mauras Y, Bonjour JP, Rizzoli R (2004): Strontium ranelate improves bone resistance by increasing bone mass and improving architecture in intact female rats. J Bone Miner Res $\underline{19}$, 2012-2020

Andress DL, Ozuna J, Tirschwell D, Grande L, Johnson M, Jacobson AF, Spain W (2002): Antiepileptic drug-induced bone loss in young male patients who have seizures. Arch Neurol $\underline{59}, 781-786$

Avenell A, Mak JCS, O'Connell D (2014): Vitamin D and vitamin D analogues for preventing fractures in post-menopausal women and older men. Cochrane Database

Bain SD, Jerome C, Shen V, Dupin-Roger I, Ammann P (2009): Strontium ranelate improves bone strength in ovariectomized rat by positively influencing bone resistance determinants. Osteoporos Int 20, 1417-1428

Balzer K, Bremer M, Lühmann D, Raspe H (2010): Sturzprophylaxe bei älteren Menschen in ihrer persönlichen Wohnumgebung: Ethisch-soziale Implikationen vor dem Hintergrund klinischer und gesundheitsökonomischer Effektivität. Gesundheitswesen $\underline{72}$

Bang CS, Shin IS, Lee SW, Kim JB, Baik GH, Suk KT, Yoon JH, Kim YS, Kim DJ (2015): Osteoporosis and bone fractures in alcoholic liver disease: a meta-analysis. World J Gastroenterol 21, 4038-4047

Bartl R: Osteoporose: Prävention, Diagnostik, Therapie. 4. Auflage; Thieme-Verlag, Stuttgart 2010

Bartl R, Bartl C: Osteoporose-Manual: Diagnostik, Prävention und Therapie. 1. Auflage; Springer-Verlag, Berlin 2004

Berg BN, Harmison CR (1957): Growth, disease, and aging in the rat. J Gerontol 12, 370377 
Black DM, Delmas PD, Eastell R, Reid IR, Boonen S, Cauley JA, Cosman F, Lakatos P, Leung PC, Man Z et al. (2007): Once-yearly zoledronic acid for treatment of postmenopausal osteoporosis. N Engl J Med $\underline{356}, 1809-1822$

Boivin G, Doublier A, Farlay D (2012): Strontium ranelate - a promising therapeutic principle in osteoporosis. J Trace Elem Med Biol 26, 153-156

Bolam KA, van Uffelen JGZ, Taaffe DR (2013): The effect of physical exercise on bone density in middle-aged and older men: a systematic review. Osteoporos Int 24 , 2749-2762

Bonewald LF (2004): Osteocyte biology: its implications for osteoporosis. J Musculoskelet Neuronal Interact $\underline{4}, 101-104$

Bonnelye E, Chabadel A, Saltel F, Jurdic P (2008): Dual effect of strontium ranelate: stimulation of osteoblast differentiation and inhibition of osteoclast formation and resorption in vitro. Bone $\underline{42}, 129-138$

Boonen S, Reginster JY, Kaufman JM, Lippuner K, Zanchetta J, Langdahl B, Rizzoli R, Lipschitz S, Dimai HP, Witvrouw R et al. (2012): Fracture risk and zoledronic acid therapy in men with osteoporosis. N Engl J Med $\underline{367}, 1714-1723$

Bouguer P (1923): Essai d'optique sur la gradation de la lumière. Nature 111, 320

Bouxsein ML, Boyd SK, Christiansen BA, Guldberg RE, Jepsen KJ, Müller R (2010): Guidelines for assessment of bone microstructure in rodents using microcomputed tomography. J Bone Miner Res 25, 1468-1486

Boyd SK, Moser S, Kuhn M, Klinck RJ, Krauze PL, Müller R, Gasser JA (2006): Evaluation of three-dimensional image registration methodologies for in vivo microcomputed tomography. Ann Biomed Eng $\underline{34}$, 1587-1599

Boyd SK, Szabo E, Ammann P (2011): Increased bone strength is associated with improved bone microarchitecture in intact female rats treated with strontium ranelate: a finite element analysis study. Bone $\underline{48}, 1109-1116$

Braux J, Velard F, Guillaume C, Bouthors S, Jallot E, Nedelec JM, Laurent-Maquin D, Laquerrière $P$ (2011): A new insight into the dissociating effect of strontium on bone resorption and formation. Acta Biomater $\underline{7}, 2593-2603$

Brennan TC, Rybchyn MS, Green W, Atwa S, Conigrave AD, Mason RS (2009): Osteoblasts play key roles in the mechanisms of action of strontium ranelate. $\mathrm{Br} \mathrm{J}$ Pharmacol 157, 1291-1300

Buache E, Velard F, Bauden E, Guillaume C, Jallot E, Nedelec JM, Laurent-Maquin D, Laquerriere $P$ (2012): Effect of strontium-substituted biphasic calcium phosphate on inflammatory mediators production by human monocytes. Acta Biomater $\underline{8}$, 3113-3119

Budsberg SC, Jevens DJ, Brown J, Foutz TL, DeCamp CE, Reece L (1993): Evaluation of limb symmetry indices, using ground reaction forces in healthy dogs. Am J Vet Res $\underline{54}, 1569-1574$

Buehler J, Chappuis P, Saffar JL, Tsouderos Y, Vignery A (2001): Strontium ranelate inhibits bone resorption while maintaining bone formation in alveolar bone in monkeys (Macaca fascicularis). Bone $\underline{29}$, 176-179 
Camacho PM, Steven M. Petak, Binkley N, Clarke BL, Harris ST, Hurley DL, Kleerekoper M, Lewiecki EM, Miller PD, Narula HS et al. (2016): Clinical practice guidelines for the diagnosis and treatment of postmenopausal osteoporosis. Endocr Pract 22, 1111-1118

Cao Y, Mori S, Mashiba T, Westmore MS, Ma L, Sato M, Akiyama T, Shi L, Komatsubara S, Miyamoto K, Norimatsu H (2002): Raloxifene, estrogen, and alendronate affect the processes of fracture repair differently in ovariectomized rats. J Bone Miner Res $\underline{17}$, 2237-2246

Carbone LD, Johnson KC, Robbins J, Larson JC, Curb JD, Watson K, Gass M, Lacroix AZ (2010): Antiepileptic drug use, falls, fractures, and BMD in postmenopausal women: findings from the women's health initiative $(\mathrm{WHI})$. J Bone Miner Res $\underline{25}$, 873-881

Caudrillier A, Hurtel-Lemaire AS, Wattel A, Cournarie F, Godin C, Petit L, Petit JP, Terwilliger E, Kamel S, Brown EM et al. (2010): Strontium ranelate decreases receptor activator of nuclear factor-KB ligand-induced osteoclastic differentiation in vitro: involvement of the calcium-sensing receptor. Mol Pharmacol $\underline{78}, 569-576$

Cauley JA, Lacroix AZ, Wu L, Horwitz M, Danielson ME, Bauer DC, Lee JS, Jackson RD, Robbins JA, Wu C et al. (2008): Serum 25-hydroxyvitamin D concentrations and risk for hip fractures. Ann Intern Med $\underline{149}, 242-250$

Caverzasio J (2008): Strontium ranelate promotes osteoblastic cell replication through at least two different mechanisms. Bone $\underline{42}, 1131-1136$

Cavolina JM, Evans GL, Harris SA, Zhang M, Westerlind KC, Turner RT (1997): The effects of orbital spaceflight on bone histomorphometry and messenger ribonucleic acid levels for bone matrix proteins and skeletal signaling peptides in ovariectomized growing rats. Endocrinology $\underline{138}, 1567-1576$

Centre for Clinical Practice at NICE (UK): Falls: assessment and prevention of falls in older people. National Institute for Health and Care Excellence (UK), London 2013

Chen B, Li Y, Yang X, Xie D (2013): Comparable effects of alendronate and strontium ranelate on femur in ovariectomized rats. Calcif Tissue Int $\underline{93}, 481-486$

Choudhary S, Halbout P, Alander C, Raisz L, Pilbeam C (2007): Strontium ranelate promotes osteoblastic differentiation and mineralization of murine bone marrow stromal cells: involvement of prostaglandins. J Bone Miner Res 22, 1002-1010

Cockerill W, Lunt M, Silman AJ, Cooper C, Lips P, Bhalla AK, Cannata JB, Eastell R, Felsenberg D, Gennari C et al. (2004): Health-related quality of life and radiographic vertebral fracture. Osteoporos Int $\underline{15}, 113-119$

Colón-Emeric CS, Pieper CF, Artz MB (2002): Can historical and functional risk factors be used to predict fractures in community-dwelling older adults? Development and validation of a clinical tool. Osteoporos Int $\underline{13}, 955-961$

Compston JE (1995): Bone density: BMC, BMD, or corrected BMD? Bone 16, 5-7

Cooper C, Campion G, Melton LJ (1992): Hip fractures in the elderly: a world-wide projection. Osteoporos Int $\underline{2}, 285-289$

Cooper C, Melton LJ (1992): Epidemiology of osteoporosis. Trends Endocrinol Metab $\underline{3}$, 224-229 
Cumming RG, Le Couteur DG (2003): Benzodiazepines and risk of hip fractures in older people: a review of the evidence. CNS Drugs $\underline{17}, 825-837$

Cummings SR, Black DM, Nevitt MC, Browner W, Cauley J, Ensrud K, Genant HK, Palermo L, Scott J, Vogt TM (1993): Bone density at various sites for prediction of hip fractures. The Study of Osteoporotic Fractures Research Group. Lancet Lond Engl $\underline{341}, 72-75$

Cummings SR, Browner WS, Bauer D, Stone K, Ensrud K, Jamal S, Ettinger B (1998): Endogenous hormones and the risk of hip and vertebral fractures among older women. Study of Osteoporotic Fractures Research Group. N Engl J Med $\underline{339}$, 733-738

Cummings SR, Karpf DB, Harris F, Genant HK, Ensrud K, LaCroix AZ, Black DM (2002): Improvement in spine bone density and reduction in risk of vertebral fractures during treatment with antiresorptive drugs. Am J Med 112, 281-289

Cummings SR, Martin JS, McClung MR, Siris ES, Eastell R, Reid IR, Delmas P, Zoog HB, Austin M, Wang A et al. (2009): Denosumab for prevention of fractures in postmenopausal women with osteoporosis. N Engl J Med 361, 756-765

Dahl SG, Allain P, Marie PJ, Mauras Y, Boivin G, Ammann P, Tsouderos Y, Delmas PD, Christiansen $C$ (2001): Incorporation and distribution of strontium in bone. Bone $\underline{28}, 446-453$

Dalle Carbonare L, Valenti MT, Bertoldo F, Zanatta M, Zenari S, Realdi G, Lo Cascio V, Giannini S (2005): Bone microarchitecture evaluated by histomorphometry. Micron Oxf Engl 1993 36, 609-616

Das S, Crockett JC (2013): Osteoporosis - a current view of pharmacological prevention and treatment. Drug Des Devel Ther $\underline{7}, 435-448$

Daub F: Kurzzeiteffekte von Estradiol, Raloxifen, Phytohormonen und Parathormon auf die metaphysäre Frakturheilung des manifest osteoporotischen Knochens der Ratte. Med. Diss. Göttingen 2010

Deeks ED, Dhillon S (2010a): Strontium ranelate: a review of its use in the treatment of postmenopausal osteoporosis. Drugs $\underline{70}, 733-759$

Deeks ED, Dhillon S (2010b): Spotlight on strontium ranelate: in postmenopausal osteoporosis. Drugs Aging 27, 771-773

Deller T: Histologie - Das Lehrbuch: Zytologie, Histologie und mikroskopische Anatomie. 5. Auflage; Urban \& Fischer Verlag/Elsevier GmbH, München 2018

Delmas PD, Genant HK, Crans GG, Stock JL, Wong M, Siris E, Adachi JD (2003): Severity of prevalent vertebral fractures and the risk of subsequent vertebral and nonvertebral fractures: results from the MORE trial. Bone $\underline{33}, 522-532$

Delmas PD, Recker RR, Chesnut CH, Skag A, Stakkestad JA, Emkey R, Gilbride J, Schimmer RC, Christiansen C (2004): Daily and intermittent oral ibandronate normalize bone turnover and provide significant reduction in vertebral fracture risk: results from the BONE study. Osteoporos Int $\underline{15}, 792-798$ 
Dempster DW, Compston JE, Drezner MK, Glorieux FH, Kanis JA, Malluche H, Meunier PJ, Ott SM, Recker RR, Parfitt AM (2013): Standardized nomenclature, symbols, and units for bone histomorphometry: a 2012 update of the report of the ASBMR Histomorphometry Nomenclature Committee. J Bone Miner Res $\underline{28}, 2-17$

Dennison E, Cole Z, Cooper C (2005): Diagnosis and epidemiology of osteoporosis. Curr Opin Rheumatol 17, 456-461

Dennison EM, Compston JE, Flahive J, Siris ES, Gehlbach SH, Adachi JD, Boonen S, Chapurlat R, Díez-Pérez A, Anderson FA et al. (2012): Effect of co-morbidities on fracture risk: findings from the Global Longitudinal Study of Osteoporosis in Women (GLOW). Bone 므, 1288-1293

Döll CJ: Einfluss der vertikalen Ganzkörpervibration unterschiedlicher Frequenz auf den osteoporotischen Lendenwirbelkörper der Ratte. Med. Diss. Göttingen 2010

Doublier A, Farlay D, Khebbab MT, Jaurand X, Meunier PJ, Boivin G (2011): Distribution of strontium and mineralization in iliac bone biopsies from osteoporotic women treated long-term with strontium ranelate. Eur J Endocrinol 165, 469-476

Drago F, Cogorno L, Broccolo F, Ciccarese G, Parodi A (2016): A fatal case of DRESS induced by strontium ranelate associated with $\mathrm{HHV}-7$ reactivation. Osteoporos Int $\underline{27}, 1261-1264$

DVO 2017: Prophylaxe, Diagnostik und Therapie der Osteoporose bei Männern ab dem 60. Lebensjahr und bei postmenopausalen Frauen. S3-Leitlinie des Dachverbands der Deutschsprachigen Wissenschaftlichen Osteologischen Gesellschaften e.V. Internetquelle: https://www.dv-osteologie.org/dvo_leit-linien/dvo-leitlinie-2017; abgerufen am 17.02.2019

Eimer C: Einfluss der vertikalen Ganzkörpervibration in Kombination mit Strontiumranelat und Parathormon auf das osteoporotische Rattenfemur. Med. Diss. Göttingen 2014

El-Khayat Z, Rasheed W, Elias T, Hussein J, Oraby F, Badawi M, Salem S (2010): Protective effect of either dietary or pharmaceutical $n-3$ fatty acids on bone loss in ovariectomized rats. Maced J Med Sci $\underline{3}, 9-16$

Engelke K, Lang T, Khosla S, Qin L, Zysset P, Leslie WD, Shepherd JA, Schousboe JT (2015): Clinical use of quantitative computed tomography (QCT) of the hip in the management of osteoporosis in adults: the 2015 ISCD Official Positions-Part I. J Clin Densitom 18, 338-358

Erben RG (1996): Trabecular and endocortical bone surfaces in the rat: modeling or remodeling? Anat $\operatorname{Rec} \underline{246}, 39-46$

Erren M: Biomechanischer Kompressionstest und Wirkung von Phytohormonen am Corpus vertebrae der osteopenischen Ratte. Med. Diss. Göttingen 2007

European Prospective Osteoporosis Study (EPOS) Group (2002): The relationship between bone density and incident vertebral fracture in men and women. J Bone Miner Res 17, 2214-2221

Fang J, Freeman R, Jeganathan R, Alderman $\mathrm{MH}$ (2004): Variations in hip fracture hospitalization rates among different race/ethnicity groups in New York City. Ethn Dis $\underline{14}, 280-284$ 
Farlay D, Boivin G, Panczer G, Lalande A, Meunier PJ (2005): Long-term strontium ranelate administration in monkeys preserves characteristics of bone mineral crystals and degree of mineralization of bone. J Bone Miner Res 20, 1569-1578

Felsenberg D, Boonen S (2005): The bone quality framework: determinants of bone strength and their interrelationships, and implications for osteoporosis management. Clin Ther $\underline{27}, 1-11$

Feskanich D, Willett W, Colditz G (2002): Walking and leisure-time activity and risk of hip fracture in postmenopausal women. JAMA $\underline{288}, 2300-2306$

Fisk JW, Baigent ML (1975): Clinical and radiological assessment of leg length. N Z Med J 81, 477-480

Fonseca JE (2008): Rebalancing bone turnover in favour of formation with strontium

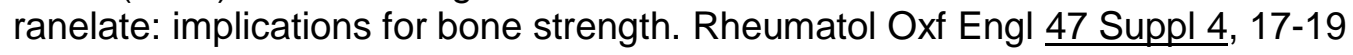

Fournier C, Perrier A, Thomas M, Laroche N, Dumas V, Rattner A, Vico L, Guignandon A (2012): Reduction by strontium of the bone marrow adiposity in mice and repression of the adipogenic commitment of multipotent C3H10T1/2 cells. Bone $\underline{50}, 499-509$

Freissmuth M, Böhm S: Pharmakologie und Toxikologie: Von den molekularen Grundlagen zur Pharmakotherapie. 1. Auflage; Springer-Verlag, Heidelberg 2012

Frost HM, Jee WS (1992): On the rat model of human osteopenias and osteoporoses. Bone Miner 18, 227-236

Fürst BM: Einfluss der vertikalen und horizontalen Ganzkörpervibration mit verschiedenen Frequenzen auf die Lendenwirbelsäule im Rattentiermodell. Med. Diss. Göttingen 2014

Gallacher SJ, Dixon T (2010): Impact of treatments for postmenopausal osteoporosis (bisphosphonates, parathyroid hormone, strontium ranelate, and denosumab) on bone quality: a systematic review. Calcif Tissue Int $\underline{87}$, 469-484

Garnero P, Sornay-Rendu E, Chapuy MC, Delmas PD (1996): Increased bone turnover in late postmenopausal women is a major determinant of osteoporosis. J Bone Miner Res 11, 337-349

Gasser JA (1995): Assessing bone quantity by pQCT. Bone 17, 145-154

Gasser JA, Green JR, Shen V, Ingold P, Rebmann A, Bhatnagar AS, Evans DB (2006): A single intravenous administration of zoledronic acid prevents the bone loss and mechanical compromise induced by aromatase inhibition in rats. Bone $\underline{39}$, 787795

Genant HK, Jiang Y (2006): Advanced imaging assessment of bone quality. Ann N Y Acad Sci 1068, 410-428

Geng T, Chen X, Zheng M, Yu H, Zhang S, Sun S, Guo H, Jin Q (2018): Effects of strontium ranelate on wear particle-induced aseptic loosening in female ovariectomized mice. Mol Med Rep 18, 1849-1857

Giangregorio LM, Leslie WD, Lix LM, Johansson H, Oden A, McCloskey E, Kanis JA (2012): FRAX underestimates fracture risk in patients with diabetes. J Bone Miner Res 27, 301-308 
Giro G, Gonçalves D, Sakakura CE, Pereira RMR, Marcantonio Júnior E, Orrico SRP (2008): Influence of estrogen deficiency and its treatment with alendronate and estrogen on bone density around osseointegrated implants: radiographic study in female rats. Oral Surg Oral Med Oral Pathol Oral Radiol Endod 105, 162-167

Grynpas MD, Hamilton E, Cheung R, Tsouderos Y, Deloffre P, Hott M, Marie PJ (1996): Strontium increases vertebral bone volume in rats at a low dose that does not induce detectable mineralization defect. Bone $\underline{18}, 253-259$

Grynpas MD, Marie PJ (1990): Effects of low doses of strontium on bone quality and quantity in rats. Bone $\underline{11}, 313-319$

Guhrauer H, Halberstaedter L, Jacoby H, Keller P, Kuznitzky E, Liechti A, Rost GA, Schreus HT, Wichmann P: Licht-Biologie und -Therapie Röntgen-Physik Dosierung: Allgemeine Röntgentherapie Radioaktive Substanzen Elektrotherapie. Spi; Springer-Verlag 1929

Gunnes M, Lehmann EH, Mellstrom D, Johnell O (1996): The relationship between anthropometric measurements and fractures in women. Bone $\underline{19}, 407-413$

Habermann B, Kafchitsas K, Olender G, Augat P, Kurth A (2010): Strontium ranelate enhances callus strength more than PTH 1-34 in an osteoporotic rat model of fracture healing. Calcif Tissue Int $\underline{86}, 82-89$

Hadji P, Klein S, Gothe H, Häussler B, Kless T, Schmidt T, Steinle T, Verheyen F, Linder R (2013): The epidemiology of osteoporosis - Bone Evaluation Study (BEST): an analysis of routine health insurance data. Dtsch Arzteblatt Int 110, 5257

Halvarsson A, Franzén E, Ståhle A (2015): Balance training with multi-task exercises improves fall-related self-efficacy, gait, balance performance and physical function in older adults with osteoporosis: a randomized controlled trial. Clin Rehabil $\underline{29}$, 365-375

Hamdy NAT (2009): Strontium ranelate improves bone microarchitecture in osteoporosis. Rheumatol Oxf Engl 48 Suppl 4, 9-13

Harlass, BL: Der Einfluss von Strontiumranelat auf die Muskulatur der osteopenen Ratte. Med. Diss. Göttingen 2019

Harris DC: Lehrbuch der Quantitativen Analyse: Mit einem Vorwort von Werner, Gerhard. 1. Auflage; Springer-Verlag, Wiesbaden 1998

Harris ST, Watts NB, Genant HK, McKeever CD, Hangartner T, Keller M, Chesnut CH, Brown J, Eriksen EF, Hoseyni MS et al. (1999): Effects of risedronate treatment on vertebral and nonvertebral fractures in women with postmenopausal osteoporosis: a randomized controlled trial. Vertebral Efficacy With Risedronate Therapy (VERT) Study Group. JAMA 282, 1344-1352

Heberer G, Köle W, Tscherne H: Chirurgie: Lehrbuch für Studierende der Medizin und Ärzte. Mit erweitertem Hinweisindex zum neuen Gegenstandskatalog. 4. Auflage; Springer-Verlag, Berlin 1983

Hegde V, Jo JE, Andreopoulou P, Lane JM (2016): Effect of osteoporosis medications on fracture healing. Osteoporos Int $\underline{27}, 861-871$ 
Heikkilä K, Pearce J, Mäki M, Kaukinen K (2015): Celiac disease and bone fractures: a systematic review and meta-analysis. J Clin Endocrinol Metab 100, 25-34

Hengsberger S, Ammann P, Legros B, Rizzoli R, Zysset P (2005): Intrinsic bone tissue properties in adult rat vertebrae: modulation by dietary protein. Bone $\underline{36}, 134-141$

Herold G: Innere Medizin 2019. Gerd Herold, Köln 2019

Hinson J, Raven P, Chew S: Organsysteme verstehen: Endokrines System. 1. Auflage; Urban \& Fischer Verlag/Elsevier $\mathrm{GmbH}$, München 2018

Hippisley-Cox J, Coupland C (2009): Predicting risk of osteoporotic fracture in men and women in England and Wales: prospective derivation and validation of QFractureScores. BMJ $\underline{339}, 1-17$

Hoffmann DB, Sehmisch S, Hofmann AM, Eimer C, Komrakova M, Saul D, Wassmann M, Stürmer KM, Tezval M (2017): Comparison of parathyroid hormone and strontium ranelate in combination with whole-body vibration in a rat model of osteoporosis. $\mathrm{J}$ Bone Miner Metab 35, 31-39

Hoffmann DB, Griesel MH, Brockhusen B, Tezval M, Komrakova M, Menger B, Wassmann M, Stuermer KM, Sehmisch S (2016): Effects of 8-prenylnaringenin and whole-body vibration therapy on a rat model of osteopenia. $\mathrm{J}$ Nutr Metab $\underline{10}$, $1-9$

Hofmann AM: Der Einfluss von Parathormon, Strontiumranelat und Ganzkörpervibration auf den osteoporotischen Lendenwirbelkörper einer ovariektomierten Ratte. Med. Diss. Göttingen 2017

Hospers IC, van der Laan JG, Zeebregts CJ, Nieboer P, Wolffenbuttel BHR, Dierckx RA, Kreeftenberg HG, Jager PL, Slart RHJA (2009): Vertebral fracture assessment in supine position: comparison by using conventional semiquantitative radiography and visual radiography. Radiology $\underline{251}, 822-828$

Iñiguez-Ariza NM, Clarke BL (2015): Bone biology, signaling pathways, and therapeutic targets for osteoporosis. Maturitas $\underline{82}, 245-255$

Ito Z, Harada A, Matsui Y, Takemura M, Wakao N, Suzuki T, Nihashi T, Kawatsu S, Shimokata H, Ishiguro N (2006): Can you diagnose for vertebral fracture correctly by plain X-ray? Osteoporos Int 17, 1584-1591

Iwaniec U, Turner R: Animal Models for Osteoporosis; in: Marcus R, Feldman D, Kelsey J (Hrsg.): Osteoporosis. 2. Auflage; Elsevier, Amsterdam 2008, 985-1009

Jamal SA, Leiter RE, Bayoumi AM, Bauer DC, Cummings SR (2005): Clinical utility of laboratory testing in women with osteoporosis. Osteoporos Int 16, 534-540

Jander G, Blasius E: Lehrbuch der analytischen und präparativen anorganischen Chemie. 14. Auflage; S. Hirzel-Verlag, Stuttgart Leipzig 1995

Jee WS, Yao W (2001): Overview: animal models of osteopenia and osteoporosis. J Musculoskelet Neuronal Interact 1 , 193-207

Jiang Y, Zhao J, Liao EY, Dai RC, Wu XP, Genant HK (2005): Application of micro-CT assessment of 3-D bone microstructure in preclinical and clinical studies. J Bone Miner Metab 23 Suppl, 122-131 
Johnell O, Kanis JA (2006): An estimate of the worldwide prevalence and disability associated with osteoporotic fractures. Osteoporos Int 17, 1726-1733

Johnell O, Kanis JA, Odén A, Sernbo I, Redlund-Johnell I, Petterson C, De Laet C, Jönsson B (2004a): Mortality after osteoporotic fractures. Osteoporos Int $\underline{15}$, 3842

Johnell O, Kanis JA, Odén A, Sernbo I, Redlund-Johnell I, Petterson C, De Laet C, Jönsson B (2004b): Fracture risk following an osteoporotic fracture. Osteoporos Int $\underline{15}, 175-179$

Jokinen H, Pulkkinen P, Korpelainen J, Heikkinen J, Keinänen-Kiukaanniemi S, Jämsä T, Korpelainen $R$ (2010): Risk factors for cervical and trochanteric hip fractures in elderly women: a population-based 10-year follow-up study. Calcif Tissue Int $\underline{87}$, 44-51

Justesen J, Stenderup K, Ebbesen EN, Mosekilde L, Steiniche T, Kassem M (2001): Adipocyte tissue volume in bone marrow is increased with aging and in patients with osteoporosis. Biogerontology 2, 165-171

Kalu DN (1991): The ovariectomized rat model of postmenopausal bone loss. Bone Miner $\underline{15}, 175-191$

Kanis JA, Delmas P, Burckhardt P, Cooper C, Torgerson D (1997): Guidelines for diagnosis and management of osteoporosis. The European Foundation for Osteoporosis and Bone Disease. Osteoporos Int $\underline{7}$, 390-406

Kanis JA, Johnell O, De Laet C, Johansson H, Oden A, Delmas P, Eisman J, Fujiwara S, Garnero P, Kroger H et al. (2004a): A meta-analysis of previous fracture and subsequent fracture risk. Bone $\underline{35}, 375-382$

Kanis JA, Johnell O, Oden A, Jonsson B, Dawson A, Dere W (2000): Risk of hip fracture derived from relative risks: an analysis applied to the population of Sweden. Osteoporos Int 11, 120-127

Kanis JA, Johnell O, Oden A, Dawson A, De Laet C, Jonsson B (2001): Ten year probabilities of osteoporotic fractures according to BMD and diagnostic thresholds. Osteoporos Int 12, 989-995

Kanis JA, Johnell O, Oden A, Johansson H, De Laet C, Eisman JA, Fujiwara S, Kroger H, McCloskey EV, Mellstrom D et al. (2005a): Smoking and fracture risk: a metaanalysis. Osteoporos Int $\underline{16}, 155-162$

Kanis JA, WHO Study Group (1994): Assessment of fracture risk and its Application to Screening for Postmenopausal Osteoporosis: Synopsis of a WHO Report. Osteoporos Int $\underline{7}, 368-381$

Kanis JA, Borgstrom $F$, De Laet $C$, Johansson $H$, Johnell $O$, Jonsson $B$, Oden $A$, Zethraeus N, Pfleger B, Khaltaev N (2005b): Assessment of fracture risk. Osteoporos Int $\underline{16}, 581-589$

Kanis JA, Oden A, Johnell O, De Laet C, Jonsson B (2004b): Excess mortality after hospitalisation for vertebral fracture. Osteoporos Int $\underline{15}, 108-112$ 
Kaptoge S, Armbrecht G, Felsenberg D, Lunt M, O'Neill TW, Silman AJ, Reeve J, EPOS Study Group (2004): When should the doctor order a spine X-ray? Identifying vertebral fractures for osteoporosis care: results from the European Prospective Osteoporosis Study (EPOS). J Bone Miner Res 19, 1982-1993

Kaufman JM, Audran M, Bianchi G, Braga V, Diaz-Curiel M, Francis RM, Goemaere S, Josse R, Palacios S, Ringe JD et al. (2013): Efficacy and safety of strontium ranelate in the treatment of osteoporosis in men. J Clin Endocrinol Metab $\underline{98}, 592$ 601

Komm BS, Morgenstern D, A Yamamoto L, Jenkins SN (2015): The safety and tolerability profile of therapies for the prevention and treatment of osteoporosis in postmenopausal women. Expert Rev Clin Pharmacol $\underline{8}, 769-784$

Komrakova M, Fiebig J, Hoffmann DB, Krischek C, Lehmann W, Stuermer KM, Sehmisch S (2018): The advantages of bilateral osteotomy over unilateral osteotomy for osteoporotic bone healing. Calcif Tissue Int 103, 80-94

Komrakova M, Hoffmann DB, Nuehnen V, Stueber H, Wassmann M, Wicke M, Tezval M, Stuermer KM, Sehmisch S (2016): The effect of vibration treatments combined with teriparatide or strontium ranelate on bone healing and muscle in ovariectomized rats. Calcif Tissue Int $\underline{99}$, 408-422

Komrakova M, Stuermer EK, Tezval M, Stuermer KM, Dullin C, Schmelz U, Doell C, Durkaya-Burchhardt N, Fuerst B, Genotte T, Sehmisch S (2014): Evaluation of twelve vibration regimes applied to improve spine properties in ovariectomized rats. Bone Rep $\underline{7}, 172-180$

Komrakova M, Weidemann A, Dullin C, Ebert J, Tezval M, Stuermer KM, Sehmisch S (2015): The impact of strontium ranelate on metaphyseal bone healing in ovariectomized rats. Calcif Tissue Int $\underline{97}, 391-401$

Komrakova M, Werner C, Wicke M, Nguyen BT, Sehmisch S, Tezval M, Stuermer KM, Stuermer EK (2009): Effect of daidzein, 4-methylbenzylidene camphor or estrogen on gastrocnemius muscle of osteoporotic rats undergoing tibia healing period. $\mathrm{J}$ Endocrinol 201, 253-262

Köstner F: Der Einfluss von Therapie und Prophylaxe mit Strontiumranelat auf das proximale Femur osteoporotischer Ratten. Med. Diss. Göttingen 2018

Kremling H (2005): Historische Betrachtungen zur präventiven Heilkunde. Würzbg Med Mitteilungen 24, 222-260

Kurth AA, Hovy L, Hennigs T: Bisphosphonattherapie von Knochenerkrankungen. Tumorosteolysen - Osteoporose - M.Paget - Endoprothetik. Steinkopff-Verlag, Darmstadt 2001

Kurth A, Lange $U$ (Hrsg.): Fachwissen Osteologie. 1. Auflage; Urban \& Fischer Verlag/Elsevier $\mathrm{GmbH}$, München 2018

Kyllönen L, D’Este M, Alini M, Eglin D (2015): Local drug delivery for enhancing fracture healing in osteoporotic bone. Acta Biomater 11, 412-434

Lambert JH: Photometria sive de mensura et gradibus luminis, colorum et umbrae. Sumptibus Viduae Eberhardi Klett, Basel 1760 
Lane NE (2006): Epidemiology, etiology, and diagnosis of osteoporosis. Am J Obstet Gynecol 194, 3-11

Law MR, Hackshaw AK (1997): A meta-analysis of cigarette smoking, bone mineral density and risk of hip fracture: recognition of a major effect. BMJ $\underline{315}, 841-846$

Leidenberger $F$, Strowitzki T, Ortmann $O$ (Hrsg.): Klinische Endokrinologie für Frauenärzte. 4. Auflage; Springer-Verlag, Berlin 2009

Lelovas PP, Xanthos TT, Thoma SE, Lyritis GP, Dontas IA (2008): The laboratory rat as an animal model for osteoporosis research. Comp Med $\underline{58}, 424-430$

Lemmer B, Brune K (Hrsg.): Pharmakotherapie: Klinische Pharmakologie. 13. Auflage; Springer-Verlag, Heidelberg 2006

Lewis CE, Ewing SK, Taylor BC, Shikany JM, Fink HA, Ensrud KE, Barrett-Connor E, Cummings SR, Orwoll E, Osteoporotic Fractures in Men (MrOS) Study Research Group (2007): Predictors of non-spine fracture in elderly men: the MrOS study. J Bone Miner Res 22, 211-219

Li C, Paris O, Siegel S, Roschger P, Paschalis EP, Klaushofer K, Fratzl P (2010): Strontium is incorporated into mineral crystals only in newly formed bone during strontium ranelate treatment. J Bone Miner Res $\underline{25}, 968-975$

Li N, Qin LP, Han T, Wu YB, Zhang QY, Zhang H (2009): Inhibitory effects of morinda officinalis extract on bone loss in ovariectomized rats. Mol Basel Switz 14, 20492061

Li YF, Luo E, Feng G, Zhu SS, Li JH, Hu J (2010): Systemic treatment with strontium ranelate promotes tibial fracture healing in ovariectomized rats. Osteoporos Int $\underline{21}$, 1889-1897

Li Z, Lu WW, Chiu PKY, Lam RWM, Xu B, Cheung KMC, Leong JCY, Luk KDK (2009): Strontium-calcium coadministration stimulates bone matrix osteogenic factor expression and new bone formation in a large animal model. J Orthop Res $\underline{27}$, 758-762

Liberman UA, Weiss SR, Bröll J, Minne HW, Quan H, Bell NH, Rodriguez-Portales J, Downs RW, Dequeker J, Favus M (1995): Effect of oral alendronate on bone mineral density and the incidence of fractures in postmenopausal osteoporosis. The Alendronate Phase III Osteoporosis Treatment Study Group. N Engl J Med $\underline{333}, 1437-1443$

Lindsay R, Nieves J, Formica C, Henneman E, Woelfert L, Shen V, Dempster D, Cosman F (1997): Randomised controlled study of effect of parathyroid hormone on vertebral-bone mass and fracture incidence among postmenopausal women on oestrogen with osteoporosis. Lancet Lond Engl $\underline{350}, 550-555$

Link TM, Majumdar S (2003): Osteoporosis imaging. Radiol Clin North Am 41, 813-839

Lippuner K, von Overbeck J, Perrelet R, Bosshard H, Jaeger P (1997): Incidence and direct medical costs of hospitalizations due to osteoporotic fractures in Switzerland. Osteoporos Int $\underline{7}, 414-425$

Lips P, van Schoor NM (2005): Quality of life in patients with osteoporosis. Osteoporos Int $\underline{16}, 447-455$ 
Loeb WF, Quimby F (Hrsg.): Clinical Chemistry of Laboratory Animals. 2. Auflage; Taylor \& Francis, Washington DC, London 1999

Lüllmann-Rauch R: Taschenlehrbuch Histologie. 6. Auflage; Thieme-Verlag, Stuttgart 2019

Lyons PM, Truswell AS, Mira M, Vizzard J, Abraham SF (1989): Reduction of food intake in the ovulatory phase of the menstrual cycle. Am J Clin Nutr $\underline{49}, 1164-1168$

Majumdar SR, Ezekowitz JA, Lix LM, Leslie WD (2012): Heart failure is a clinically and densitometrically independent risk factor for osteoporotic fractures: populationbased cohort study of 45,509 subjects. J Clin Endocrinol Metab 97, 1179-1186

Manolagas SC (2000): Birth and death of bone cells: basic regulatory mechanisms and implications for the pathogenesis and treatment of osteoporosis. Endocr Rev 21, 115-137

Marie PJ, Felsenberg D, Brandi ML (2011): How strontium ranelate, via opposite effects on bone resorption and formation, prevents osteoporosis. Osteoporos Int 22, $1659-1667$

Marshall D, Johnell O, Wedel H (1996): Meta-analysis of how well measures of bone mineral density predict occurrence of osteoporotic fractures. BMJ $\underline{312}, 1254-1259$

McClung MR, Brown JP, Diez-Perez A, Resch H, Caminis J, Meisner P, Bolognese MA, Goemaere S, Bone HG, Zanchetta JR et al. (2018): Effects of 24 months of treatment with romosozumab followed by 12 months of denosumab or placebo in postmenopausal women with low bone mineral density: a randomized, doubleblind, phase 2, parallel group study. J Bone Miner Res $\underline{33}, 1397-1406$

McClung MR, Grauer A, Boonen S, Bolognese MA, Brown JP, Diez-Perez A, Langdahl BL, Reginster JY, Zanchetta JR, Wasserman SM et al. (2014): Romosozumab in postmenopausal women with low bone mineral density. $\mathrm{N}$ Engl $\mathrm{J}$ Med $\underline{370}, 412-420$

McLendon AN, Woodis CB (2014): A review of osteoporosis management in younger premenopausal women. Womens Health Lond Engl 10, 59-77

Mela V, Vargas A, Meza C, Kachani M, Wagner EJ (2016): Modulatory influences of estradiol and other anorexigenic hormones on metabotropic, Gi/o-coupled receptor function in the hypothalamic control of energy homeostasis. J Steroid Biochem Mol Biol $\underline{160}, 15-26$

Melton LJ, Atkinson EJ, Cooper C, O'Fallon WM, Riggs BL (1999): Vertebral fractures predict subsequent fractures. Osteoporos Int 10, 214-221

Mendoza N, Sánchez-Borrego R, Villero J, Baró F, Calaf J, Cancelo MJ, Coronado P, Estévez A, Fernández-Moya JM, González S et al. (2013): 2013 Up-date of the consensus statement of the Spanish Menopause Society on postmenopausal osteoporosis. Maturitas $\underline{76}$, 99-107

Meunier P, Aaron J, Edouard C, Vignon G (1971): Osteoporosis and the replacement of cell populations of the marrow by adipose tissue. A quantitative study of 84 iliac bone biopsies. Clin Orthop 으, 147-154 
Meunier PJ, Roux C, Seeman E, Ortolani S, Badurski JE, Spector TD, Cannata J, Balogh A, Lemmel EM, Pors-Nielsen S et al. (2004): The effects of strontium ranelate on the risk of vertebral fracture in women with postmenopausal osteoporosis. N Engl J Med 350, 459-468

Meyer HE, Pedersen JI, Løken EB, Tverdal A (1997): Dietary factors and the incidence of hip fracture in middle-aged Norwegians. A prospective study. Am J Epidemiol $\underline{145}$, 117-123

Meyer HE, Tverdal A, Falch JA (1995): Body height, body mass index, and fatal hip fractures: 16 years' follow-up of 674,000 Norwegian women and men. Epidemiol Camb Mass $\underline{6}, 299-305$

Michaëlsson K, Melhus H, Bellocco R, Wolk A (2003): Dietary calcium and vitamin D intake in relation to osteoporotic fracture risk. Bone $\underline{32}, 694-703$

Miller PD, Siris ES, Barrett-Connor E, Faulkner KG, Wehren LE, Abbott TA, Chen YT, Berger ML, Santora AC, Sherwood LM (2002): Prediction of fracture risk in postmenopausal white women with peripheral bone densitometry: evidence from the National Osteoporosis Risk Assessment. J Bone Miner Res 17, 2222-2230

Mohamed G, Omar S (2010): Light microscopic and environmental scanning electron microscopic study on the effect of exercise on bone microstructure in ovariectomized rats. Egypt J Histol $\underline{33}, 431-440$

Moise H, Adachi JD, Chettle DR, Pejović-Milić A (2012): Monitoring bone strontium levels of an osteoporotic subject due to self-administration of strontium citrate with a novel diagnostic tool, in vivo XRF: a case study. Bone $\underline{51}, 93-97$

Moise H, Chettle DR, Pejović-Milić A (2014): Monitoring bone strontium intake in osteoporotic females self-supplementing with strontium citrate with a novel in-vivo $\mathrm{X}$-ray fluorescence based diagnostic tool. Bone $\underline{61}, 48-54$

Mora S, Gilsanz V (2003): Establishment of peak bone mass. Endocrinol Metab Clin North Am 32, 39-63

Morin S, Lix LM, Azimaee M, Metge C, Majumdar SR, Leslie WD (2012): Institutionalization following incident non-traumatic fractures in community-dwelling men and women. Osteoporos Int 23, 2381-2386

Naim MM (2011): Histological assessment of zoledronic acid (Aclasta) in protection against induced osteoporosis in female albino rats. Egypt J Histol $\underline{34}$, 129-138

Nakamura T, Imai Y, Matsumoto T, Sato S, Takeuchi K, Igarashi K, Harada Y, Azuma Y, Krust A, Yamamoto $Y$ et al. (2007): Estrogen prevents bone loss via estrogen receptor alpha and induction of Fas ligand in osteoclasts. Cell 130, 811-823

National Osteoporosis Foundation: Physician's Guide to Prevention and Treatment of Osteoporosis. National Osteoporosis Foundation, Washington DC 2005

Neer RM, Arnaud CD, Zanchetta JR, Prince R, Gaich GA, Reginster JY, Hodsman AB, Eriksen EF, Ish-Shalom S, Genant HK et al. (2001): Effect of parathyroid hormone (1-34) on fractures and bone mineral density in postmenopausal women with osteoporosis. N Engl J Med $\underline{344}, 1434-1441$ 
Nielsen SP, Slosman D, Sørensen OH, Basse-Cathalinat B, De Cassin P, Roux CR, Meunier PJ (1999): Influence of strontium on bone mineral density and bone mineral content measurements by dual X-ray absorptiometry. J Clin Densitom 2 , $371-379$

$\mathrm{NIH}$ Consensus Development Panel on Osteoporosis Prevention, Diagnosis and Therapy (2001): Osteoporosis prevention, diagnosis, and therapy. JAMA $\underline{285}, 785-795$

Oliveira JP, Querido W, Caldas RJ, Campos APC, Abraçado LG, Farina M (2012): Strontium is incorporated in different levels into bones and teeth of rats treated with strontium ranelate. Calcif Tissue Int $\underline{\text { 91, }}$ 186-195

Orwoll E, Ettinger M, Weiss S, Miller P, Kendler D, Graham J, Adami S, Weber K, Lorenc R, Pietschmann $P$ et al. (2000): Alendronate for the treatment of osteoporosis in men. N Engl J Med $\underline{343}, 604-610$

Ozturan KE, Demir B, Yucel I, Cakıcı H, Yilmaz F, Haberal A (2011): Effect of strontium ranelate on fracture healing in the osteoporotic rats. J Orthop Res $\underline{29}, 138-142$

Pacifici R, Brown C, Puscheck E, Friedrich E, Slatopolsky E, Maggio D, McCracken R, Avioli LV (1991): Effect of surgical menopause and estrogen replacement on cytokine release from human blood mononuclear cells. Proc Natl Acad Sci U S A $\underline{88}, 5134-5138$

Parfitt AM, Drezner MK, Glorieux FH, Kanis JA, Malluche H, Meunier PJ, Ott SM, Recker RR (1987): Bone histomorphometry: standardization of nomenclature, symbols, and units. Report of the ASBMR Histomorphometry Nomenclature Committee. J Bone Miner Res 2, 595-610

Pelletier JP, Kapoor M, Fahmi H, Lajeunesse D, Blesius A, Maillet J, Martel-Pelletier J (2013): Strontium ranelate reduces the progression of experimental dog osteoarthritis by inhibiting the expression of key proteases in cartilage and of IL-1 $\beta$ in the synovium. Ann Rheum Dis $\underline{72}, 250-257$

Pluijm SMF, Koes B, de Laet C, Van Schoor NM, Kuchuk NO, Rivadeneira F, Mackenbach JP, Lips P, Pols HA, Steyerberg EW (2009): A simple risk score for the assessment of absolute fracture risk in general practice based on two longitudinal studies. J Bone Miner Res 24, 768-774

Querido W, Campos APC, Martins Ferreira EH, San Gil RAS, Rossi AM, Farina M (2014): Strontium ranelate changes the composition and crystal structure of the biological bone-like apatite produced in osteoblast cell cultures. Cell Tissue Res $\underline{357}, 793$ 801

Raffalt AC, Andersen JET, Christgau S (2008): Application of inductively coupled plasmamass spectrometry (ICP-MS) and quality assurance to study the incorporation of strontium into bone, bone marrow, and teeth of dogs after one month of treatment with strontium malonate. Anal Bioanal Chem 391, 2199-2207

Ravn P, Cizza G, Bjarnason NH, Thompson D, Daley M, Wasnich RD, McClung M, Hosking D, Yates AJ, Christiansen C (1999): Low body mass index is an important risk factor for low bone mass and increased bone loss in early postmenopausal women. Early Postmenopausal Intervention Cohort (EPIC) study group. J Bone Miner Res $\underline{14}$, 1622-1627 
Reginster JY, Seeman E, De Vernejoul MC, Adami S, Compston J, Phenekos C, Devogelaer JP, Curiel MD, Sawicki A, Goemaere S et al. (2005): Strontium ranelate reduces the risk of nonvertebral fractures in postmenopausal women with osteoporosis: Treatment of Peripheral Osteoporosis (TROPOS) study. J Clin Endocrinol Metab $\underline{90}, 2816-2822$

Reginster JY, Brandi ML, Cannata-Andía J, Cooper C, Cortet B, Feron JM, Genant H, Palacios S, Ringe JD, Rizzoli R (2015): The position of strontium ranelate in today's management of osteoporosis. Osteoporos Int 26, 1667-1671

Reginster JY, Kaufman JM, Goemaere S, Devogelaer JP, Benhamou CL, Felsenberg D, Diaz-Curiel M, Brandi ML, Badurski J, Wark J et al. (2012): Maintenance of antifracture efficacy over 10 years with strontium ranelate in postmenopausal osteoporosis. Osteoporos Int $\underline{23}, 1115-1122$

Reginster JY, Felsenberg D, Boonen S, Diez-Perez A, Rizzoli R, Brandi ML, Spector TD, Brixen K, Goemaere S, Cormier C et al. (2008): Effects of long-term strontium ranelate treatment on the risk of nonvertebral and vertebral fractures in postmenopausal osteoporosis: Results of a five-year, randomized, placebocontrolled trial. Arthritis Rheum $\underline{58}, 1687-1695$

Rickard D, Russell G, Gowen M (1992): Oestradiol inhibits the release of tumour necrosis factor but not interleukin 6 from adult human osteoblasts in vitro. Osteoporos Int $\underline{2}$, 94-102

Rizzoli R, Laroche M, Krieg MA, Frieling I, Thomas T, Delmas P, Felsenberg D (2010): Strontium ranelate and alendronate have differing effects on distal tibia bone microstructure in women with osteoporosis. Rheumatol Int $\underline{30}, 1341-1348$

Roux C, Fechtenbaum J, Kolta S, Briot K, Girard M (2007): Mild prevalent and incident vertebral fractures are risk factors for new fractures. Osteoporos Int 18 , 16171624

Roux C, Fechtenbaum J, Kolta S, Isaia G, Andia JBC, Devogelaer JP (2008): Strontium ranelate reduces the risk of vertebral fracture in young postmenopausal women with severe osteoporosis. Ann Rheum Dis $\underline{67}, 1736-1738$

Rozman C, Reverter JC, Feliu E, Berga L, Rozman M, Climent C (1990): Variations of fat tissue fraction in abnormal human bone marrow depend both on size and number of adipocytes: a stereologic study. Blood $\underline{76}, 892-895$

Ryan CS, Petkov VI, Adler RA (2011): Osteoporosis in men: the value of laboratory testing. Osteoporos Int 22, 1845-1853

Safty FEE, Habeby MME, Mehi AEE, Sherif NME, Essa EA (2018): Induction of osteoporosis by ovariectomy in adult albino rats. Anat Physiol Biochem Int $\mathrm{J} \underline{4}, 1-4$

Saul D, Harlass BL, Ahrabi A, Kosinsky RL, Hoffmann DB, Wassmann M, Wigger R, Böker KO, Sehmisch S, Komrakova M (2018a): Effect of strontium ranelate on the muscle and vertebrae of ovariectomized rats. Calcif Tissue Int 102, 705-719

Saul D, Ninkovic M, Komrakova M, Wolff L, Simka P, Gasimov T, Menger B, Hoffmann DB, Rohde V, Sehmisch S (2018b): Effect of zileuton on osteoporotic bone and its healing, expression of bone, and brain genes in rats. J Appl Physiol Bethesda Md 1985 124, 118-130 
Saul D, Geisberg LK, Gehle T, Hoffmann DB, Tezval M, Sehmisch S, Komrakova M (2019): Changes in musculoskeletal system and metabolism in osteoporotic rats treated with urocortin. Front Endocrinol $\underline{10}$, 1-13

Scardueli CR, Bizelli-Silveira C, Marcantonio RAC, Marcantonio E, Stavropoulos A, SpinNeto $R$ (2018): Systemic administration of strontium ranelate to enhance the osseointegration of implants: systematic review of animal studies. Int J Implant Dent $\underline{4} ; 1-19$

Schwartz AV, Sellmeyer DE, Ensrud KE, Cauley JA, Tabor HK, Schreiner PJ, Jamal SA, Black DM, Cummings SR, Study of Osteoporotic Features Research Group (2001): Older women with diabetes have an increased risk of fracture: a prospective study. J Clin Endocrinol Metab $\underline{86}, 32-38$

Schwartz AV, Vittinghoff E, Bauer DC, Hillier TA, Strotmeyer ES, Ensrud KE, Donaldson MG, Cauley JA, Harris TB, Koster A et al. (2011): Association of BMD and FRAX score with risk of fracture in older adults with type 2 diabetes. JAMA $\underline{305}, 2184-2192$

Schwedt G, Schmidt TC, Schmitz OJ: Analytische Chemie: Grundlagen, Methoden und Praxis. 3. Auflage; John Wiley \& Sons, Weinheim 2016

Seeman E (2003): The structural and biomechanical basis of the gain and loss of bone strength in women and men. Endocrinol Metab Clin North Am 32, 25-38

Sehmisch S, Komrakova M, Kottwitz L, Dullin C, Schmelz U, Stuermer KM, Tezval M (2015): Effects of urocortin on spine? Osteologie 24, 99-106

Sehmisch S, Erren M, Rack T, Tezval M, Seidlova-Wuttke D, Richter J, Wuttke W, Stuermer KM, Stuermer EK (2009): Short-term effects of parathyroid hormone on rat lumbar vertebrae. Spine 34, 2014-2021

Seibel MJ (2000): Molecular markers of bone turnover: biochemical, technical and analytical aspects. Osteoporos Int 11 Suppl 6, 18-29

Sennerby U, Melhus H, Gedeborg R, Byberg L, Garmo H, Ahlbom A, Pedersen NL, Michaëlsson K (2009): Cardiovascular diseases and risk of hip fracture. JAMA 302, 1666-1673

Shen GS, Li Y, Zhao G, Zhou HB, Xie ZG, Xu W, Chen HN, Dong QR, Xu YJ (2015): Cigarette smoking and risk of hip fracture in women: a meta-analysis of prospective cohort studies. Injury $\underline{46}, 1333-1340$

Siegenthaler W, Blum HE (Hrsg.): Klinische Pathophysiologie. 9. Auflage; Thieme-Verlag, Stuttgart 2006

Silva BC, Broy SB, Boutroy S, Schousboe JT, Shepherd JA, Leslie WD (2015): Fracture risk prediction by non-BMD DXA measures: the 2015 ISCD official positions part 2: trabecular bone score. J Clin Densitom 18, 309-330

Silverman S, Viswanathan HN, Yang YC, Wang A, Boonen S, Ragi-Eis S, Fardellone P, Gilchrist N, Lips P, Nevitt M et al. (2012): Impact of clinical fractures on healthrelated quality of life is dependent on time of assessment since fracture: results from the FREEDOM trial. Osteoporos Int $\underline{23}$, 1361-1369 
Siris E, Adachi JD, Lu Y, Fuerst T, Crans GG, Wong M, Harper KD, Genant HK (2002): Effects of raloxifene on fracture severity in postmenopausal women with osteoporosis: results from the MORE study. Multiple Outcomes of Raloxifene Evaluation. Osteoporos Int 13, 907-913

Smith MR, Egerdie B, Hernández Toriz N, Feldman R, Tammela TLJ, Saad F, Heracek J, Szwedowski M, Ke C, Kupic A et al. (2009): Denosumab in men receiving androgen-deprivation therapy for prostate cancer. N Engl J Med $\underline{361}, 745-755$

Stubbs B, Gaughran F, Mitchell AJ, De Hert M, Farmer R, Soundy A, Rosenbaum S, AVancampfort D (2015): Schizophrenia and the risk of fractures: a systematic review and comparative meta-analysis. Gen Hosp Psychiatry $\underline{37}, 126-133$

Sturm A: Wirkung einer intermittierenden Parathormon-Therapie auf die Lendenwirbelsäule männlicher Ratten in Abhängigkeit vom Applikationsintervall. Med. Diss. Göttingen 2018

Stürmer EK, Komrakova M, Werner C, Wicke M, Kolios L, Sehmisch S, Tezval M, Utesch C, Mangal O, Zimmer S et al. (2010): Musculoskeletal response to wholebody vibration during fracture healing in intact and ovariectomized rats. Calcif Tissue Int $\underline{87}, 168-180$

Stürmer EK, Seidlová-Wuttke D, Sehmisch S, Rack T, Wille J, Frosch KH, Wuttke W, Stürmer KM (2006): Standardized bending and breaking test for the normal and osteoporotic metaphyseal tibias of the rat: effect of estradiol, testosterone, and raloxifene. J Bone Miner Res 21, 89-96

Takaoka S, Yamaguchi T, Yano S, Yamauchi M, Sugimoto T (2010): The Calciumsensing Receptor $(\mathrm{CaR})$ is involved in strontium ranelate-induced osteoblast differentiation and mineralization. Horm Metab Res 42, 627-631

Tannenbaum C, Clark J, Schwartzman K, Wallenstein S, Lapinski R, Meier D, Luckey M (2002): Yield of laboratory testing to identify secondary contributors to osteoporosis in otherwise healthy women. J Clin Endocrinol Metab 구, 4431-4437

Tarantino U, Celi M, Saturnino L, Scialdoni A, Cerocchi I (2010): Strontium ranelate and bone healing: report of two cases. Clin Cases Miner Bone Metab ㄱ, 65-68

Tenti S, Cheleschi S, Guidelli GM, Galeazzi M, Fioravanti A (2014): What about strontium ranelate in osteoarthritis? Doubts and securities. Mod Rheumatol 24, 881-884

Tomkinson A, Gevers EF, Wit JM, Reeve J, Noble BS (1998): The role of estrogen in the control of rat osteocyte apoptosis. J Bone Miner Res $\underline{13}, 1243-1250$

Tomkinson A, Reeve J, Shaw RW, Noble BS (1997): The death of osteocytes via apoptosis accompanies estrogen withdrawal in human bone. J Clin Endocrinol Metab $\underline{82}, 3128-3135$

Toth MJ, Poehlman ET, Matthews DE, Tchernof A, MacCoss MJ (2001): Effects of estradiol and progesterone on body composition, protein synthesis, and lipoprotein lipase in rats. Am J Physiol Endocrinol Metab $\underline{280}$, 496-501

Tromp AM, Ooms ME, Popp-Snijders C, Roos JC, Lips P (2000): Predictors of fractures in elderly women. Osteoporos Int $\underline{11}, 134-140$ 
Trovas GP, Lyritis GP, Galanos A, Raptou P, Constantelou E (2002): A randomized trial of nasal spray salmon calcitonin in men with idiopathic osteoporosis: effects on bone mineral density and bone markers. J Bone Miner Res $\underline{17}$, 521-527

Turner RT, Maran A, Lotinun S, Hefferan T, Evans GL, Zhang M, Sibonga JD (2001): Animal models for osteoporosis. Rev Endocr Metab Disord 2, 117-127

Turner RT, Vandersteenhoven JJ, Bell NH (1987): The effects of ovariectomy and 17 beta-estradiol on cortical bone histomorphometry in growing rats. $\mathrm{J}$ Bone Miner Res 2, 115-122

van Staa TP, Geusens P, Bijlsma JWJ, Leufkens HGM, Cooper C (2006): Clinical assessment of the long-term risk of fracture in patients with rheumatoid arthritis. Arthritis Rheum $\underline{54}, 3104-3112$

van Staa TP, Leufkens HG, Abenhaim L, Zhang B, Cooper C (2000): Use of oral corticosteroids and risk of fractures. J Bone Miner Res $\underline{15}$, 993-1000

van Staa TP, Leufkens HGM, Cooper C (2002): The epidemiology of corticosteroidinduced osteoporosis: a meta-analysis. Osteoporos Int $\underline{13}, 777-787$

Vegger JB, Brüel A, Sørensen TG, Thomsen JS (2016): Systemic treatment with strontium ranelate does not influence the healing of femoral mid-shaft defects in rats. Calcif Tissue Int $\underline{98}, 206-214$

Verberckmoes SC, De Broe ME, D'Haese PC (2003): Dose-dependent effects of strontium on osteoblast function and mineralization. Kidney Int $\underline{64}, 534-543$

Verma S, Rajaratnam JH, Denton J, Hoyland JA, Byers RJ (2002): Adipocytic proportion of bone marrow is inversely related to bone formation in osteoporosis. J Clin Pathol 토, 693-698

Vestergaard $P$ (2007): Discrepancies in bone mineral density and fracture risk in patients with type 1 and type 2 diabetes - a meta-analysis. Osteoporos Int $\underline{18}, 427-444$

Vestergaard P, Mosekilde L (2003): Hyperthyroidism, bone mineral, and fracture risk - a meta-analysis. Thyroid $\underline{13}, 585-593$

Warriner AH, Patkar NM, Curtis JR, Delzell E, Gary L, Kilgore M, Saag K (2011): Which fractures are most attributable to osteoporosis? J Clin Epidemiol $\underline{64}, 46-53$

Wei J, Wang J, Gong Y, Zeng R (2015): Effectiveness of combined salmon calcitonin and aspirin therapy for osteoporosis in ovariectomized rats. Mol Med Rep 12, 17171726

Weidemann A: Der Einfluss von Strontiumranelat auf die metaphysäre Frakturheilung osteopener Ratten. Med. Diss. Göttingen 2013

Welz B, Sperling M: Atomabsorptionsspektrometrie. John Wiley \& Sons, Weinheim 2012

Wohl GR, Chettle DR, Pejović-Milić A, Druchok C, Webber CE, Adachi JD, Beattie KA (2013): Accumulation of bone strontium measured by in vivo XRF in rats supplemented with strontium citrate and strontium ranelate. Bone $\underline{52}, 63-69$

Wopenka B, Pasteris JD (2005): A mineralogical perspective on the apatite in bone. Mater Sci Eng C 25, 131-143 
Wu Y, Adeeb SM, Duke MJ, Munoz-Paniagua D, Doschak MR (2013): Compositional and material properties of rat bone after bisphosphonate and/or strontium ranelate drug treatment. J Pharm Pharm Sci $\underline{16}$, 52-64

Yan Z, Huang H, Li J, Wang J (2016): Relationship between subclinical thyroid dysfunction and the risk of fracture: a meta-analysis of prospective cohort studies. Osteoporos Int 27, 115-125

Zhang X, Yu Z, Yu M, Qu X (2015): Alcohol consumption and hip fracture risk. Osteoporos Int 26, 531-542

Zhao S, Wang X, Li N, Chen Y, Su Y, Zhang J (2015): Effects of strontium ranelate on bone formation in the mid-palatal suture after rapid maxillary expansion. Drug Des Devel Ther $\underline{9}, 2725-2734$

Zhong ZM, Chen JT (2009): Anti-fracture efficacy of risedronic acid in men: a metaanalysis of randomized controlled trials. Clin Drug Investig 29, 349-357 


\section{Danksagung}

Zunächst möchte ich mich bei den Direktoren der Klinik für Unfallchirurgie, Orthopädie und Plastische Chirurgie Herrn Prof. Dr. med. Wolfgang Lehmann sowie dem emeritierten Herrn Prof. Dr. med. Klaus Michael Stürmer als Abteilungsleiter für die Ermöglichung dieses Projekts bedanken.

Besonderer Dank gilt meinem Doktorvater Herrn Prof. Dr. med. Stephan Sehmisch für die Überlassung des Dissertationsthemas, die freundliche Betreuung und die zügige Korrektur.

Ganz herzlich möchte ich mich bei Frau Dr. rer. nat. Marina Komrakova für die fachlich Expertise und nette Betreuung bedanken. Durch ihre fortwährende Präsenz, konstruktive Kritik und die schnellen Korrekturen war ein zügiger Fortschritt - sowohl der Versuche als auch Verschriftlichung der Dissertation überhaupt möglich.

Mein abschließender Dank gilt den MTAs Frau Ramona Castro-Machguth und Frau Annette Witt, Herrn PD Dr. Christian Dullin sowie Herrn Dr. med. Ulrich Schmelz, die mich mit ihren Tipps und Hilfestellungen unterstützt haben. 